
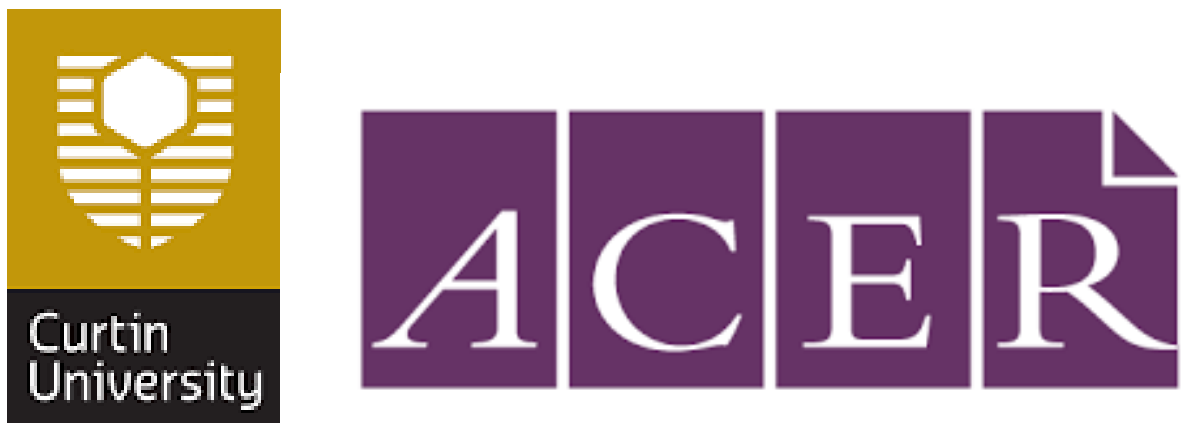

NCSEHE

\title{
Australian Higher Education Equity Ranking Project Final Report
}

Submission date: June 2019

This project was funded by the Australian Government Department of Education, Skills and Employment through National Priorities Pool Program (NPPP)

Tim Pitman,

Curtin University

Paul Koshy,

National Centre for Student Equity in Higher Education

Daniel Edwards, Liang-Cheng Zhang \& Julie McMillan, Australian Council for Educational Research 
The Australian Council for Educational Research Ltd

19 Prospect Hill Road

Camberwell VIC 3124

Tel: +61 392775555

ABN 19004398145

www.acer.org

ISBN 978-1-74286-666-6

(C) Curtin University 2022

Curtin University

Kent St, Bentley WA 6102

Tel: +61 892667335

www.curtin.edu.au

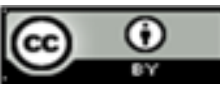

With the exception of any material protected by a trademark, and where otherwise noted, all material presented in this document is provided under a Creative Commons Attribution 4.0 International (https://creativecommons.org/licenses/by/4.0) licence.

\section{Recommended attribution}

Australian Higher Education Equity Ranking Project: Final Report by T Pitman, P Koshy, D Edwards, LC Zhang \& J McMillan is licensed under a Creative Commons Attribution licence 4.0.

\section{Recommended citation (APA 7th edition)}

Pitman, T., Koshy, P., Edwards, D., Zhang, L.-C., \& McMillan, J. (2019). Australian Higher Education Equity Ranking Project: Final Report. Australian Council for Educational Research. https://doi.org/10.37517/978-1-74286-666-6

\section{Acknowledgement}

This project was funded by the Australian Government Department of Education, Skills and Employment through National Priorities Pool Program (NPPP). 


\section{Contents}

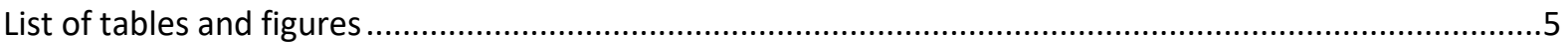

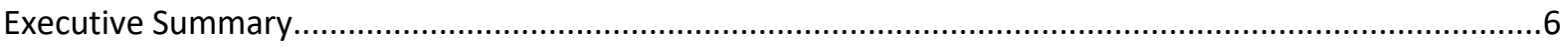

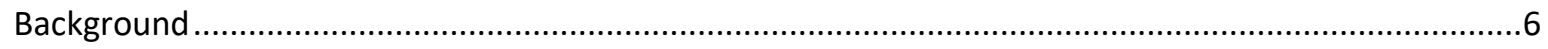

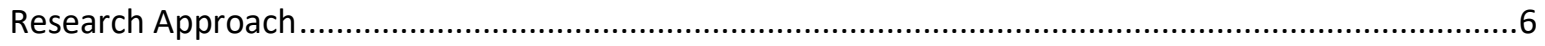

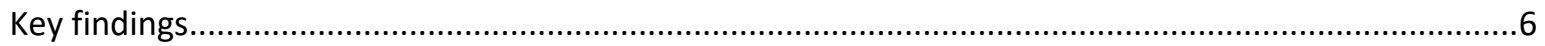

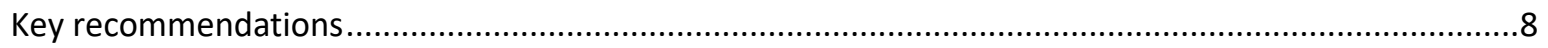

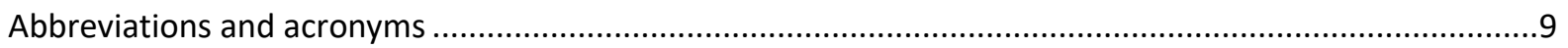

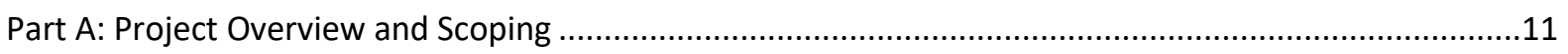

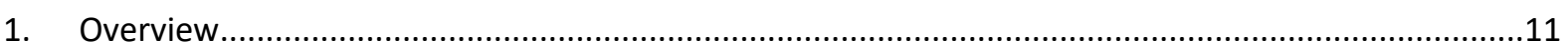

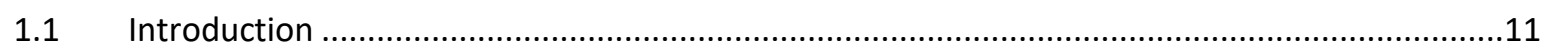

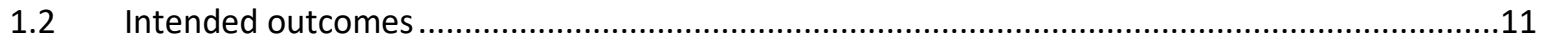

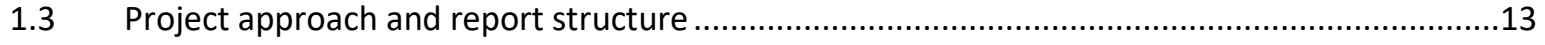

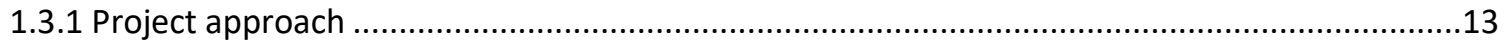

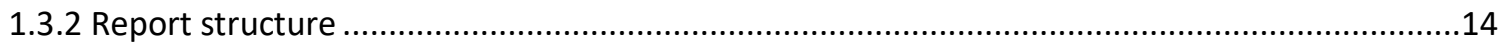

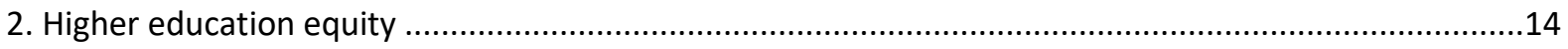

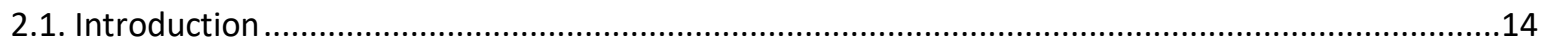

2.2. Defining equity in higher education policy, enactment and practice............................................15

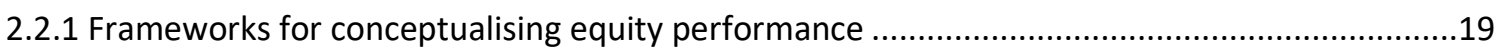

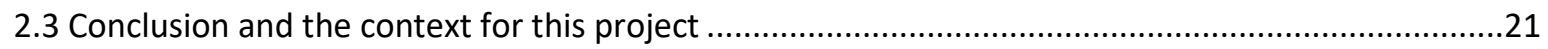

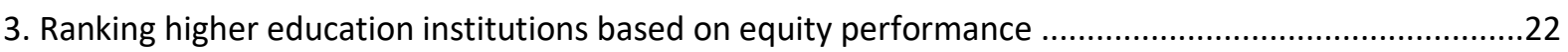

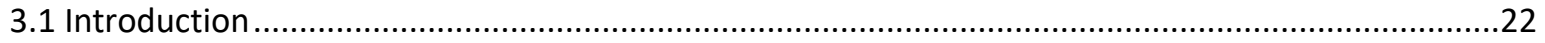

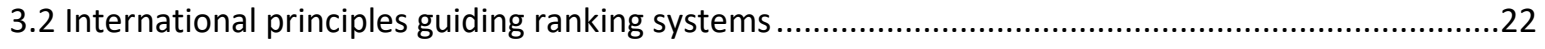

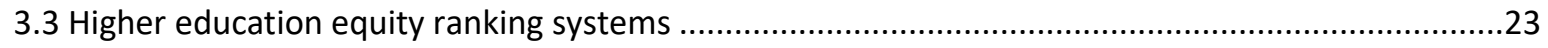

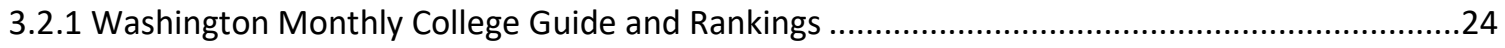

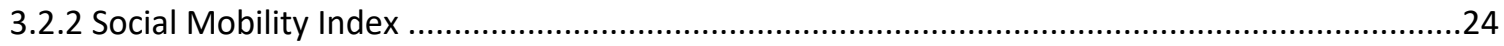

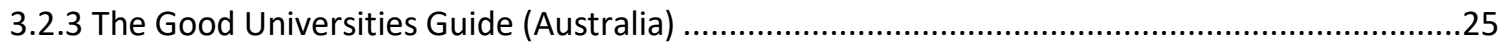

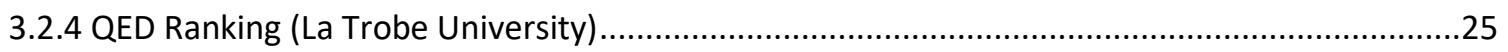

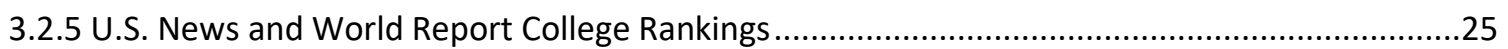

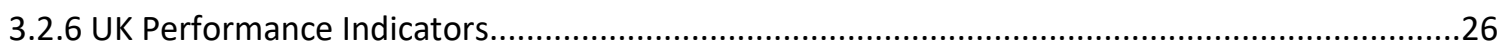

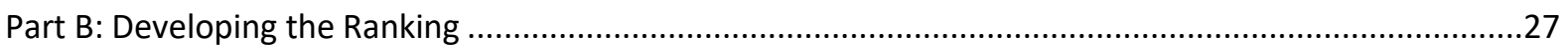

4. Identifying Indicators for Inclusion in an Equity Ranking .....................................................................27 
4.1 Introduction .27

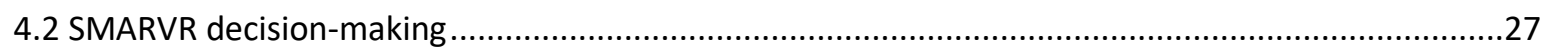

4.3 Domains and Data Sources for Australian Higher Education Equity Ranking.................................28

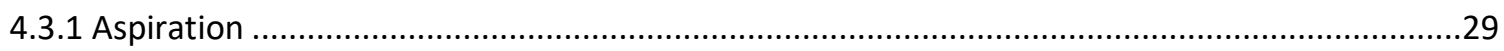

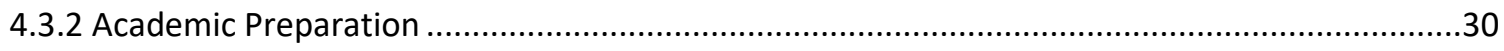

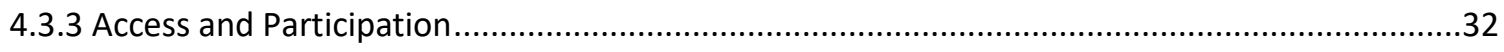

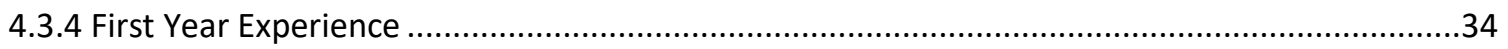

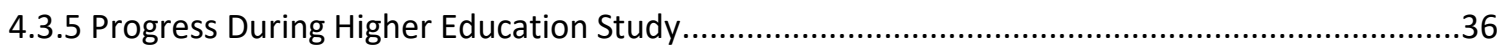

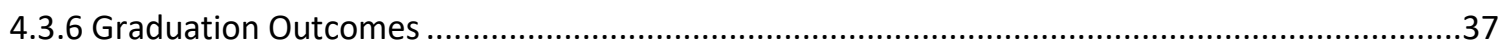

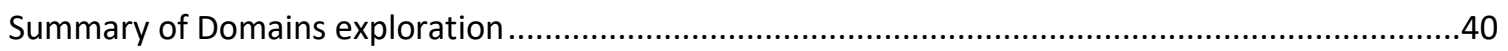

4.4 Calculating measures from the selected higher education equity indicators .................................40

4.4.1 The Overall Rationale for Calculating Measures .............................................................40

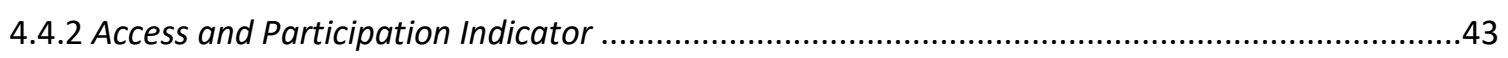

4.4.3 First Year Experience (Retention and Success), Outcomes During Higher Education, and

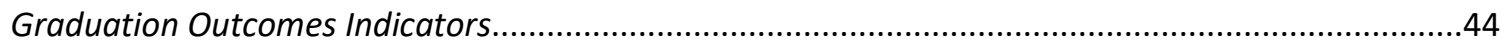

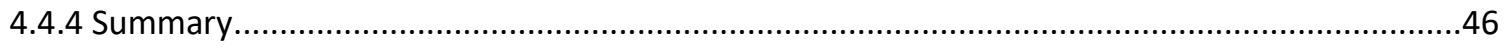

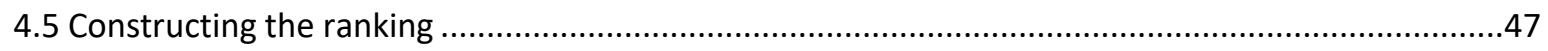

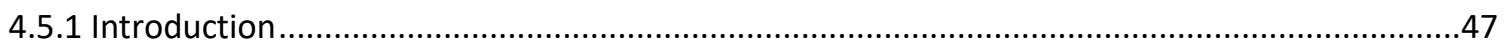

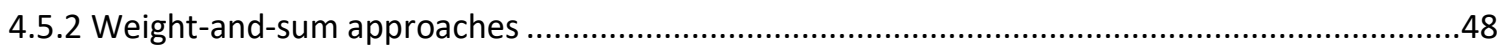

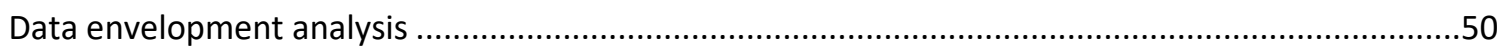

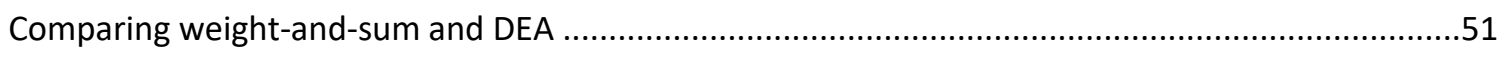

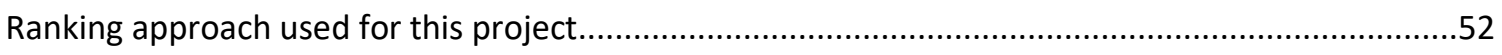

Part C: Testing the Higher Education Indicators in Various Ranking Scenarios ......................................58

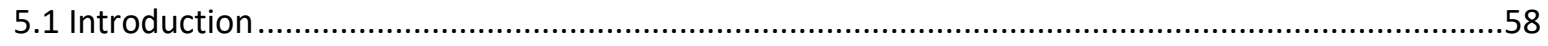

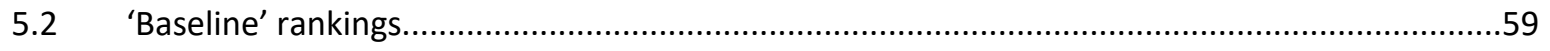

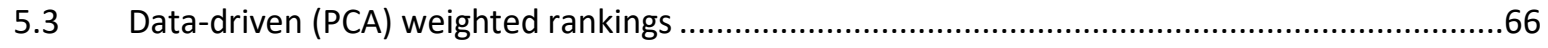

5.4 Rankings based on a range of expert-determined weighting scenarios .................................68

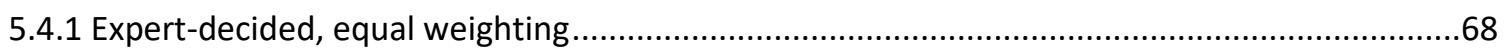

5.4 .2 Expert-decided, access-focussed weighting ...................................................................70

5.4.3 Expert-decided, retention-focussed weighting ............................................................71

5.4.4 Expert-decided, graduate outcomes-focussed weighting ................................................72

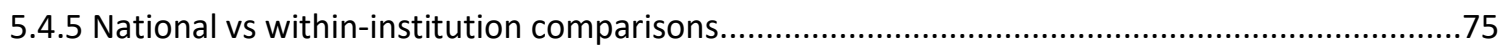

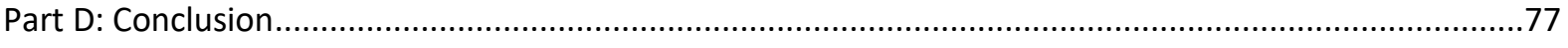

6.1 Using a higher education ranking system to measure equity performance ................................77 
6.2 Domains of higher education equity performance .77

6.3 Indicators for measuring higher education equity performance .............................................78

6.4 Measuring equity performance through the indicators ..........................................................78

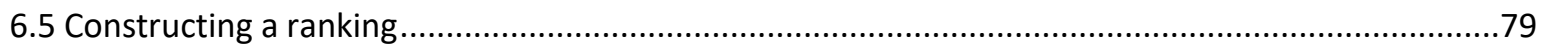

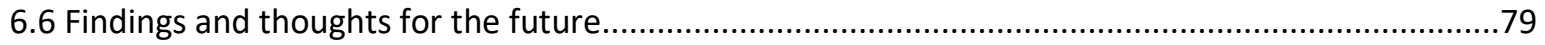

6.7 Alternative approaches to measuring higher education equity performance ..............................80

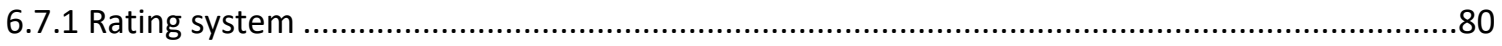

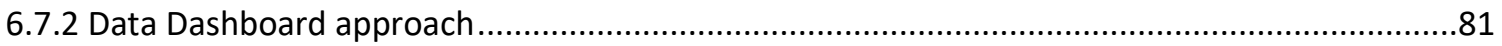

APPENDIX A: Berlin Principles on Ranking of Higher Education Institutions ...........................................82

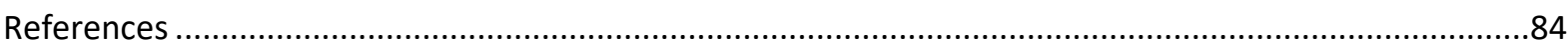




\section{List of tables and figures}

Figure 1 Equity Performance Framework for Higher Education ...............................................................21

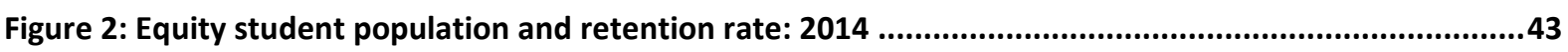

Figure 3: Completion Rates Nine Years after Commencement, By SES and ATAR, Domestic Undergraduate

Commencers in 2005

Figure 4: Illustration of calculating DEA performance score (adapted from Andersen and Petersen (1993))..51

Figure 5: Illustrative example of stacked bar-chart display for rankings output ...........................................56

Figure 6: 'Baseline’ Ranking equal weights - Low SES ............................................................................61

Figure 7 ‘Baseline’ Ranking equal weights - Regional And Remote...................................................62

Figure 8: 'Baseline’ Ranking equal weights - Indigenous ....................................................................63

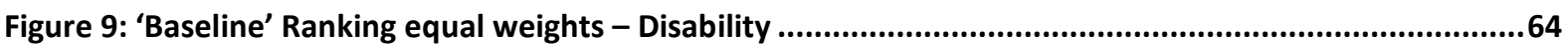

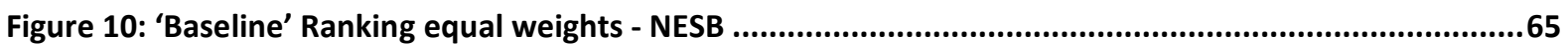

Figure 11: PCA-derived weighting contribution (dimension 1) - Low SES...............................................66

Figure 12: Data-driven Ranking (PCA weights) - Low SES.................................................................67

Figure 13: Expert-decided ranking, focus on access, retention and graduate outcomes - Low SES ...............69

Figure 14: Ranking weighted towards access measures - Low SES students ............................................70

Figure 15: Ranking weighted towards retention measures - low SES students .........................................71

Figure 16: Ranking weighted towards graduate outcome measures - low SES students .............................72

Figure 17: Ranking result comparison with bump chart ..................................................................74

Figure 18: Rankings comparison, National comparison weights to within-institution weights - low -SES ......76

Table 1: Four broad approaches to achieving higher education equity ..................................................18

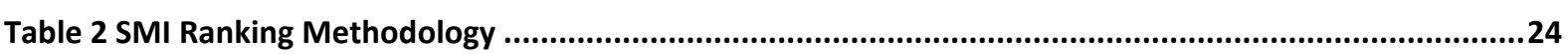

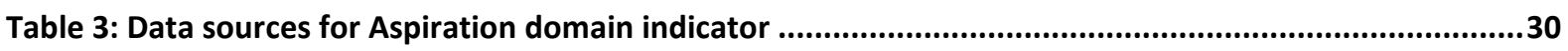

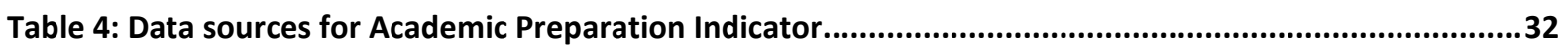

Table 5: Data sources for Access and Participation Indicator ................................................................33

Table 6: Correlation between retention and success: Table A/B institutions ..............................................35

Table 7: Data sources for First-Year Experience Indicator .......................................................................35

Table 8: Data sources for Progress During Higher Education Study Indicators .............................................37

Table 9: Data sources for Graduation Outcomes Indicators .................................................................39

Table 10: Inclusion of Domains for the Equity Ranking Index.............................................................40

Table 11: State and Territory Population Reference Values for Equity Groups, \% of population....................44

Table 12 Comparisons between approaches of building indices ..........................................................52

Table 13: Indicators and Measures utilised for developing the Equity Rankings .........................................59 


\section{Executive Summary}

\section{Background}

This report details the findings of a feasibility study for the Department of Education and Training (DET) into the development of a higher education student equity ranking index. The purpose of study was to determine whether it was possible to measure higher education equity performance at the institutional level and convey each institution's relative performance through an 'equity rank'. The ranking was to be based on institutional performance in regard to equity-group students, including students from low socioeconomic backgrounds; students from regional/remote areas of Australia; Indigenous students; students with disability; and students from non-English speaking backgrounds. The study examined:

- What prior research and policy work (both in Australia and internationally) had been done in respect of creating higher education equity ranking systems;

- Whether a ranking system could be developed specifically for the Australian higher education context, including its methodology; and

- If possible, whether such a ranking system would assist stakeholders in identifying best practice, as well as areas needing improvement.

Further detail regarding the project background and aims is outlined in the Overview section of this report.

\section{Research Approach}

The research was conducted in five stages:

1. (Background and scoping), where a review of relevant research (peer-reviewed, commissioned reports, policy documents, etc.) was undertaken. Preliminary analyses of possible equity performance indicators, measures for these indicators and ranking methodology were undertaken.

2. (Stakeholder consultation), to assist in defining the broad dimensions of higher education equity, its performance indicators and means of measurement.

3. (Preliminary report), a key milestone with DET.

4. (Ranking construction), including data testing and expert feedback.

5. (Final Report), delivered to DET.

The full research approach and method is laid out in the Project approach and report structure section.

\section{Key findings}

1. 'Higher education equity' is a notion that has a fair degree of definitional latitude. It encompasses commutative principles (i.e. treating people equally) and distributive principles (i.e. treating people differently, according to their needs). It involves both raising the absolute number of equity-group students in higher education and their proportional representation. In Australia since the late 1980s, the focus of higher education equity policy has been on increasing the proportional representation of equity-group students. However, in more recent times greater attention has been paid to the wider dimensions of higher education equity; including pre-tertiary preparation, students' retention and completion and post-graduation outcomes.

See 2.2. Defining equity in higher education policy, enactment and practice. 
2. Higher education ranking systems (HERS) are ubiquitous and have impact. However, relatively few incorporate dimensions of higher education equity, let alone prioritise them. Those that do tend to focus on the dual issues of participation and affordability.

See 3. Ranking higher education institutions based on equity performance.

3. Higher education equity encompasses pre and post-tertiary aspects. This project identified six broad domains in which higher education equity occurs, and where higher education institutions can have an influence. They are:

I. Aspiration: Raising the aspirations of equity-group students to participate.

II. Academic Preparation: Supporting equity-group students to be academically prepared for higher education.

III. Access and Participation: Offering places to and enrolling equity-group students.

IV. $\quad$ First Year Experience: Providing equity students with the academic and other support necessary to succeed in the critical first year of study.

V. Progress during Higher Education Study: Supporting equity-group students to continue with and complete their studies.

VI. Graduation Outcomes: Ensuring that equity-group students have the same opportunities to realise the benefit of their studies as do other students.

However, at this time sufficient data do not yet exist to accurately measure institutional performance within and across these six domains, for the Australian higher education sector. Therefore, currently, any ranking system would not be able to fully address the totality of higher education equity performance.

See 4. Identifying Indicators for Inclusion in an Equity Ranking.

4. Displaying higher education equity performance by means of a rank raises issues, which may be counterproductive to performance assessment. Specifically:

I. Due to the lack of a universally-agreed definition of what higher education equity is, and how it can be measured, it may be difficult to achieve consensus in relation to which aspects of higher education equity should be given greater weight, or importance, over others - or whether all aspects should be considered equally.

II. A ranking system can hide sub-optimal performance where the majority, or all, institutions are performing poorly. In such situations, a ranking system may give the impression that institutions at the top-end of the rank are performing well when they are not.

III. Due to the relatively small sizes of some equity-group student populations and/or the relatively small sample sizes of data informing the relative performance indicator, a small change in outcome can have a disproportionate effect on the position of the institution in the final ranking.

See Part C: Testing the Higher Education Indicators in Various Ranking Scenarios. 


\section{Key recommendations}

1. Any system for measuring higher education equity performance should:

I. Be able to recognise diversity: of institutional mission; student equity group; and aspect of higher education equity being addressed.

II. Be transparent: in its design, purpose and methodology.

III. Be ethical in how it collects data for the ranking system.

IV. Present the data in an understandable manner, preferably offering choices on how data can be displayed.

See 3.2 International principles guiding ranking systems.

2. Any performance measurement system should assess the performance of each equity group individually and not collate the results into an overall measurement. Such an approach would not consider the diverse characteristics and needs of the particular groups.

See 4.4 Constructing the ranking.

3. The relative equity performance of an institution should consider both national and local contexts and benchmarks. Specifically:

I. Participation should account for both national and state population distributions. For example, whilst nationally the low-SES population is, by definition, $25 \%$ of the overall population, in some states/territories it is higher and in some it is lower. Any assessment of institutional performance should consider both distributions.

II. The equity performance of an institution regarding retention, success, completion and graduate outcomes should consider intra and extra institutional performance. That is, for any of these outcomes overall performance should be judged by considering both how the institution performs in relation to the equity group compared how other institutions perform for the same measure; and how the institution performs in relation to the equity group, compared to how its non-equity group students perform for the same measure.

See 4.3 Calculating measures from the selected higher education equity indicators.

4. Given the limitations of a ranking system, other options for measuring performance should be explored. These might include:

I. A rating system, where an institution's performance is compared to an external benchmark, rather than against the performance of other institutions. Benchmarks could be set by policymakers, informed by researchers, practitioners and international best practice.

II. A 'data dashboard' approach, which includes the use of an information tool to track, analyse and display higher education equity performance. Dashboards have the potential to provide more detailed information than other systems.

See 6.7 Alternative approaches to measuring higher education equity performance. 


\section{Abbreviations and acronyms}

ACER

Australian Council for Educational Research

AEDC

Australian Early Development Census

AlHW

Australian Institute for Health and Welfare

ARWU

Academic Ranking of World Universities

ASGS

Australian Statistical Geography Standard

ATAR

Australian Tertiary Admission Rank

ATO

Australian Taxation Office

BGS

Beyond Graduation Survey

CHESSN

Commonwealth Higher Education Student Support Number

CEEHE

Centre of Excellence for Equity in Higher Education

CWA

Course-Weighted Average

CSHE

Centre for Studies in Higher Education

DEA

Data Envelopment Analysis

DET

Department of Education and Training

DIISRTE

Department of Industry, Innovation, Science, Research and Tertiary Education

DMU

Decision Making Units

EPF

Equity Performance Framework

GOS

Graduate Outcomes Survey

HE

Higher Education

HEIMS

Higher Education Information Management System

HEPI Higher Education Policy Institute

HEPPP Higher Education Participation and Partnerships Program

HESA Higher Education Statistics Agency (UK)

HILDA Household, Income and Labour Dynamics in Australia

LSAY

Longitudinal Surveys of Australian Youth

NAPLAN

National Assessment Program - Literacy and Numeracy 


\begin{tabular}{|c|c|}
\hline NCSEHE & National Centre for Student Equity in Higher Education \\
\hline NEON & National Education Opportunities Network (UK) \\
\hline NESB & Non-English Speaking Background \\
\hline NPS & Normalised Performance Score \\
\hline PCA & Principal Component Analysis \\
\hline POLAR & Participation of Local Areas \\
\hline PWD & People with Disability \\
\hline QILT & Quality Indicators for Learning and Teaching \\
\hline QS & Quacquarelli Symonds (World University Rankings) \\
\hline RPS & Raw Performance Score \\
\hline SES & Socio-Economic Status \\
\hline SMART & Specific, Measurable, Accountable, Relevant and Timely \\
\hline SMARVR & Specific, Measurable, Accountable, Relevant, Value, and Revision \\
\hline STAT & Special Tertiary Admissions Test \\
\hline TAC & Tertiary Admission Centre \\
\hline THE & Time Higher Education (World University Rankings) \\
\hline UNESCO & United Nations Educational, Scientific and Cultural Organization \\
\hline WEF & World Economic Forum \\
\hline WINTA & Women in Non-Traditional Areas \\
\hline WPLS & Widening Participation Longitudinal Study \\
\hline WPS & Weighted Performance Scores \\
\hline
\end{tabular}




\section{Part A: Project Overview and Scoping}

\section{Overview}

\subsection{Introduction}

In September 2017, the Australian Government Department of Education and Training (DET)

commissioned a project team from Curtin University and the Australian Council for Educational Research (ACER) to conduct a feasibility study into development of a higher education student equity ranking index or collection of indices, to describe the performance of Table A universities (Australia's major public universities and the Australian Catholic University) in relation to the participation and performance of equity students.

This study examines how institutional equity performance might be measured so as to improve access to, and participation, retention and completion in undergraduate study for Australia's identified higher education student equity groups:

- $\quad$ Students from low socio-economic (SES) backgrounds (low SES); ${ }^{1}$

- Students from regional areas of Australia; ${ }^{2}$

- Students from remote areas of Australia; ${ }^{3}$

- Indigenous students;

- Students with disability; and

- $\quad$ Students from non-English speaking backgrounds (NESB).

Another identified group, Women in Non-traditional Areas (WINTA), is excluded from this analysis as it is not currently reported as an equity group by DET.

\subsection{Intended outcomes}

The objective of this feasibility study is to produce a framework and supporting methodology for an index or indices to rank universities in terms of their higher education student outcomes for the specified student groups. The index or collection of indices, and supporting methodology is intended to be factual, transparent, objective and easily accessible to a range of stakeholders.

The primary audience for the ranking system is intended to be persons and/or units within higher education institutions and government, charged with enacting equity policy. The ranking system is intended to inform these persons, so that they may:

- better gauge the equity performance of their institution, relative to both the overall sector and institutions with similar profiles;

\footnotetext{
${ }^{1}$ Low socio-economic status is determined by an 'area measure', the Statistical Area 1 (SA1) area of a student's permanent residence. Australian SA1s are ranked by DET using the Australian Bureau of Statistics (ABS) SocioEconomic Index For Areas (SEIFA) (Education and Occupation Index), with SA1 areas containing the lowest25 per cent of the population aged 15-64 in this ranking being classified as low SES.

${ }^{2}$ Regionality is based on the SA1 area of a student's permanent residence and determined using the ABS'S Australian Statistical Geography Standard (ASGS) -Remoteness Structure.

${ }^{3}$ Remoteness is based on the SA1 area of a student's permanent residence and determined using the ABS'S ASGS - Remoteness Structure.
} 
- Identify areas of best practice within their institution, institutions with similar profiles and nationally; and

- Identify areas requiring improvement. 


\subsection{Project approach and report structure}

\subsubsection{Project approach}

The project approach comprised five stages:

\section{Stage 1 - Background and scoping}

Building on the project team's previous research in this and related areas (e.g. Edwards \& McMillan, 2015a, 2015b; Pitman \& Koshy, 2015; Pitman, Roberts, Bennett, \& Richardson, 2017), a review of relevant research (peer-reviewed, commissioned reports, policy documents, etc) was undertaken. Preliminary analyses of possible equity performance indicators, measures for these indicators and ranking methodology were undertaken.

Stage 2 - Stakeholder consultation

The project team identified key experts to provide feedback, ensuring broad representation across the sector. In line with the aims of the project, feedback was sought from:

- Higher education researchers/experts with knowledge and understanding of ranking systems and/or equity in higher education and/or governance in the Australian higher education sector;

- Higher education equity practitioners;

- Senior executives in higher education institutions, including those charged with equity policy; and

- Higher education institution planners.

Furthermore, feedback was specifically sought from each higher education strategic alliance:

- The Australian Technology Network (ATN);

- The Group of Eight (Go8);

- The Innovative Research Universities (IRU); and

- The Regional Universities Network (RUN).

Finally, feedback was also received from the Equity Practitioners in Higher Education Australasia (EPHEA) organisation.

Feedback was collected by the project team primarily through interviews. For those not able to be interviewed, emailed responses were provided to specified discussion items. In all, detailed feedback was received from 30 stakeholders.

\section{Stage 3 - Preliminary report and review}

Based on Stages 1 and 2, a preliminary report, including draft recommendations, was provided to the DET Project Advisory Team. Detailed feedback was provided by the project team, which has been incorporated into this final report. Based on the stakeholder and DET feedback, as well as further research, the initial ranking indicators and methodology were refined.

\section{Stage 4 - Ranking construction, data testing and stakeholder feedback}

Based on Stages 1-3, an approach to ranking Australia's 37 Table A universities was identified. Data were tested and the preliminary rankings were shared with expert and technical stakeholders, as well as those from DET, too gather additional feedback. 
Stage 5 - Final report

The final report was delivered to the DET Project Advisory Team.

\subsubsection{Report structure}

The final report is in four parts:

Part A: Comprises the project overview, discussion of relevant higher education equity policy, and analysis of existing higher education equity ranking systems.

Part B: Outlines how the project team's higher education equity ranking system has been developed, including how the indicators have been selected, how measures are calculated for the indicators and the methodological approach constructed.

Part C: Details the results obtained when the ranking system was tested. This includes a discussion of the approach to testing the ranking, in which we show possible rankings for each equity group and discuss/describe broadly the outcomes and implications of constructing rankings based on equity performance.

Part D: Provides concluding comments arising from the project.

\section{Higher education equity}

\subsection{Introduction}

The concept of equity is connected with principles of 'justice' and 'fairness' (Raphael, 1946), which are socially constructed. Hence, the idea of 'equity' has definitional latitude. The can be seen in the distinction between commutative and distributive equity, which is at least as old as Aristotle's Ethics (e.g. Bronfenbrenner, 1973). Commutative equity requires a society to treat all individuals equally, whereas distributive equity requires individuals who are disadvantaged to be treated differently, in recognition of their needs.

In higher education, these two definitions often generate conflicting answers as to the effectiveness of policies designed to widen access and participation. Commutatively, the growth in the absolute number of people from groups previously under-represented in higher education demonstrates the effectiveness of some policies. From a distributive point of view however, such policies have been less effective in increasing representation (Marginson, 2011). That is, efforts to increase the absolute number of students from disadvantaged background in higher education are, generally, more successful than efforts to increase the proportion, or share, of higher education places to students from disadvantaged backgrounds.

It is this tension which underlies discussion about the place of equity in higher education. Equity policy has a longstanding history in Australia. Indeed, principles of fair and equitable access to higher education are written into the founding acts of many of Australia's universities. However, research regularly shows that in Australia, participation in higher education is conditional on a range of factors including: prior access to a quality primary and secondary education experience; social and cultural aspirations towards higher education; and geographical location (e.g.Dalley-Trim \& Alloway, 2010; Gemici, Bednarz, \& Karmel, 2014; James, 2001; Parker, Stratton, Gale, Rodd, \& Sealey, 2013). Consequently, successive Governments have sought to implement and enact higher education equity policy to ameliorate educational 
disadvantage. In Australia, widening access and participation for groups of students historically underrepresented in higher education came into particular prominence with the 1990 publication of $A$ Fair Chance for All, the first national framework for student equity in higher education (Harvey, Burnheim, \& Brett, 2016). The overall objective, as set out in the paper, was to:

"... Ensure that Australians from all groups in society have the opportunity to participate successfully in higher education. This will be achieved by changing the balance of the student population to reflect more closely the composition of society as a whole." (Department of Employment Education and Training, 1990, p. 2)

The paper discussed a ranged of strategies for institutions to adopt, including outreach programs, retention programs, special admission arrangements, bridging and support programs and units; or making teaching materials and processes more relevant to the needs of disadvantaged students (Department of Employment Education and Training, 1990, pp. 16-48). This eventuated in the Martin Review of Equity and General Performance Indicators in Higher Education, whereby the Australian Government sought to develop and trial equity performance indicators for these groups of students and to produce the necessary IT and software for institutions to measure and report their performance (Martin, 1994). The aims were therefore to support institutions in their own analyses of their equity performance, and to develop a planning measure suitable for the assessment of broad institutional or national equity policy (Martin, 1994). The recording, reporting and assessing mechanisms have matured over time to the extent that the DET is now in the position to provide detailed analyses, down to the institutional and course level, regarding rates of access, participation, retention, attrition, success and attainment. DET also collects academic staff demographics in relation to gender ratios, and employment of Indigenous academic staff.

With this context in mind, the following sections examine how higher education equity has been defined and operationalised in Australia and internationally. By exploring the evolution of higher education policy across various domains, greater insight can be gained into how higher education equity is defined and what indicators might be used to measure success.

\subsection{Defining equity in higher education policy, enactment and practice}

Across many jurisdictions and domains, higher education equity is founded upon two basic indicators of success: access and affordability. This is reflected in the United Nations' International Covenant on Economic, Social and Cultural Rights, which requires that education must be accessible in three respects. First it should be non-discriminatory. Second, it should be physically accessible. Third, it should be economically accessible. Specifically in regard to higher education, Article 13 of the Covenant requires signatories "to progressively introduce free secondary and higher education" (UN Economic and Social Council, 1999).

The first efforts to widen access and participation in Australian universities focussed on broad conceptualisations of equity and/or equality. These included access for women and students from lower socio-economic backgrounds, as well as ensuring prejudice was not enacted based on religious affiliation (e.g. Horne \& Sherington, 2012; Selleck, 2003). Early efforts to widen access, such as the Commonwealth Scholarship Scheme from the 1950s, focussed on merit and did not explicitly target any particular group of persons. 
The decision by the Whitlam Government in 1974 to abolish tuition fees at universities and colleges of advanced education was a more conscious attempt to democratise higher education (Department of Employment Education and Training, 1993). Persons from poor or working-class backgrounds were the primary target of the policy. The inequity in the system that was being challenged was, in the words of the then Leader of the Opposition in 1972, that "the quality of the education a child received [is] determined not by his capacity to learn but by his family's capacity to earn" (Canberra Times, 1972, p. 4). Inherent in the statement, and the subsequent policy, are three key dimensions that has defined much of Australia's higher education policy landscape. First, a group, or groups, of persons, was identified as being the target for action. In this instance, students from poor or working-class backgrounds were the target; albeit a somewhat imprecise and vague definition for operational purposes. Second, the aim(s) of the policy were explicated: participation in higher education in the case of the Whitlam policy. Third, how the aim would be achieved was described, namely with the abolition of tuition fees, as well as provision of a means-tested living allowance.

These dimensions were further refined throughout the 'Dawkins reforms' to higher education of the late 1980s, starting with the White Paper, Higher Education: A Policy Statement, issued in July 1988. Under the broad rubric of 'disadvantaged', the paper provided greater clarity regarding which Australians this term referred to; namely: "Capable and qualified people from families with relatively low income levels, from rural areas and the disabled [and] Aboriginals" as well as women enrolling in non-traditional areas of study (Dawkins, 1988, pp. 20-21). The equity aims largely remained the same i.e. accessing and participating in higher education. However, for the first time, precision was provided:

The overall objective for equity in higher education is to ensure that Australians from all groups in society have the opportunity to participate successfully in higher education. This will be achieved by changing the balance of the student population to reflect more closely the composition of society as a whole (Department of Employment Education and Training, 1990, p. 2)

In regard to means: the binary system of higher education (i.e. universities and colleges/institutes) was unified to dramatically increase the number of university places available, as the primary means of widening participation. Tuition fees were re-introduced (albeit subsidised) but offset by a new, incomecontingent loan scheme.

Following the release of the discussion paper A Fair Chance for All by the Department of Employment, Education and Training/National Board of Employment, Education and Training, the first systematic attempt to define and measure target groups of students resulted in the formulation of the Martin Indicators (Martin, 1994), which remain the basis by which higher education equity outcomes are measured today. These indicators are constructed using student characteristics data to generate measures such as: access rates (equity group share of commencing enrolment), participation rates (equity group share of total enrolment) and comparative ratios, for instance, the retention rate of first year students from an equity group compared to the retention rate of all first year students.

The 2008 Review of Australian Higher Education (Bradley, Noonan, Nugent, \& Scales, 2008) ("the Bradley Review") maintained the focus on six tightly-defined groups of students ${ }^{4}$, adding specific participation

\footnotetext{
${ }^{4}$ Now identified as: Low SES students; students with disability; Indigenous students; students from remote and regional areas; students from NESB students; and women in non-traditional areas of study (WINTA).
} 
targets for low SES, regional, remote and Indigenous students. However, success, retention and completion rates were also recommended, meaning for the first time higher education equity goals other than access and participation were explicated, rather than inferred. The 2008 Review can be viewed as one bookend of a suite of equity reforms, with the other being the implementation of a demand-driven system of funding from 2013. The new funding arrangement meant that higher education institutions were not limited by the Commonwealth as to how many students they could enrol.

Across these three dimensions, various approaches to achieving higher education equity have been enacted, each revealing certain assumptions about the nature of disadvantage (Pitman, 2017). These are summarised in Table 1. The various approaches place different emphases on each of the dimensions. For example, policies of massification affect all students, whereas policies of redistribution specifically focus on one or more equity groups. 
TABLE 1: FOUR BROAD APPROACHES TO ACHIEVING HIGHER EDUCATION EQUITY

\begin{tabular}{|c|c|c|}
\hline Broad approach & Description & Australian examples \\
\hline Massification & $\begin{array}{l}\text { Significantly increasing the number of student } \\
\text { places available, to reduce competitive pressure for } \\
\text { a scarce resource and widen access. }\end{array}$ & $\begin{array}{l}\text { - } \quad \text { Creation of the Unified National } \\
\text { System (1989) } \\
\text { - Demand-driven funding system } \\
\text { (2013) }\end{array}$ \\
\hline Redistribution & $\begin{array}{l}\text { Policy specifically designed to increase proportional } \\
\text { representation of disadvantaged students. }\end{array}$ & $\begin{array}{l}\text { Means-tested living allowance } \\
\text { (1974) } \\
\text { - Additional funding to higher } \\
\text { education institutions per low- } \\
\text { SES enrolment (2012) }\end{array}$ \\
\hline Re-normalisation & $\begin{array}{l}\text { Policies designed to alter the normative behaviour } \\
\text { or culture of the higher education sector, making it } \\
\text { more inclusive and embracing of student diversity }\end{array}$ & $\begin{array}{l}\text { - Setting progressive targets for } \\
\text { Indigenous staff employment in } \\
\text { higher education institutions } \\
\text { (2012) }\end{array}$ \\
\hline Benefit & $\begin{array}{l}\text { Shifting focus from participation to the subsequent } \\
\text { benefits of enrolling in/completing higher } \\
\text { education }\end{array}$ & $\begin{array}{l}\text { - Setting retention and } \\
\text { completion targets for equity } \\
\text { students (2012) }\end{array}$ \\
\hline
\end{tabular}

Source: Adapted from Pitman (2017)

Internationally, higher education equity is defined and measured in both absolute and proportional terms. A background report to a meeting of OECD education ministers in 2006 gave examples of both, in providing evidence that equity policies were having a positive effect. The rise of enrolments of students with disabilities for Sweden and France were measured by percentage growth, for Ontario, Canada in actual numbers, and for NSW, Australia in proportional terms (Organisation for Economic Co-operation and Development, 2006, p. 10).

Higher education - especially the university sector - generally remains elitist, with most enrolled students coming from wealthier segments of society. Although relatively few countries and institutions systematically collect data on the socio-economic origin of students, where national statistics and household survey data are available, patterns of inequality appear (Salmi \& Bassett, 2012). Historically, participation in tertiary education has been strongly correlated with family socio-economic status and the educational attainment of parents (OECD, 2006, p. 14, as cited in Salmi \& Bassett, 2012).

In 2015, the Pell Institute published a report on the state of higher education equity in the US, mapping trends over a 45-year period (The Pell Institute \& PennAhead, 2015). The aims of the report were to analyse the status of higher education equity in the United States and to identify changes over time in measures of equity. To this end, the report focussed on six indicators of student equity:

1. Who enrols in postsecondary education?

2. What type of postsecondary educational institution do students attend?

3. Does financial aid eliminate the financial barriers to paying college costs?

4. How do students in the United States pay for college?

5. How does bachelor's degree attainment vary by family income?

6. How do educational attainment rates in the U.S. compare with rates in other nations?

These indicators still relate, fundamentally, to the core principles of access and affordability. More recently however, greater consideration has been given to broadening the scope of higher education 
equity. In 2009, a report released by the Cabinet Office in the UK observed that access to higher education had not, in and of itself, addressed the continuing inequitable access to professional employment, which remained heavily skewed towards persons from higher socio-economic circumstances (Cabinet Office Strategy Unit, 2009). That report recommended more work be done to bridge the gap between vocational and higher education, to widen participation by developing university partnerships with low-attaining schools and with the professions, and increase the level of professional work experience in higher education courses.

This statement reflects a desire to move beyond the established indicators - access and affordability - to incorporate additional, 'downstream' indicators of success, such as employment outcomes. In the US, publications such as Education Pays by the College Board regularly report the positive correlation between higher education attainment and such outcomes as earnings, social mobility, health factors and civic engagement (The Pell Institute \& PennAhead, 2015). Therefore, implicit higher education equity aims now extend to a realisation of these, post-graduation socio-economic benefits.

Work into developing meaningful higher education performance indicators dates back, in Europe and North America, to the 1970s (Dougherty et al., 2014; Martin, 1994). In Australia in 1989, the Higher Education Performance Indicators Research Group was formed to trial and refine a set of indicators, and its terms of reference included the need to address equity performance, which it defined as Participation and Social Equity (Martin, 1994). The Research Group also suggested that equity indicators should be considered in association with other measures relating to institutional context, in order to obtain a comprehensive view of participation and social equity issues at both institution and system levels (Linke \& et al., 1984 cited in ; Martin, 1994).

The standards or targets against which higher education equity performance has been measured over the last quarter of a century have been a mixture of implicit, explicit and aspirational. For example, A Fair Chance for All, proposed hard targets for Indigenous persons, women enrolled in non-traditional areas and people with disability (PWD), but not for low SES persons, regional and remote persons; and NESB persons. In 2008, the Bradley Review set a specific target only for low SES student enrolments, equal to $20 \%$ of total institutional undergraduate enrolment (Bradley et al., 2008, p. xiv). However, each institution was also required to enter into a compact with the Commonwealth to nominate at least one other target equity group. For the low SES student group, a university was deemed as being "excellent" if they achieved or exceed their target. The national target was subject to various lines of criticism, such as its failure to consider the different low SES catchments in each state and territory (Phillimore \& Koshy, 2010), highlighting the rising importance of contextual analysis in shaping the discussion around equity targets The target set for the 'other' equity group nominated by the institution was individually negotiated between it and the Commonwealth (Higher Education Group, 2011).

\subsubsection{Frameworks for conceptualising equity performance}

In 2013, two equity evaluation framework proposals were published, commissioned by the former Department of Industry, Innovation, Science, Research and Tertiary Education (DIISRTE). The first was 'Developing a critical interventions framework for advancing equity in Australian higher education' (the 'Critical Interventions Framework') by Ryan Naylor, Chi Baik and Richard James at the Centre for Study of Higher Education (CSHE) (Naylor, Baik, \& James, 2013). The second was 'Towards a performance measurement framework for equity in higher education' (the 'AlHW Framework') by the Australian Institute of Health and Welfare(AlHW, 2013). 
The Critical Interventions Framework was a more theoretical approach to the issue, with the framework intended to be mainly a resource to inform future equity initiatives and help evaluate them. It was narrower in scope than the AIHW framework, focussing as it did on low SES students and activities directed towards, or managed by the universities themselves. It was not intended to be operationalized (NCSEHE, 2013).

The AlHW Framework was much broader in scope and considered not only the equity inputs (e.g. government funding) and equity outputs (e.g. equity student enrolments) of the higher education sector, but also the wider socio-economic factors affecting educational disadvantage and subsequent underrepresentation in higher education. This framework provided detailed equity indicators, data sources and data collection methods for various equity groups and it was therefore possible for it to be operationalized. However, the substantial quantity of data collected under the proposed AlHW Framework presented several challenges, including additional reporting requirements by universities, better sharing of information between some government departments and the need to standardise diverse data formats (NCSEHE, 2013).

In 2014, the National Centre for Student Equity in Higher Education (NCSEHE) was commissioned by the Department of Education to develop an Equity Performance Framework (EPF). The equity groups covered by the EPF were the six identified in the 1994 Martin Report. ${ }^{5}$ The EPF was hierarchical in structure and comprised of three tiers: Context, Performance and Outcomes. The first tier (Context) measured the factors that contributed to educational disadvantage even before a person sought to access higher education. These started at the earliest developmental ages, through to Year 12 and focussed on educational participation, attendance, literacy and numeracy. The second tier (Performance) considered the performance of the higher education sector itself, including applications, offers, enrolments, retention, success and completion. The third tier (Outcomes) focussed on post-graduation outcomes, such as graduate outcomes and student satisfaction. In total, the framework provided 24 indicators, of which 22 drew upon existing data sources (Pitman \& Koshy, 2014). The EPF highlighted that equity in higher education was conditional upon input factors (e.g. Indigenous Year 12 completion rates affect Indigenous higher education participation), higher education performance (e.g. retention and success) and outcomes (e.g. completion and graduate outcomes) (See Figure 1).

This latest iteration of higher education equity performance illuminates how early, narrow conceptualisations based on access and affordability have now expanded to include many more 'upstream' (e.g. early childhood education) and 'downstream' (e.g. lifetime earnings) considerations. Whilst measures of access, participation and public financial support remain the dominant indicators, internationally, of higher education, increasing attention is being paid to equality of educational outcomes (e.g. Organisation for Economic Co-operation and Development, 2018).

\footnotetext{
${ }^{5}$ Low SES students; Indigenous students; NESB students; students with disability; regional and remote students; and WINTA students.
} 


\section{Equity Performance Framework}

\section{NCSEHE}

Curtin University

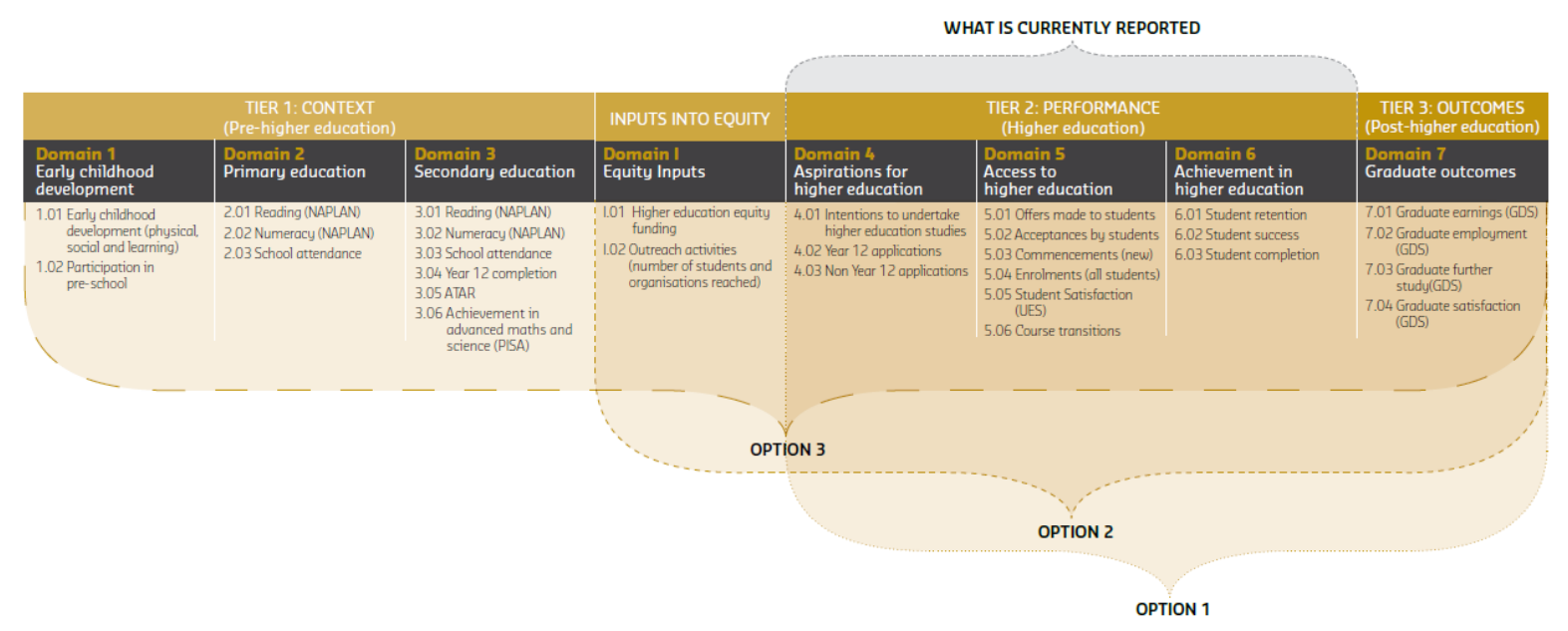

Source: (Pitman \& Koshy, 2015)

\subsection{Conclusion and the context for this project}

In 2018, UNESCO released its Handbook on Measuring Equity in Education (UNESCO, 2018). In the Handbook, Cameron, Daga and Outhred highlight the difficulties in defining 'equity', since any definition "is likely to be contested and also because there are likely to be several potential indicators that could be used to measure a particular conception of equality of opportunity"(Cameron, Daga, \& Outhred, 2018, p. 19). As noted above and elsewhere (e.g. McCowan, 2016), the UNESCO conclusions above highlight the fact that there is substantial disagreement about what constitutes a fair and equitable system. This is not to say efforts to measure and/or rank higher education equity performance are fruitless. It does, however, mean that any instrument developed should be viewed as capturing a facet of the impact of equity status on higher education participation and outcomes. Further, a ranking system should be implemented, ideally, in conjunction with higher education policy that explicates a definition of equity within.

For this reason, an ongoing challenge for the measurement of equity performance has been the development of methodologies that can incorporate a necessary range of quantitative and qualitative factors to accurately measure performance. From a pragmatic perspective, choosing what indicators to use is largely constrained by what data are available. For example, of the three frameworks listed above, the AlHW Framework was the most comprehensive, but relied on many data sources that would need to be developed, as well as incorporating a wider range of qualitative assessments. In contrast, the EPF used fewer indicators, all of which were quantitative, to achieve a more realistic level of operability. This balancing act goes back to the earliest attempts to measure higher education equity performance. In their final report, the Martin Review observed:

Most institutions which commented on system-wide measures in their equity plans for 1994-96 emphasised that quantitative measures were insufficient by themselves. However, 
there is not yet general agreement on what may be suitable qualitative equity measures... While many of these proposals have merit the Project Management Team does not believe that there would be sufficiently broad agreement that the results obtained would justify the additional information collection and analysis required for application nationally. (Martin, 1994, p. 12)

This mirrors a continuing trend, for pragmatic reasons, to preference a relatively narrow range of quantitative measures, over a wider range of quantitative and qualitative measures, to assess higher education equity performance.

To summarise: notwithstanding a degree of definitional latitude in conceptualising equity, higher education policy and practice to date, both in Australia and internationally, has focussed on widening access and participation for specific groups of students, with more recent attention also being paid to student success (e.g. retention and completion) and post-graduation outcomes.

\section{Ranking higher education institutions based on equity performance}

\subsection{Introduction}

A ranking is a means of establishing a relationship between multiple items so that they can ordered against one another according to an easily recognisable set of criteria. A significant difference between rankings and other performance evaluations mechanisms is that rankings are always relative, whereas many other evaluations are absolute. For example, with the equity compacts developed after the Bradley Review in 2008, it was theoretically possible for all institutions to achieve a performance rating of "excellent" since targets were set individually and therefore were independent to performance elsewhere. By contrast, ranking systems require that each institution be ranked against others, regardless of performance against their individual targets. Thus, in a scenario where all institutions over-perform, one will still be ranked worst and in a scenario where all fail to achieve the desired target, one would still be ranked best.

Rankings are useful when many variables, or indicators are necessary or available, thus making comparative assessment across all of them difficult. In higher education, ranking systems have become pervasive in relation to perceptions of overall quality and research excellence. One of the earliest was initiated by the Shanghai Jiao Tong University in the People's Republic of China. Its intention in doing so was to explore empirically-based methods for identifying the factors that led to excellence in universities (Soh, 2017). The publication of the ranking system sparked much interest, emulation and specialisation. Today, there are multiple higher education rankings for research, teaching and engagement.

\subsection{International principles guiding ranking systems}

In response to the proliferation of higher education ranking systems, in 2004 the United Nations Educational, Scientific and Cultural Organization (UNESCO) released several principles to guide good ranking practice. The primary impetus for developing these guidelines was to ensure "that those producing rankings and league tables hold themselves accountable for quality in their own data collection, methodology, and dissemination" (International Ranking Expert Group, 2006, p. 1). 
These principles (The Berlin Principles on Ranking of Higher Education Institutions) are included as Appendix A. To summarise, there are 16 principles, grouped into four main categories:

A. Purpose and goal of ranking: recognising the diversity of approaches seeking clarity regarding the purpose of the ranking and considering relevant contexts (social, economic, etc);

B. Design and weighting of Indicators: the need for transparency, validity and with a preference on outcome indicators as opposed to inputs;

C. Collection and processing of data: ethical behaviour, quality assurance, audited and verifiable data; and

D. Presentation of ranking results: Making the data understandable, offering choices on how data can be displayed and avoiding errors in data translation. (International Ranking Expert Group, 2006)

Equity can be applied with different theories of justice in mind and with different understandings of the wider ramifications of the distribution of education (Cameron et al., 2018). Furthermore, all ranking systems contain, inherently, a degree of subjectivity, regardless of which methodology they employ. This subjectivity is largely a consequence of determining which indicators to use, as well as availability of data. Research conducted by Moed (2017) clearly illustrates this fact. His comparative analysis of five world university rankings systems (ARWU, Leiden, THE, QS and U-Multirank) demonstrated that there was no such set of a top 100 universities in terms of excellence. Only 35 institutions appeared in the top 100 lists of all systems. Furthermore, each had a particular geographical bias: for example, the ARWU was viewed as preferencing North American (US and Canadian) institutions, whereas QS and THE were viewed as being more oriented more towards higher education systems based on the British model, such as those in the UK, Canada and Australia.

Nonetheless, many ranking systems display certain similarities, evidencing, to some degree, a shared understanding of how a normative concept (e.g. higher education equity) might be understood and measured. As Dill and Soo (2005) observe, performance measures in higher education can be divided into measures of input, output and process. Similarly, higher education equity performance can be considered in terms of inputs (e.g. availability of qualified applicants) outputs (e.g. equity student completions) and process (e.g. alternative pathways to higher education).

\subsection{Higher education equity ranking systems}

Rankings of higher education institutions and systems are common. However, they overwhelmingly focus on academic quality and research excellence, with rankings on the basis of equity performance being less common. From time to time one-off reports, or rankings of higher education equity performance occur. For example, in 2017 The Equality of Opportunity Project published its (US) college-level data on the percentage of students from lower-income families who reached higher income quintiles by their early 30s (Equality of Opportunity Project, 2017). In 2016, researchers from the Centre of Excellence for Equity in Higher Education (CEEHE) at the University of Newcastle released their report Charting Equity in Higher Education: Drawing the Global Access Map (Atherton, Dumangane, \& Whitty, 2016). That report focussed on access only, however the authors observed that the ultimate aim would be to develop a contextsensitive, cross-national analysis to provide insight into the entire student 'life cycle', which they defined as being "access, retention, progression, success and subsequent destinations" (Atherton et al., 2016, p. 11). 
To date, there are only a few ranking systems published regularly and with a focus on equity. However, those that exist provide other insights into how the notion of higher education equity might be defined, delineated and measured.

\subsubsection{Washington Monthly College Guide and Rankings}

This ranking is one of the few college ranking systems to consider issues of equity explicitly in its calculation. Washington Monthly is a bimonthly non-profit magazine, focussing on US politics and has published college rankings since 2005. The authors argue the College Guide and Rankings rates colleges "based on what they are doing for the country [as opposed to] measures of wealth, exclusivity, and prestige to evaluate schools" (Washington Monthly, 2016a).

Washington Monthly rate schools and colleges based on their contribution to the public good in three broad categories:

- Social Mobility (recruiting and graduating low-income students);

- Research (producing cutting-edge scholarship and PhDs); and

- Service (encouraging students to give something back to their country).

Each category was weighted equally, adjusted for statistical outliers and all measures used an average of the three most recent years of data in an effort to get a better picture of a college's performance rather than statistical noise (Washington Monthly, 2016b).

Here, equity is conceptualised in both individual and national terms; that is, widening access and participation at the input stage, then delivering a social 'dividend' through the altruistic actions of the graduates.

\subsubsection{Social Mobility Index}

As with the Washington Monthly ranking, the Social Mobility Index (SMI) is an explicit effort to shift policy focus away from historical conceptualisations of higher education prestige to encourage institutions to compete around factors which improve access. The SMI only ranks US colleges. The SMI considers five main variables and assigns weightings or 'sensitivity score', as detailed in Table 2.

\section{TABle 2 SMI RANKIng Methodology}

\begin{tabular}{|l|l|}
\hline Indicator & Weighting \\
\hline Tuition fees: the higher the tuition, the lower the SMI ranking & 291 \\
\hline $\begin{array}{l}\text { Economic background of students: the percentage of students within the student body whose } \\
\text { family incomes are less than or equal to the national median. }\end{array}$ & 318 \\
\hline Graduation rate & 207 \\
\hline Early career salary outcomes for graduates & 160 \\
\hline $\begin{array}{l}\text { Endowment (e.g. donations to the school) - the higher the endowment, the lower the SMI } \\
\text { ranking }\end{array}$ & 74 \\
\hline
\end{tabular}

The weightings are significantly biased towards tuition fees and widening access, issues which have been historically central to the equity discussion in the US. The rationale for this is not only that tuition and economic background are the most critical front-end determinants for access, they are also the two variables over which policy makers have the greatest control. By contrast, improving early career salary or graduation rates tend to require more substantial policy and system changes over a longer term 
(CollegeNet, 2017). The SMI considers a longer phase of the student's higher education experience, starting with access and affordability, including success (graduation) and on to early-career incomes.

\subsubsection{The Good Universities Guide (Australia)}

The Good Universities Guide is provided by the Good Education Group. The Guide is available in printed and e-book form and as a website. Its search function allows the user to search for courses and sort them by various criteria. They also provide several ratings systems including: Student/Teacher ratio; Overall Experience; Skills Development; Student Demand; and Student Retention.

The guide also includes a rating for Social Equity, which shows what proportion of domestic students enrolling at each university "come from low socio-economic or disadvantaged backgrounds" (https://www.gooduniversitiesguide.com.au/university-ratings-rankings/2018/social-equity/).

Comparative searches result in a ranked list of universities, sorted from highest to lowest equity population. The equity population percentage is provided, and each institution is also rated between zero and five stars. No information, however, is given to illuminate where the percentage is sourced from or how the star rating is calculated.

\subsubsection{QED Ranking (La Trobe University)}

In 2015, Jane Long and Andrew Harvey from La Trobe University devised a ranking taking in measures of equity and diversity, to re-define academic quality as a more inclusive concept. The ranking was devised to start "a conversation, not to be definitive" (O'Hare, 2015). The methodology was never published, however media releases relating to the ranking indicate that the primary equity indicator used was participation rates of students who were from regional, Indigenous or low SES backgrounds and students with a disability (Long \& Harvey, 2015). Unlike the other equity ranking systems described above, the Long/Harvey rank was incorporated into a wider ranking system of academic performance, that also considered research performance and teaching and learning quality.

\subsubsection{U.S. News and World Report College Rankings}

U.S. News provides nearly 50 different types of numerical rankings and lists of US Colleges. In 2018, the ranking for the 2019 college year incorporated aspects of social mobility for the first time into its methodology. Specifically, in its outcomes section, it incorporated the graduation rates of Pell Grant recipients ${ }^{6}$, and Pell-recipient graduation rates to those of all students. Both of those figures were then adjusted for the share of all students who were Pell recipients. This indicator was worth five percent of the overall ranking (Jaschik, 2018). U.S. News also removed from its methodology the acceptance rate, whereby colleges would be raked higher if they rejected more applicants. The methodology also decreased the weighting of 'expert opinion', which critics claimed rewarded historical prestige (Jaschik, 2018).

\footnotetext{
${ }^{6}$ Pell Grants are needs-based grants that are intended to provide low-income students access to postsecondary education. Pell Grants are sometimes used as a proxy for educational disadvantage, in the same way AUSTUDY payments are in Australia.
} 


\subsubsection{UK Performance Indicators}

In the UK, the Higher Education Statistics Agency (HESA) has developed performance indicators for higher education providers. The indicators cover: widening participation indicators; non-continuation rates; and graduate employment. The purpose of the indicators is to:

- Provide reliable information on the nature and performance of the UK higher education sector;

- Allow comparison between individual HE (higher education) providers of a similar nature, where appropriate;

- Enable HE providers to benchmark their own performance;

- Inform policy developments; and

- Contribute to the public accountability of higher education.

(Higher Education Statistics Agency, n.d.)

Specifically, HESA counselled against the use of a ranking index, or 'league table' for the following reasons:

No meaningful league table could fairly demonstrate the performance of all HE providers relative to each other. The HE sector is extremely diverse. Each HE provider has its own distinct mission, and each emphasises different aspects of higher education. Because of this diversity, and the need to compare providers fairly, we have used a range of indicators and benchmarks. Even so, we do not cover all aspects of a HE provider's performance. In particular, these indicators concentrate on performance relative to full-time undergraduates. (Higher Education Statistics Agency, n.d.)

Instead, the performance indicators used a benchmark, which was a sector average calculated then adjusted for each higher education provider to consider significant differences at the institutional level. These included subjects of study, qualifications on entry, and age on entry. From this is derived an 'adjusted sector benchmark' and 'location-adjusted' benchmarks.

The overall benchmark is designed to see how well an institution is performing compared to a sector average. A ' + ' or '-' symbol against an institution identifies those performing significantly better or worse.

Further, the location-adjusted benchmarks can be used to compare 'similar' universities. For example, HESA believe, any HE provider where most students enter with very good A-level qualifications should not usually be compared with one whose students come from a wider range of educational backgrounds. Similarly, a medical school and a college that mainly concentrates on engineering subjects are not comparable, as medical students have much lower non-continuation rates than engineering students (Higher Education Statistics Agency, n.d.).

Widening participation indicators show, for each provider: the percentage of students who attended a school or college in the state sector; and the percentage who come from a low participation neighbourhood (as denoted by its postcode). For mature students and for young part-time students, there is just one participation indicator, the percentage of entrants who have no previous HE qualification and come from a low-participation neighbourhood. 


\section{Part B: Developing the Ranking}

\section{Identifying Indicators for Inclusion in an Equity Ranking}

\subsection{Introduction}

Part B of this report explores the approach taken by the project team to developing the core aspects of the Higher Education Equity Ranking in regard to determining appropriate indicators and identifying a feasible methodological approach for constructing the ranking. Overall, the approach taken draws on the background literature, higher education equity policies (both past and present, and national and international), wide consultation within the HE sector, and guidance from DET.

For identifying appropriate indicators for the ranking, the decision-making processes used by the research team is similar to the approach taken in the development of the EPF by Pitman \& Koshy (2014). This involves three distinct steps.

- First, a broad series of domains need to be identified. These are the highest level of classification in an indicator table;

- Second, key sources of indicators are identified under each domain. These provide data from which indicators can be generated; and

- Third, individual indicators need to be identified from given sources.

In following this approach, this part of the report begins by examining the domains that have been considered for the ranking. It maps out six broad domains. For each domain the discussion explores its relevance to equity policy (based on literature, consultation and the expertise of the research team), possible indicators and their sources for 'measuring' the domain, data and its potential for inclusion in the ranking (including a 'data availability' perspective and validity perspective).

The specific indicators identified as potential measures for inclusion in the ranking are then examined. This discussion is framed around the way in which a chosen indicator could be calculated to best be prepared for inclusion in the ranking.

The discussion then examines potential methodologies that could be applied to constructing the ranking. In this section a range of options are presented, and their individual merits and feasibility are explored.

\subsection{SMARVR decision-making}

The approach outlined above for identifying suitable domains, then indicators and methodological approaches involves the use of SMARVR criteria. SMARVR is the project team's systematic approach to assessment of ranking elements, and is derived from SMART -Specific, Measurable, Accountable, Relevant and Timely - a mnemonic acronym first used by Doran (1981), which is regularly used as a part of organisational management practice, as a means of setting objectives. It has since evolved and been adapted for use in diverse settings.

In respect to measuring performance in public and/or NFP organisations, Positer (2008, p. 63), SMART and SMART-like objectives can assist in providing a clear definition of tangible results to be accomplished, accompanied by an indication of the specific measures that will be used to evaluate success or failure in 
achieving them. The SMART criteria were employed by Pitman \& Koshy (2014) in their development of the EPF. Our adaptation of the criteria is focussed on identifying those indicators of higher education institutional practice with the potential to have a positive impact on equity outcomes. In this context, SMARVR refers to:

- Specific-Using indicators that target a specific area for improvement.

- Measurable - The indicator uses quantitative data which are robust and available on a regular basis; and which will measure performance against the objective.

- Accountable - The indicator relates to a performance measurement where it is possible for the institution to influence the outcome, even if not entirely.

- Relevant - the indicator relates to an area of improvement that is relevant to higher education equity.

- Value - That which the indicator measures adds value to the final ranking system.

- Revision - The indicators and their supporting data are regularly re-visited and re-assessed for relevance so that, if and where applicable, they can be updated or even replaced.

An error sometimes made when constructing ranking systems is to include indicators that are highly correlated with others and/or do not provide relevant information (Soh, 2017). Adding these types of indicators may give the appearance of comprehensiveness, but do not add value and may instead cause unintended negative consequences, such as additional resources required to construct the ranking system or making it less transparent to stakeholders. Consequently, the SMARVR approach, where appropriate, excludes such indicators. In some cases, where the case of redundancy is arguable, the relevant indicator is left in and the final decision made during the testing phase.

Finally, the part of the assessment in relation to revision $(R)$ will be addressed at a later stage in this report, as it is partly contingent upon the final logic of the ranking system. Therefore, the assessment below only encompasses the first five elements, i.e. SMARV.

\subsection{Domains and Data Sources for Australian Higher Education Equity Ranking}

Based on the background work undertaken in this study, six domains have been identified as being important to higher education equity. In the discussion below, each of these domains is briefly explained and indicators are identified and then assessed based on the SMARV criteria to examine relevance and feasibility for consideration of use in the Higher Education Equity Ranking. These domains are:

1. Aspiration

2. Academic Preparation

3. Access and Participation

4. First Year Experience

5. Progress During Higher Education Study

6. Graduation Outcomes

In order for an indicator to be included in the project's ranking system, the first five criterion (i.e. SMARV) have to be met. 


\subsubsection{Aspiration}

\section{Outline of Aspiration domain}

Aspiring to higher education is the critical first step towards participation. In broad terms, aspiration is a capacity to imagine a particular future (Sellar \& Gale, 2011). Aspiration is a complex construction, encompassing issues of identity, social expectation, preferences, understandings of certain possibilities, and the capacity and resources to realise these aspirations (Gale et al., 2013). Khattab (2015) makes the distinction between aspiration and expectation, with the latter including the compounding effects of students' perceptions and experience of potential barriers to participation. This is a particularly relevant distinction in equity where the compounding effect of disadvantage inhibit participation. Research has established that, along with financial costs (real or perceived), a key barrier to higher education participation by low SES students is a perception by many in the target group that higher education is neither appropriate or of value to them (Dow, Adams, Dawson, \& Phillips, 2010). The sense that university is a realistic option is significantly affected by individuals' beliefs about their own academic capabilities and their preparedness for university. An inquiry by the Victorian Parliament's Education and Training Committee established that many capable young people from disadvantaged backgrounds lacked confidence in their academic abilities, and believe that they would not be able to gain entry to university, or to succeed in higher education (Victorian Parliament's Education and Training Committee, 2009).

\section{SMARV assessment of Aspiration Domain}

Universities play an important role in nurturing higher education aspirations for equity-group students. This is recognised in the Partnerships component of DET's Higher Education Participation and Partnerships Program (HEPPP), which "provides funding to universities to raise the aspirations and build the capacity of people from low SES backgrounds to participate in higher education"

(https://www.education.gov.au/higher-education-participation-and-partnerships-programme-heppp).

Evaluations have established the effectiveness of such activities (e.g. Gale et al., 2010; Hahn, Leavitt, \& Aaron, 1994). Currently however, there is no widespread nor systematic collection of data of the aspirational activities undertaken by Australian higher education institutions, though evaluations occur regularly at the individual, programmatic level.

Data on higher education aspiration are collected through the Longitudinal Surveys of Australian Youth (LSAY) (e.g.Gemici et al., 2014). However, LSAY data do not collect individual institutional data. Therefore, whilst the LSAY can provide data regarding an individual's intention to enter higher education, and how that decision may have been influenced by institutional activity, it does not record which institution. It may however be possible to link LSAY data to the Higher Education Information Management System (HEIMS) - DET's primary data reporting platform for universities. Alternatively, this could, potentially, be done using data sourced through the Widening Participation Longitudinal Study (WPLS) project, funded through HEPPP from 2014-16.

Some data exist for measuring the 'value add' of individual higher education institutions on student aspiration. Mostly this is collected by individual institutions, to gauge the effectiveness of their outreach activities. However, data are not collected in a uniform nor regular fashion.

A more robust data source might be found in tertiary admission centre (TAC) application data, which records, for example, the percentage share of low SES applications to particular university groups 
(Department of Education and Training, 2017b). However, further investigation would be required to establish whether data are collected for each of the equity groups and if so, whether the same definitions are used as those in HEIMS (e.g. students with disability, NESB students, etc.). Even were the data found to be robust and encompassing all equity groups, the value of adding application data is limited. Although TAC applications are an indication of aspiration, they are highly correlated to enrolment data. Not surprisingly, universities or university groups that receive below-average numbers of offers, enrol belowaverage numbers of students, from the relevant equity group; and vice versa (Department of Education and Training, 2017b; National Centre for Student Equity in Higher Education, 2017). Information derived from the TAC applications data is therefore rendered largely redundant by the HEIMS enrolment data, which is covered in the Access and Participation domain.

TABLE 3: DATA SOURCES FOR ASPIRATION DOMAIN INDICATOR

\begin{tabular}{|l|l|l|l|}
\hline Type of Indicator & Data source & SMARV criterion met & Status in project \\
\hline $\begin{array}{l}\text { Intentions towards HE } \\
\text { study }\end{array}$ & LSAY & S, A, R, V & Not included \\
\hline $\begin{array}{l}\text { Intentions towards HE } \\
\text { study }\end{array}$ & WPLS & $\mathrm{S}, \mathrm{A}, \mathrm{R}, \mathrm{V}$ & Not included \\
\hline $\begin{array}{l}\text { Developing aspirations to } \\
\text { study HE }\end{array}$ & Individual HE institutions & $\mathrm{S}, \mathrm{A}, \mathrm{R}, \mathrm{V}$ & Not included \\
\hline Application to study HE & TAC & $\mathrm{S}, \mathrm{M}, \mathrm{A}, \mathrm{R}$ & Not included \\
\hline
\end{tabular}

\section{Final assessment}

- Based on the SMARV assessment, no indicators from this domain are included in the project ranking.

- It is recommended that further work be undertaken to establish whether indicators could be developed to incorporate measurements of aspiration in a future iteration of a higher education ranking system.

\subsubsection{Academic Preparation}

\section{Outline of Academic Preparation Domain}

Academic preparation relates to student academic preparedness and performance in pre-tertiary or previous tertiary experience. Prior academic achievement is the primary indicator of subsequent academic success (e.g. Gemici, Lim, \& Karmel, 2013). It is an important consideration when exploring equity issues because academic potential has been shown to be influenced by socio-economic factors (e.g. Department of Education Employment and Workplace Relations, 2010; Lim, Bednarz, \& Karmel, 2014).

Academic preparation occurs either as part of a non-tertiary specific programme or a tertiary specific program. For example, secondary schooling is a non-tertiary specific environment in that it caters to all students, regardless of whether they are progressing to higher education or not. However, within secondary schooling systems, tertiary-specific academic programs are sometimes provided. Furthermore, higher education institutions frequently run their own tertiary-preparation programs. The most common are enabling programs, which attract higher than average enrolments from equity group students (Hodges et al., 2013; Pitman, Harvey, et al., 2017). Therefore, whether as part of an integrated secondary-school curriculum or a standalone educational venture, higher education institutions can have a direct influence on increasing the academic preparation of equity group students. 


\section{SMARV assessment of Academic Preparation Domain}

Academic Preparation is a broad domain in that it captures the effects of not only institutional and course selection by students but, more generally, those influences contributing to the decision to enter higher education. It also encompasses all of compulsory education and potentially includes a wide spectrum of activities designed for all students, not just those entering higher education.

A wealth of data is available through NAPLAN results, as well as ATAR results and other, alternative admissions entry tests, such as the Special Tertiary Admissions Test (STAT). However, generally there is no direct line of responsibility among higher education institutions for a prospective student's academic performance in any of these. Pre-tertiary academic performance is therefore treated as a context for the equity ranking system, rather than as an element to be tracked as an indicator.

More specifically to the higher education sector, institutions can and do deliver activities and programs designed to improve the academic preparation of pre-tertiary students. Adult education courses are also run, sometimes in conjunction with higher education institutions, for people who have not previously completed Year 12 studies. Some of these activities specifically target equity groups. For example, in 2015 a total of 48 enabling programs were offered by 27 out of 38 of Australia's higher education institutions. Of these, 14 institutions ran programs specifically for Indigenous students (Pitman, Harvey, et al., 2017). In other research, a 2011 review found that approximately $50 \%$ of students enrolled in all enabling courses were identified as being from several equity groups such as Indigenous students, regional and remote students and low SES status students, compared with $30 \%$ of all domestic undergraduate enrolments (Lomax-Smith, Watson, \& Webster, 2011).

Institutional activity in respect of academic preparation is closely linked to their aspirational activities, for example through outreach programs. As with the aspirational indicators, most data are collected by individual institutions, to gauge the effectiveness of their outreach activities. It is therefore not collected in a uniform nor regular fashion. Reliable data, adding value, do not yet exist for the domain of academic preparation. With the recent move to make Commonwealth funding for enabling courses Commonwealth-supported (e.g. HECS-HELP), presumably this will lead to all enabling students receiving a Commonwealth Higher Education Student Support Number (CHESSN). This could provide a potential source of data for an indicator, in the future.

A final potential source of data might come from the recognition of prior learning (RPL) processes adopted by some universities, in order to recognise various forms of non-formal and informal learning a person has acquired, in lieu of more traditional formal learning experiences. These assessments have been shown to have the potential to create alternative pathways to higher education for disadvantaged students (Pitman, 2009). As with outreach activities however, institutional data collection practices are ad hoc. 
TABle 4: DATA SOURCES For ACAdemic Preparation Indicator

\begin{tabular}{|l|l|l|l|}
\hline Type of Indicator & Data source & SMARV criterion met & Status in project \\
\hline $\begin{array}{l}\text { Pre-tertiary academic } \\
\text { performance }\end{array}$ & NAPLAN & S, M, R & Not included \\
\hline $\begin{array}{l}\text { Pre-tertiary academic } \\
\text { performance }\end{array}$ & ATAR & S, M, R & Not included \\
\hline $\begin{array}{l}\text { Pre-tertiary academic } \\
\text { performance }\end{array}$ & $\begin{array}{l}\text { STAT (also other } \\
\text { alternative, nationally- } \\
\text { recognised tests) }\end{array}$ & S, M, R & Not included \\
\hline $\begin{array}{l}\text { Non-traditional } \\
\text { assessments of academic } \\
\text { preparation }\end{array}$ & $\begin{array}{l}\text { Individual HE institutions } \\
\text { (e.g. portfolio, RPL, etc) }\end{array}$ & S, A, R, V & Not included \\
\hline $\begin{array}{l}\text { Alternative academic } \\
\text { preparation }\end{array}$ & Enabling programs/CHESSN & S, A, R, V & Not included \\
\hline
\end{tabular}

\section{Final assessment}

- Based on the SMARV assessment, no indicators from this domain are included in the project ranking.

- It is recommended that further work be undertaken to establish whether indicators should be developed to incorporate measurements of academic preparation in a future iteration of a higher education ranking system.

\subsubsection{Access and Participation}

\section{Outline of Access and Participation Domain}

As identified earlier in this report, access and participation remains one of the cornerstones of higher education equity policy and practice internationally as well as in Australia. Access and participation can be measured in both actual and relative terms. Since the early 90s, Australian higher education policy formulated at the national level has focussed on relative targets or goals (e.g. Bradley et al., 2008; Department of Employment Education and Training, 1990). Although no relative goals currently exist, the underlying principle that higher education participation should aspire towards proportional representation remains in place.

\section{SMARV assessment of Access and Participation Domain}

Participation is key to contextualising many other performance indicators, such as retention and success. It is well-established by research that the resources, support and even teaching and learning approaches for certain under-represented groups differ to those for the homogenous, mainstream student population (Behrendt, Larkin, Griew, \& Kelly, 2012; Nelson, Duncan, \& Clarke, 2009; Stephens, Fryberg, Markus, Johnson, \& Covarrubias, 2012).

There are several, high-quality data sources from which access and participation indicators can be constructed (see below). All meet the first four criterion for SMARV. However, these indicators are mostly measuring the same elements of access and participation, with minor variances. Therefore, inclusion of one renders the others redundant. 
TAC data can be sourced to information university offers and subsequent acceptance rates. HEIMS data can be used to develop an enrolment indicator. Of all the data, the HEIMS enrolment data is considered by the project team to be the most consistently defined and readily accessible for all institutions, and therefore should take precedence in an equity ranking system.

It is also important to consider not only which institutions students enrol in, but which degrees. Positive employment outcomes are more highly correlated with the course the student studied, than the institution they graduated from (e.g. Graduate Careers Australia, 2014; Koshy, Seymour, \& Dockery, 2016). Most notably this includes courses of study in medicine. However, since not all universities offer these courses, inclusion of this indicator could disadvantage some institutions. Furthermore, Australian higher education institutions vary significantly in terms of overall courses offerings and in some cases, course delivery. For example, the universities of Melbourne and Western Australia have adopted a professional postgraduate model, meaning that students now complete more generic undergraduate degree (e.g. in science, arts, etc) before moving on to a professional, full-fee paying degree. A ranking system, measuring at the undergraduate level would therefore not accurately reflect the professional trajectory of the student. Therefore, whilst enrolment in elite degrees is an important consideration for higher education equity policy, a ranking system is not the most appropriate way to measure nor encourage action.

Financial barriers are a large impediment to higher education access for many disadvantaged students. In Australia, the provision of an income-contingent loan system has ameliorated some of these pressures in comparison to other countries (Chapman \& Ryan, 2005); however cost-of-living and other expenses cause financial hardship for many students (Baik, Naylor, \& Arkoudis, 2015). Higher education institutions play a part by offering means-tested or equity-specific financial support, such as fee waivers, emergency loans or scholarships. However, currently relevant data are not collected systematically for the purposes of a higher education ranking system.

\section{TABLE 5: DATA SOURCES FOR ACCESS AND PARTICIPATION INDICATOR}

\begin{tabular}{|l|l|l|l|}
\hline Type of Indicator & Data source & SMARV criterion met & Status in project \\
\hline $\begin{array}{l}\text { Offer to study at HE } \\
\text { institution }\end{array}$ & TAC & S, M, A, R & Not included \\
\hline $\begin{array}{l}\text { Acceptance of offer to } \\
\text { study at HE institution }\end{array}$ & TAC & $\mathrm{S}, \mathrm{M}, \mathrm{A}, \mathrm{R}$ & Not included \\
\hline $\begin{array}{l}\text { Deferment of offer to study } \\
\text { at HE institution }\end{array}$ & TAC & $\mathrm{S}, \mathrm{M}, \mathrm{A}, \mathrm{R}$ & Not included \\
\hline Enrolment in 'elite' degrees & HEIMS & $\mathrm{S}, \mathrm{M}, \mathrm{R}$ & Not included \\
\hline $\begin{array}{l}\text { Provision of equity } \\
\text { scholarships/other financial } \\
\text { support }\end{array}$ & Individual HE institutions & $\mathrm{S}, \mathrm{A}, \mathrm{R}, \mathrm{V}$ & Not included \\
\hline Enrolment in HE institution & HEIMS & $\mathrm{S}, \mathrm{M}, \mathrm{A}, \mathrm{R}, \mathrm{V}, \mathrm{R}$ & Included \\
\hline
\end{tabular}

\section{Final assessment}

- Based on the SMARV assessment, it is recommended that HEIMS enrolment data be used to inform the Access and Participation domain. 


\subsubsection{First Year Experience}

\section{Outline of First Year Experience Domain}

As the name suggests, the First Year Experience domain relates to 'surviving' the first year of research, the criticality of this having been well-established by research (e.g. Luzeckyj, King, Scutter, \& Brinkworth, 2011; Southgate et al., 2014). The first-year experience encompasses aspects such as establishing a sense of belonging, adjusting to studies, managing finances, succeeding in subject and of course, continuing to the second year and beyond.

\section{SMARV assessment of First Year Experience Domain}

Many stakeholders consulted throughout this project reinforced the importance of first-year retention, with some describing it as the most important equity indicator of all. Deferral and discontinuation rates of first year students are a key concern of institutions across the sector. Support programs and pastoral care are essential for many students, as they struggle to balance personal and work commitments with study, as well as establish a sense of purpose and belonging. (Bexley, 2008). Many groups of students under-represented in higher education can feel a stronger sense of alienation in the first year, compared to other students (Reay, Crozier, \& Clayton, 2009). A 2014 analysis of Australian higher education students in their first year found:

- Low SES students felt less academically prepared and experienced more financial stress than high SES students;

- A larger proportion of Indigenous students reported having withdrawn from subjects in their first year, compared to other students;

- Students from regional and remote backgrounds were more likely to have deferred their enrolment prior to first year than other students; and

- Compared to other students, a larger proportion of disabled students reported difficulties with maintaining their motivation or with comprehending the material. They were also more likely to feel overwhelmed by their workloads, to frequently skip classes and to frequently come to class without completing readings or assignments (Baik et al., 2015).

In current equity reporting by the Department of Education and Training, retention is defined as:

The number of students who commenced a bachelor course in year( $x)$ and did not complete in year $(x)$ or year $(x+1)$ and continued in year $(x+1)$ (retained students), as a proportion of all students who commenced a bachelor course in year $(x)$ and did not complete in year $(x)$ or year(x+1). (Department of Education and Training, 2017a)

Furthermore, DET draws a distinction between the "crude" retention rate (i.e. students retained at the same university) and the "adjusted" retention rate (i.e. students retained at any institution).

The DET also calculates attrition rates, which are essentially the obverse of retention. Therefore, for the purposes of an equity ranking system, inclusion of a retention indicator would render an attrition indicator redundant.

DET also calculates success rates for commencing students, which is defined as: 
(for year $x$ ) the proportion of actual student load (EFTSL) for units of study that are passed divided by all units of study attempted (passed + failed + withdrawn) (Department of Education and Training, 2017a).

Success is an important consideration for a number of reasons; chief amongst them being that a) higher success rates set up a positive feedback loop for the student and improve future study outcomes and $b$ ) higher success rates reduce both the amount of time and cost of studying higher education, by avoiding repeating units.

There is some correlation between success and retention; that is, institutions with higher retention rates have higher success rates and vice versa. However, the correlation is not definitive (see Table 6). Therefore, it is recommended that success also be included in the initial stages of testing, to see what effect its inclusion has on the rankings.

TABle 6: Correlation between retention AND SUCCESS: TABle A/B InStitutions

\begin{tabular}{|l|l|l|l|}
\hline 2011 & 2012 & 2013 & 2014 \\
\hline 0.616 & 0.647 & 0.629 & 0.672 \\
\hline
\end{tabular}

$0=$ no correlation

$1=$ perfect correlation

Source: derived from Higher Education Statistics Series 2016: Appendix 5- Equity performance data

Another means by which the first-year experience might be assessed is through a student survey. QILT collects information about the student experience via their Student Experience Survey. Around 148,000 undergraduate students and 58,000 postgraduate coursework students from Australian universities and non-university higher education institutions (NUHEls) participated in the 2017 SES $^{7}$. Also, for over twenty years, the Melbourne Centre for the Study of Higher Education has undertaken a national survey of firstyear students every five years. Questions have focused on: the sense of purpose and transition to university; quality of teaching; and overall course experience (Baik et al., 2015). However, the lack of disaggregated data (i.e. no systematic identification of the target equity groups), plus the fact that it would be unlikely for a ranking system to prioritise student satisfaction over first-year retention and success, mean even it could be collected, any data collected through the surveys would likely have little if any effect on the final rankings.

TABLE 7: DATA SOURCES FOR FIRST-YEAR EXPERIENCE INDICATOR

\begin{tabular}{|l|l|l|l|}
\hline Type of Indicator & Data source & SMARV criterion met & Status in project \\
\hline First-year retention & HEIMS & S, M, A, R, V, R & Included \\
\hline First-year attrition & HEIMS & S, M, A, R & Not included \\
\hline First-year success & HEIMS & S, M, A, R, V, R & Included \\
\hline First-year student survey & $\begin{array}{l}\text { Melbourne Centre for the } \\
\text { Study of Higher Education }\end{array}$ & S, A, R & Not included \\
\hline First-year student survey & $\begin{array}{l}\text { QILT Student Experience } \\
\text { Survey }\end{array}$ & S, A, R & Not included \\
\hline
\end{tabular}

\footnotetext{
${ }^{7}$ https://www.qilt.edu.au/about-this-site/student-experience
} 
Final assessment

- Based on the SMARV assessment, it is recommended that HEIMS first-year retention and success data be used to inform the First Year Experience domain.

\subsubsection{Progress During Higher Education Study \\ Outline of Progress during Higher Education Study Domain}

Whilst access and participation remain the foundation of higher education equity policy and practice, attention is increasingly turning to what happens to the students after they enrol. There are social and economic benefits derived from higher education participation; however greater benefit is associated with successful completion of studies. It is therefore concerning that equity group students regularly report lower levels of completion from higher education studies, compared to the general cohort (e.g. Department of Education, 2015; Edwards \& McMillan, 2015b). A recent review in higher education standards recommended that each institution:

should have its own comprehensive student-centred retention strategy, which is regularly evaluated. These strategies could include institutional retention benchmarks and, as appropriate, processes for entry and exit interviews, the integration of data-based risk analytics and targeted support interventions, a suite of support services and a means to reengage with students who have withdrawn. (Higher Education Standards Panel, 2017, p. 9)

Key outcomes include ongoing retention, ongoing success, student satisfaction and, ultimately, timely completion of the degree.

\section{SMARV assessment of Progress During Higher Education Study Domain}

As with the first-year experience, key indicators in this domain are retention (or attrition) and success (i.e. the proportion of units passed). Data for these indicators are currently collected by higher education institutions, however they are not systematically reported to the Commonwealth Department of Education and Training. Furthermore, as retention and success data are included in the First Year Experience domain, the value of adding additional data here may be marginal.

Course-weighted average (CWA) was also considered as a possible indicator. Data are not currently collected nation-wide, nor in some cases at the institutional level. Furthermore, there is a degree of subjectivity regarding CWA calculations for two reasons. First, CWA is assessed at the institutional level and not necessarily benchmarked against any universal standard. Second, not all courses of study use CWA, using instead other metrics such as a simpler pass/fail assessment.

DET regularly conducts cohort analyses to analyse completion rates (Department of Education, 2014, 2015) and the associated reports provide valuable data for the higher education sector. Completion can be assessed at multiple points i.e. four, six, eight or nine years after the cohort enrolled. There was a majority view in the stakeholder feedback process that completion should be assessed at the further end of the spectrum i.e. at the nine-year point. This was due to the perception that certain groups of students take longer to complete and taking an earlier point of comparison would bias against some institutions. In fact, the evidence from the data collected so far is that student groups with below-average completion rates at the four-year point also have below-average completion rates at the nine-year level. However, to 
alleviate stakeholder concern, using the nine-year completion rate could be used in the proposed equity ranking system.

Other aspects of completion were also considered for indicators; namely: time to completion; and completed share of 'elite' degrees. The major objection to time to completion, as noted in the recent review of higher education standards, is that 'timely' is a largely subjective construct (Higher Education Standards Panel, 2017). The reservations to using an 'elite' degree indicator in this domain are the same as those expressed for using it in the previous (i.e. Access and Participation) domain (see above).

Finally, using a measure of student satisfaction was considered as an indicator. Relevant data are collected by DET and reported through the Quality Indicators for Learning and Teaching website (QILT). However, the valency of this indicator was rejected for the same reasons the Student Experience Survey was rejected for the previous (i.e. First Year Experience) domain (see above).

\section{TAble 8: Data sources for Progress During Higher Education Study Indicators}

\begin{tabular}{|l|l|l|l|}
\hline Type of Indicator & Data source & SMARV criterion met & Status in project \\
\hline Course success & HEIMS & S, M, A, R, & Not included \\
\hline Course weighted average & Individual HE institutions & $\mathrm{S}, \mathrm{M}, \mathrm{A}, \mathrm{R}$ & Not included \\
\hline Completions & HEIMS & $\mathrm{S}, \mathrm{M}, \mathrm{A}, \mathrm{R}, \mathrm{V}, \mathrm{R}$ & Included \\
\hline $\begin{array}{l}\text { Completed share of 'elite' } \\
\text { degrees }\end{array}$ & HEIMS & $\mathrm{S}, \mathrm{M}, \mathrm{A}, \mathrm{R}$ & Not included \\
\hline Time to completion & HEIMS & & \\
\hline Student experience survey & QILT & $\mathrm{S}, \mathrm{M}, \mathrm{A}, \mathrm{R}$ & Not included \\
\hline
\end{tabular}

\section{Final assessment}

- Based on the SMARV assessment, it is recommended that completion data be used to inform the Progress During Higher Education Study domain.

\subsubsection{Graduation Outcomes \\ Outline of Graduation Outcomes Domain}

The primary public policy drivers for action specific to equity group students have been described mostly in terms of social justice, however the assumption, generally, is that educational access translates into similar post-graduation success for all students, regardless of prior educational or social disadvantage (Pitman, Roberts, et al., 2017). However, this is not necessarily the case. A recent study found that:

- Low SES graduates earned below-median wages compared to other full-time employed graduates;

- Graduates from non-English-speaking backgrounds earned below-median wages in both full- and part-time employment; and

- A lower-than-average proportion of graduates with a disability secured employment in permanent or open-ended contracts. (Pitman, Roberts, et al., 2017)

Students engage with higher education for a number of reasons; many graduates do socially valuable jobs that are not necessarily higher paying. Nonetheless, reliable information on graduates' earnings is crucially important from a public policy perspective (Britton, Dearden, Shephard, \& Vignoles, 2016). 
Further studies in higher education is also an outcome directly attributed to undergraduate success. Research suggests the lower level of participation of low SES students in postgraduate education may reflect 'thin' undergraduate educational experiences, with a greater proportion enrolled part-time, and in external and multi-modal modes of study (Bell \& May, 2016).

\section{SMARV assessment of Graduation Outcomes Domain}

Based on prior research, public policy direction and stakeholder consultation, the project team conceptualised two broad spheres of graduate outcomes: employment and further study. However, depending on how these are delineated, there are multiple options for constructing indicators, such as whether or not:

- Employment is full or part-time;

- The graduate is 'under employed';

- The graduate is employed in a field or profession relevant to the degree they studied; or

- The further studies are in an 'elite' field or with an 'elite' institution.

Added to this were considerations about:

- How soon after graduation the assessment should be made;

- How much the graduate was earning; and

- What source of data should be used, in cases where multiple sources of data exist

Currently, QILT measures employment and further studies outcomes less than twelve months after graduation, and more than three years after graduation. Both approaches have advantages and disadvantages. For the less-than-twelve month survey, the advantage is that contact details for graduates are relatively current and there tends to be more responses to the survey. The primary disadvantage is that this may not be enough time for many graduates to full realise the benefit of their degree. For the greater-than-three years survey, the advantage and disadvantage are the reverse i.e. more time for employment outcomes to be realised, but fewer survey participants.

Data is also possible through the Australian Taxation Office (ATO). This has the advantage of offering much more - and in many respects more detailed - data, at any point in time required. However, there were some issues with using ATO data. For example, it is not possible to easily determine whether the graduate is over or under-employed or even working part-time or full-time. Nor is it possible to easily determine whether the graduate is working in a field relevant to the degree studied. Furthermore, data regarding further study - to the level of detail required - were not available through the ATO. Discussions with the QILT Team revealed that currently, some issues with the data-matching process remain. The future potential for ATO data to inform higher education equity performance could be significant, if these issues can be resolved. For example, ATO data can be disaggregated to both the institutional and individual level and report actual income, not self-reported.

A further source of data is the Household, Income and Labour Dynamics in Australia (HILDA) survey. This has the advantage of providing a very rich level of data, at both the demographic and economic/expenditure level. However, the specific sample sizes (i.e. participants recently attending university) are relatively small, which could prove problematic for a ranking system. Furthermore, as with the ATO data, some of the measurements being sought for the ranking system, such as levels of employment and relationship to the degree studied, might have to be inferred rather than described. 
Accordingly, the project team preferred the QILT data, due to its greater relevance to the ranking system's objectives. The less-than-twelve month data was also preferred, to improve sample sizes. ${ }^{8}$ Whilst this presented an issue regarding timeliness (namely, that it might be too early for all graduates to realise employment outcomes), this potential problem was ameliorated by the design of the ranking system, which adopted a comparative approach, rather than a relative approach (see next section). That is, since the ranking system was designed to compare equity student graduate outcomes against nonequity student outcomes, and/or equity-student outcomes at one institution versus equity student outcomes at other institutions, the point in time at which the measurement was taken became less important than the comparison itself.

Another consideration in choosing an indicator of outcomes based on graduate pathways was that the concept of graduate 'success' varies greatly. Stakeholder consultation in particular highlighted that a narrow focus only on employment outcomes in this indicator is probably not sufficient. For this reason, the project team preferred a relatively broad measure of graduate outcome, denoted the 'earning or learning' indicator. As the name suggests, this indicator measures whether or not, within twelve months of graduation, the student is either employed, undertaking further studies, or both.

TABLE 9: DATA SOURCES FOR GRADUATION OUTCOMES INDICATORS

\begin{tabular}{|c|c|c|c|}
\hline Type of Indicator & Data source & SMARV criterion met & Status in project \\
\hline \multirow{3}{*}{$\begin{array}{l}\text { Employment }<12 \text { months } \\
\text { after graduation }\end{array}$} & QILT & $\mathrm{S}, \mathrm{M}, \mathrm{A}, \mathrm{R}$ & Not included \\
\hline & ATO & $\mathrm{S}, \mathrm{A}, \mathrm{R}$ & Not included \\
\hline & HILDA & $S, A, R$ & Not included \\
\hline \multirow{3}{*}{$\begin{array}{l}\text { Employment }>3 \text { years } \\
\text { months after graduation }\end{array}$} & QILT & $S, A, R$ & Not included \\
\hline & ATO & $S, A, R$ & Not included \\
\hline & HILDA & $S, A, R$ & Not included \\
\hline \multirow{3}{*}{$\begin{array}{l}\text { Earnings }<12 \text { months after } \\
\text { graduation }\end{array}$} & QILT & $S, A, R$ & Not included \\
\hline & ATO & $S, A, R$ & Not included \\
\hline & HILDA & $S, A, R$ & Not included \\
\hline \multirow{3}{*}{$\begin{array}{l}\text { Earnings }>3 \text { years after } \\
\text { graduation }\end{array}$} & QILT & $S, A, R$ & Not included \\
\hline & ATO & $S, A, R$ & Not included \\
\hline & HILDA & $\mathrm{S}, \mathrm{A}, \mathrm{R}$ & Not included \\
\hline \multirow[b]{3}{*}{ Further HE studies } & QILT & $S, M, A, R$ & Not included \\
\hline & ATO & $\mathrm{S}, \mathrm{A}, \mathrm{R}$ & Not included \\
\hline & HILDA & $\mathrm{S}, \mathrm{A}, \mathrm{R}$ & Not included \\
\hline \multirow{3}{*}{$\begin{array}{l}\text { Earnings or learning }<12 \\
\text { months after graduation }\end{array}$} & QILT & $S, M, A, R, V, R$ & Included \\
\hline & ATO & $S, A, R, V$ & Not included \\
\hline & HILDA & $S, A R, V$ & Not included \\
\hline \multirow{3}{*}{$\begin{array}{l}\text { Earnings or learning }>3 \\
\text { years after graduation }\end{array}$} & QILT & $\mathrm{S}, \mathrm{A}, \mathrm{R}, \mathrm{V}$ & Not included \\
\hline & ATO & $S, A, R, V$ & Not included \\
\hline & HILDA & $S, A, R, V$ & Not included \\
\hline
\end{tabular}

Final assessment

- Based on the SMARV assessment, it is recommended that an 'earning or learning' indicator, based on QILT data, be used to inform the Graduation Outcomes domain.

\footnotetext{
${ }^{8}$ Even though the use of this version of Graduate Outcomes Survey from QILT gives larger sample sizes, there were still issues for reporting relating to Indigenous students and students with disability. For the data used in deriving the rankings for Indigenous students, 30 of the 37 institutions had responses from this survey lower than the Department's threshold for publication (which is 25 responses). For students with disability, 1 institution fit this category.
} 


\section{Summary of Domains exploration}

The analysis of domains above removes two from consideration. Academic Preparation does not satisfy the SMARV criteria; and Aspiration due to non-availability of reliable data.

The four domains retained for analysis at the indicator level-Access and Participation, Retention, Outcomes During Higher Education Study and Graduation Outcomes- have indicators which satisfy the SMARV criteria. Indicators in these domains all draw on data from HEIMS or QILT and can be based on currently collected and calculated measures which are readily understood by institutions, policymakers and analysts in Australian higher education. The outcomes are summarised in the table below.

TABLE 10: INCLUSION OF DOMAINS FOR THE EQUITY RANKING INDEX

\begin{tabular}{|l|c|l|}
\hline Domain & Inclusion $(\mathbf{Y} / \mathbf{N})$ & Indicators included \\
\hline Academic Preparation & N & n.a. \\
\hline Aspiration & N & n.a. \\
\hline Access and Participation & Y & Enrolment in higher education studies \\
\hline First Year Experience & Y & $\begin{array}{l}\text { First-year retention } \\
\text { First-year success }\end{array}$ \\
\hline $\begin{array}{l}\text { Progress During Higher Education } \\
\text { Study }\end{array}$ & Y & Completion after nine-years \\
\hline Graduation Outcomes & Y & $\begin{array}{l}\text { 'Earning or learning' within the first year after } \\
\text { graduation }\end{array}$ \\
\hline
\end{tabular}

A caveat to this analysis is that this determination relates to the equity groups in general and it may be the case that in the instances of groups with smaller students numbers (notably Indigenous and students with disability) that the measures of relevant indicators need to be treated with caution in the case of several institutions.

\subsection{Calculating measures from the selected higher education equity indicators}

\subsubsection{The Overall Rationale for Calculating Measures}

Having identified four domains and five indicators using the SMARV criteria, it was necessary to refine and evaluate the way in which each indicator will be measured. The choice and calculation of measures for each indicator needed to ensure that SMARV criteria were also met when assessing equity performance in view of the institutional operating environment. Furthermore, any methodology had to compensate for the complexity of measuring higher education equity performance in a policy environment where there are no explicit targets. Equity targets have been previously adopted following recommendation, most notably as part of the 2008 Review of Higher Education (Bradley et al., 2008), however following the 2014 Review of the demand Driven System of Funding (Kemp \& Norton, 2014), equity targets were dropped. Therefore, higher education equity performance cannot currently be measured against a quantifiable benchmark. This is problematic since, whilst there is broad agreement on what constitutes equity in higher education, there remains significant divergence when the specifics of definition and measurement are considered more closely (Hnat, Mahony, Fitzgerald, \& Crawford, 2014; Meyer, 2013; Pitman, 2014).

Consequently, the project team sought to address the issue of measurement by adopting a methodology that could accommodate more than one definition of equity and that was transparent in how these definitions were operationalised. As summarised in Table 10 below, the selection of indicators, this involved adjustments to the five core indicators. 
Table 10: Calculating Measures from Selected Domains and Indicators

\begin{tabular}{|l|l|l|l|}
\hline Domain & Indicators included & $\begin{array}{l}\text { SMARV Criteria to be } \\
\text { Addressed by the } \\
\text { measure }\end{array}$ & Measure \\
\hline Access and Participation & $\begin{array}{l}\text { Enrolment in higher education } \\
\text { studies }\end{array}$ & $\mathrm{A}, \mathrm{V}, \mathrm{R}$ & $\begin{array}{l}\text { (1) Access Rate; (2) Access } \\
\text { Ratio - Access Rate/Equity } \\
\text { share of relevant } \\
\text { population }\end{array}$ \\
\hline First Year Experience & $\begin{array}{l}\text { First-year retention } \\
\text { First-year success }\end{array}$ & A, V, R & $\begin{array}{l}\text { Ratio to: (1) National rate } \\
\text { for equity group; (2) } \\
\text { Overall institutional rate }\end{array}$ \\
\hline $\begin{array}{l}\text { Outcomes During Higher } \\
\text { Education }\end{array}$ & Completion after nine years & $\mathrm{A}, \mathrm{V}, \mathrm{R}$ & $\begin{array}{l}\text { Ratio to: (1) National rate } \\
\text { for equity group; (2) } \\
\text { Overall institutional rate }\end{array}$ \\
\hline Graduation Outcomes & $\begin{array}{l}\text { 'Earning or learning' within the } \\
\text { first year after graduation }\end{array}$ & $\mathrm{A}, \mathrm{V}, \mathrm{R}$ & $\begin{array}{l}\text { Ratio to: (1) National rate } \\
\text { for equity group; (2) } \\
\text { Overall institutional rate }\end{array}$ \\
\hline
\end{tabular}

The first adjustment was in relation to Access and Participation domain and the 'Enrolment in higher education studies' indicator. Institutions' outcomes in relation to access are somewhat determined by their location in a given state or territory, whereby their equity enrolment profile will, in part, reflect the distribution of equity groups in their local population. Institutions in states and territories with larger equity populations have a natural tendency to enrol higher numbers of equity students (Phillimore \& Koshy, 2010). The use of standalone measures, without reference to population shares for equity groups can therefore present outcomes out of context and makes the indicator less accountable. This reduces its value to the overall ranking and precludes future adjustments to ensure its relevance. The response to this problem is to include two measures in the ranking: (1) the Access Rate (equity group enrolment/total enrolment); and (2) the Access Ratio, the Access Rate/Share of Equity Group in State Population. The Access Rate is the participation rate for the institution, while the Access Ratio adjusts this for the relative population share of the relevant equity group in the institution's home state or territory.

In this way, the access and participation performance of an institution can be evaluated both with the reference to the entire higher education sector and in reference to the demographics of the region in a state or territory in which it operates and largely draws its students from. The following example is provided for illustration. Nationally, the Indigenous population (18-64 y.o.) is calculated as being $2.76 \%$ of the overall population. However, in Victoria it is only $0.82 \%$ of the population. A Victorian university with an Indigenous student proportional population of $1.5 \%$ would be, simultaneously, well-below the national rate but well-above the state rate. Our methodology allows both 'realities' to be taken into consideration when evaluating performance.

The second adjustment pertains the three domains for student experience and outcomes: First Year Experience (the retention and success indicators), Outcomes During Higher Education (Completion after nine years indicator), and Graduation Outcomes (the 'Earning or learning' within the first year after graduation' indictor). In relation to these, there is a requirement to balance a comparison between outcomes among equity students with those of the overall student population in their institution and those of equity students elsewhere. The use of standalone measures for these indicators without reference to both these factors, limits the capacity of the performance ranking to reflect the effects of an institution's overall mission. A university's equity student population might match or outperform its 
national peers on an in-group comparison yet at the same time significantly underperform their institutional peers in comparison with students at other institutions.

To account for these effects, two measures are included in the ranking for the for these domains: (1) a ratio measure of an institutions measure for a given equity group to that of the national rate for the equity group; and (2) a ratio measure of an institution's measure for a given equity group to that of the overall institutional rate. The first ratio measures the performance of an institution against the entire sector, for the particular equity group. The second measures the performance of an institution for the particular equity group relative to the other students in the same institution. These two ratios can be expressed as hypothetical questions asked by someone within an institution, using the retention rate of low-SES students as an illustrative example:

Ratio 1: How well do we retain low-SES students in our institution, compared to how well other institutions retain their low-SES students?

Ratio 2: Do we retain our low-SES students as well as we retain our other students?

The first ratio focuses primarily on the entire sector and allows absolute comparisons to be made; for example identifying institutions with higher (again, in absolute terms) levels of performance. However, taken in isolation, this measurement cannot properly accommodate or compensate for unequal educational equity 'inputs'. Prior research has demonstrated the positive correlation between ATAR and tertiary academic performance (Cherastidtham \& Norton, 2018). Therefore, any measurement system must address a particular dichotomy in Australian higher education equity performance. Essentially, there is an inverse relationship between higher education equity participation and higher education equity progression. The relationship is highlighted in Figure 2 . With a few exceptions, institutions with equity representation between $40-50 \%$ have retention rates between $75-90 \%$, whilst those with representation between $70 \%-85 \%$ have retention rates between $65-77 \%$. Consequently, institutions with lower retention rates generally prefer a focus on their efforts to widen participation, and vice versa. 
FIGURE 2: EQUITY STUDENT POPULATION AND RETENTION RATE: 2014

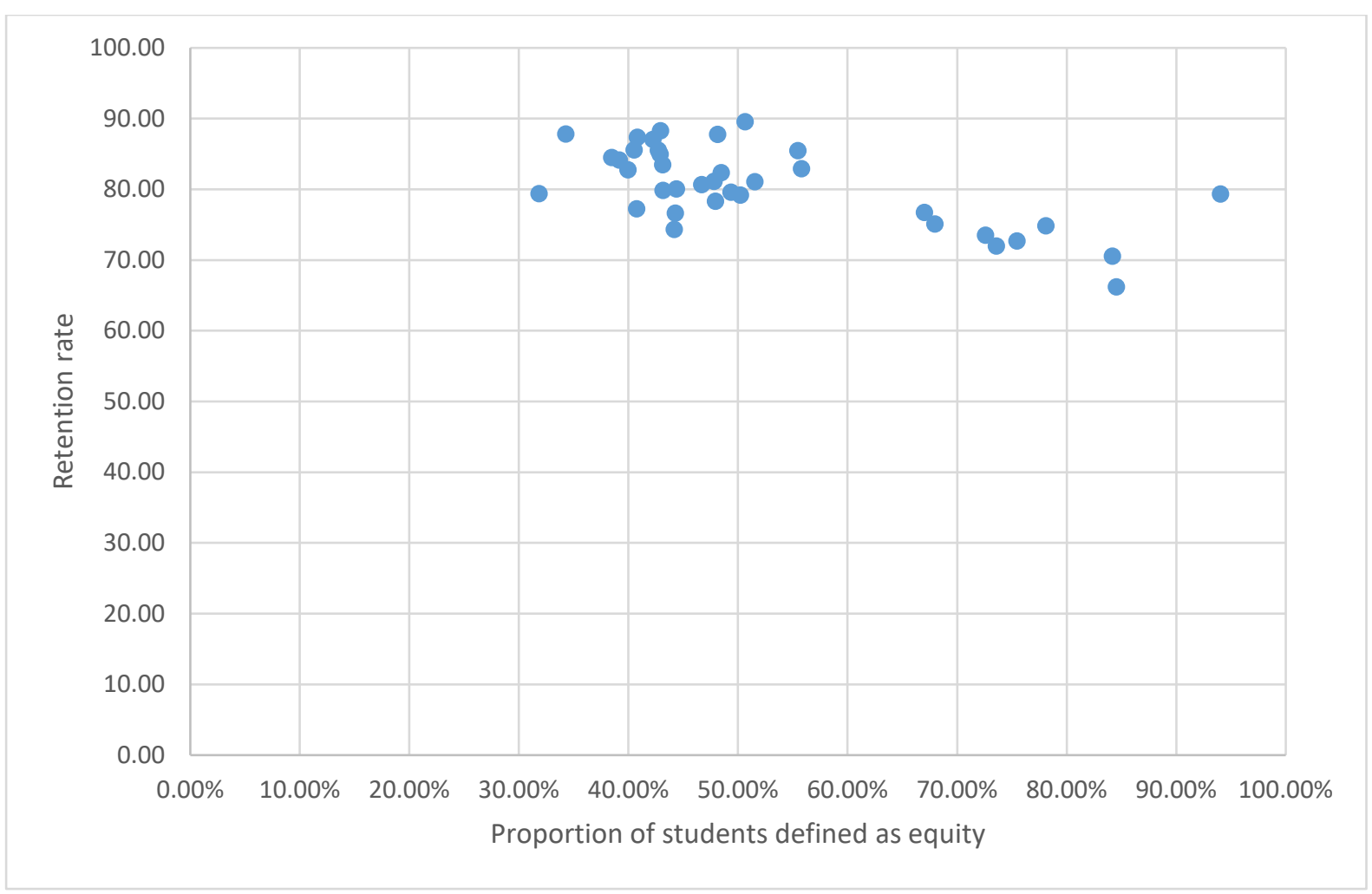

Source: Higher Education Statistics Series 2016: Appendix 5- Equity performance data (for retention); equity student representation data provided on request

However, regardless of whether an institution is high-participation/low-retention, low-retention/highparticipation, or an outlier, there is widespread consensus on the following imperative: that outcomes for equity students should be the same for other students. This aim is a central tenet of social inclusion and in the Australian context and is perhaps exemplified by the National Indigenous Reform Agreement 2008, which seeks to addresses Indigenous disadvantage by improving outcomes between Indigenous and nonIndigenous Australians in the areas of life expectancy, health, education and employment (Council of Australian Governments, 2009)

Therefore, there is merit in adopting an internal comparative approach to equity performance measurement; that is, measuring the performance of equity students in comparison to non-equity students at the same institution. A ratio is a simple means of expressing this comparison, with a ratio of 1 representing parity between the two groups.

Such an approach helps resolve many tensions concerning externalities, such as the geographical location of an institution, its particular strategic mission, its relative cultural capital (i.e. prestige) accrued over generations - and in some cases with generous bequests by pre-Federation governments - and the particular demographics of its local student population.

\subsubsection{Access and Participation Indicator}

The rationale for the inclusion of both an Access Rate and Access Ratio can be seen in Table 11. While the raw access rate is an intuitive measure of an institution's ability to extend access to equity students, the 
location of an institution shapes the population of equity students from which it can draw students. For instance, whereas low SES students are defined as residing in the bottom $25 \%$ of the Australian population using a national comparison, there is a considerable range in the percentage of each state and territory population who are classified as low SES on this ranking, ranging from $43.40 \%$ of the population in Tasmania to $0.2 \%$ in the Australian Capital Territory (ACT). A similar analysis applies to other equity groups, including Regional and Remote ( $100 \%$ of the population in Tasmania, $0.11 \%$ in the ACT), Indigenous ( $28.7 \%$ of the population in the Northern Territory, compared with $0.82 \%$ in Victoria) and NESB populations (11.07\% in Victoria compared with 3.13\% in Tasmania).

Phillimore \& Koshy (2010) suggest the use of state and territory population values for the low SES population to weight institutional participation rates, and we follow this example across all equity groups in view of the divergence in equity population shares across these.

Table 11: State and Territory Population Reference Values for Equity Groups, \% of population

\begin{tabular}{|l|c|c|c|c|c|}
\hline State/territory & Low SES & $\begin{array}{c}\text { Regional and } \\
\text { Remote }\end{array}$ & Indigenous & $\begin{array}{c}\text { Students With } \\
\text { a disability }\end{array}$ & $\begin{array}{c}\text { Non-English } \\
\text { speaking } \\
\text { background }\end{array}$ \\
\hline NSW & 24.40 & 23.08 & 2.80 & 8.40 & 9.66 \\
\hline Victoria & 20.70 & 20.81 & 0.82 & 8.40 & 11.07 \\
\hline Queensland & 29.80 & 35.56 & 4.13 & 8.40 & 6.25 \\
\hline Western Australia & 24.10 & 21.74 & 3.73 & 8.40 & 9.67 \\
\hline South Australia & 31.00 & 25.27 & 2.41 & 8.40 & 7.89 \\
\hline Tasmania & 43.30 & 100.00 & 5.19 & 8.40 & 3.13 \\
\hline Northern Territory & 23.30 & 100.00 & 28.70 & 8.40 & 8.40 \\
\hline Australian Capital Territory & 0.20 & 0.11 & 1.77 & 8.40 & 10.36 \\
\hline
\end{tabular}

\subsubsection{First Year Experience (Retention and Success), Outcomes During Higher Education, and Graduation Outcomes Indicators}

The indicators in the three domains relating to outcomes after enrolment, are influenced by the natural stratification of higher education in Australia, whereby universities have enrolling cohorts of different levels of academic preparedness as well as equity status (Koshy, 2016). This means that outcomes-related reflects both the influence of course-readiness and equity status and these impacts need to be accounted for separately.

This can be seen in evidence on one of these indicators: 9-year completion rates for students on the basis of their socio-economic status. Edwards and McMillan (Edwards \& McMillan, 2015b) examined outcomes for the 2005 cohort for a period up to nine years after their initial enrolment. In this study, around 68.9 per cent of low SES students who commenced their degree in 2005 completed a qualification within nine years later, compared with $\mathbf{7 2 . 6}$ per cent of medium SES and 77.7 per cent of high SES students. This is shown in Figure 3 below.

Further, these data show a significant gradient between ATAR score and completion, but with low SES students always being less likely to complete their degrees across all ATAR bands, particularly where the ATAR rank is below 50.0. This is an important point, because as Pitman, Koshy and Phillimore (2014) point out, the number of students entering higher education with ATARs below 50.0 expanded considerably during the introduction of the demand-driven system of funding, with Koshy (2016) noting a rise from $1.8 \%$ of acceptances in 2007 to $4.0 \%$ in 2014. A similar analysis applies for all equity groups, and also to indicators that measure retention, success and to a lesser, but still observable extent, graduation outcomes. For 
instance, University Australia's Survey of Student Finances reports considerable impediments to retention among low SES students in relation to financial and work pressures in comparison with middle and high SES groups (Koshy, 2016). And in respect of graduation, Pitman et al. (2017) have found distinct differences between equity group employment outcomes. 
Figure 3: Completion Rates Nine YeArs after Commencement, By SES and ATAR, Domestic UNDERGRADUATE COMMENCERS IN 2005

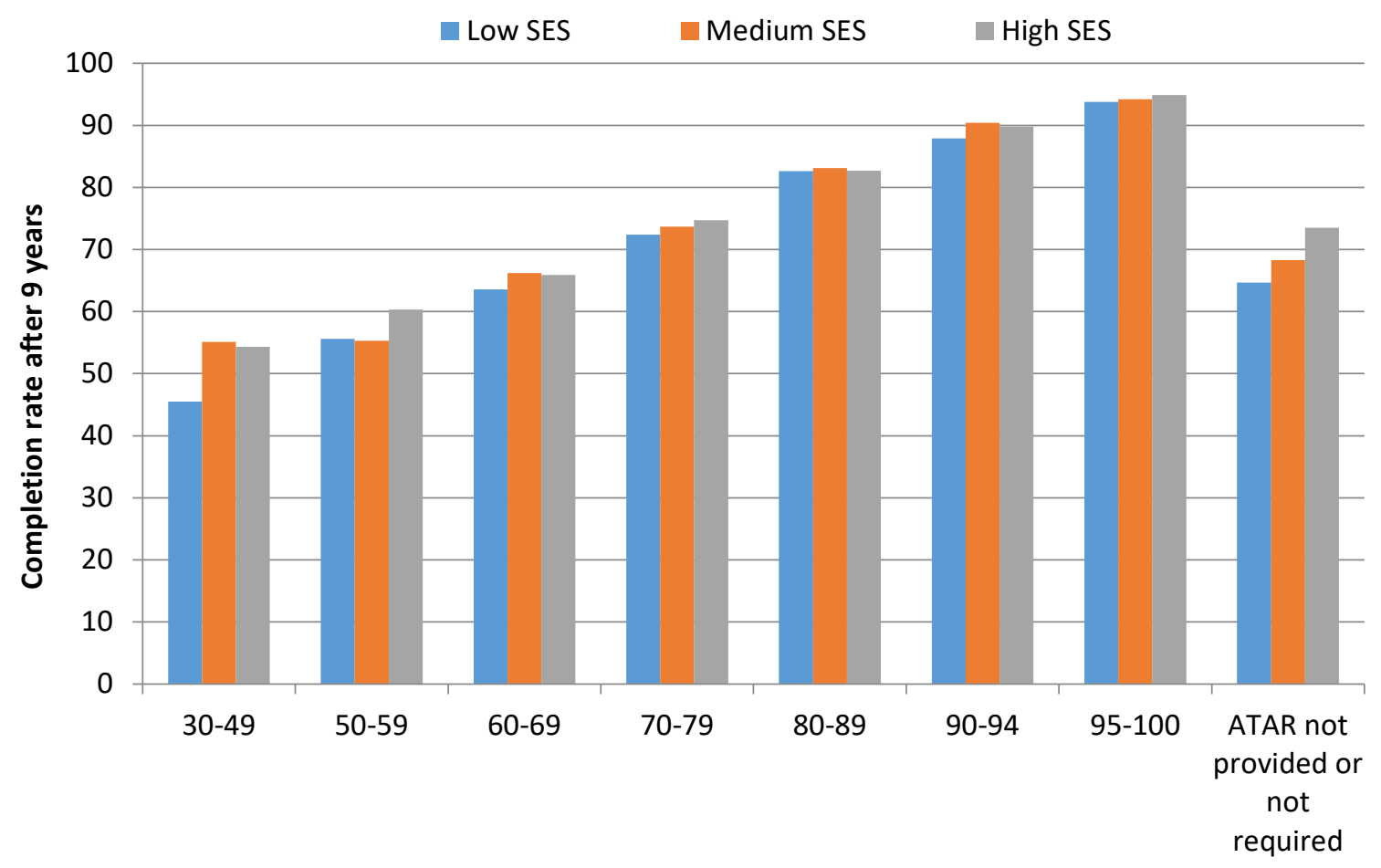

ATAR band

Source: Based on Figure 16 of Edwards and McMillan (2015, p.28).

Given these two observations, we would expect that institutional outcomes for equity students reflect two trends. First, equity students with higher levels of academic preparation see higher levels of retention, success, completion and post-graduation employment and education participation. Accordingly, institutions with larger numbers of such students would see more favourable assessments. In addition, there is likely to be differences between equity students and other students who have similar levels of academic preparedness, and the assessment on performance needs to take this into account. These outcomes are driven by factors tied to financing, time constraints due to part-time work engagement, and the provision of infrastructure and support systems.

\subsubsection{Summary}

As a consequence of the above adjustments, a total of 10 measures are proposed - two for each indicator.

In Access and Participation, this includes a measure for observed performance against the institutional population and a 'ratio' measure that divides the indicator by equity group share of the institution's state or territory population.

In relation to the four indicators for student outcomes after their initial access to higher education - First Year Experience (Retention and Success), Outcomes During Higher Education, and Graduation Outcomes 
Indicators - these are each measured based on weighted against overall outcomes in the national equity group student enrolment and based on the total enrolment of their institution. That is; the first ratio measures the performance of an institution against the entire sector, for the particular equity group. The second measures the performance of an institution for the particular equity group relative to the other students in the same institution

\subsection{Constructing the ranking}

\subsubsection{Introduction}

With a decision made on the indicators to be used and the calculation of the measures, an approach to how these measures will be 'combined' in order to develop a ranking of Australia's 37 Table A universities was identified. In this section, the various options for constructing the ranking are discussed.

In essence, a ranking involves the merging of measures into a single summary measure (Poister, Aristigueta, \& Hall, 2014). However, each equity group is distinctly different, meaning that important information would be lost in the aggregate. Prior research and published data support this position. For example, although low-SES, NESB, Indigenous students and students with disability all experience underrepresentation in Australian higher education, outcomes vary for some of these groups. NESB students experience high rates of retention than the others, indeed, higher than all students on average ${ }^{9}$. Indigenous students experience significant disadvantage in accessing and completing degrees, but conversely have been shown to experience higher-than-average post-graduation employment outcomes (Pitman, Roberts, et al., 2017). Furthermore, there is the issue of volume. On the one hand, there are over 160,000 low-SES students in higher education, representing around 16 per cent of enrolments. At the other end there are only a little over 9,000 students from remote Australia or less than one per cent of all enrolments (Department of Education and Training, 2017a). Equity groups with low, raw numbers, could therefore have a disproportionate effect (either positive or negative) on the aggregate ranking of the university.

Furthermore, a composite ranking might allow an institution to hide poor performance in one or more areas, by better achievements elsewhere. This would be the case particularly for poor performance in the categories of remote, Indigenous and students with disability, offset by good performance in low-SES and regional enrolments. Therefore, for this project, given the significant differences between the five equity groups (Low SES; Regional, Rural and Remote; Disability; Indigenous; and NESB), a separate university ranking was constructed for each equity group.

As demonstrated in the examples provided Part A of this report, there are several potential approaches to forming a ranking. The process of forming indices varies with different approaches; however, they share a common trait: all approaches combine all performance measures, which might have different scales, into a new measure with a common scale.

This section explores how to approach ranking Australia's 37 public universities using the measures for each of the indicators described in the section above. The approaches considered for developing the ranking are discussed, beginning by considering two broad approaches to rankings (and multiple iterations within the first). These approaches are:

- Weight-and-sum

\footnotetext{
${ }^{9}$ See https://docs.education.gov.au/node/51496
} 
- Expert-decided weighting approaches

○ Data-decided weighting approaches

- Data envelopment analysis

The discussion then examines the pros and cons of these options before detailing the approach applied to the construction of the rankings for this project.

\subsubsection{Weight-and-sum approaches}

The weight-and-sum approach is a well-accepted ranking method (Soh, 2017), and is popular due to its transparency and computational simplicity. This approach has been widely used in measuring university performance such as the QS World University Rankings (QS, 2014) and the Academic Ranking of World Universities (Academic Ranking of World Universities, 2014; Zhang \& Worthington, 2017). This approach is also popular in measuring education performance such as the Worldwide Educating for the Future Index (The Economist Intelligence Unit, 2017) and in measuring environmental performance (Hsu \& Zomer, 2016).

In developing a ranking based on this approach, several steps are involved:

1. Raw performance scores (RPS) for each measure are determined (in our case, these measures are calculated from the indicators identified in the SMARV approach).

2. The raw performance scores are converted to normalised performance scores (NPS), to ensure a common scale for comparison - i.e. a scale of 0 to 100 (Hsu \& Zomer, 2016; Lewis, Johnson, Erikson, \& Bruininks, 1994).

3. Each normalised performance score is multiplied by its weight to form a weighted performance score (WPS) for each measure.

4. An overall score for each university is calculated by summing the weighted performance scores.

5. Universities are ranked based upon their overall score.

A critical issue in the weight-and-sum approach is how to decide the weight associated to each individual measure. All weights could be positive or negative depending on the weighting method assumptions. Final weights for each measure (weighted importance) are calculated by multiplying the measure weight by the relevant dimension weight. Broadly, the approaches taken to weighting can be classified in two categories: expert-decided method and data-decided method (Podinovskii, 1994). Different variations of each of these categories are further discussed below.

\section{Expert-decided weighting method}

Expert-decided methods, also called direct explication methods (Zeleny, 1982), rely mainly on the opinions of a group of experts to determine the relative importance (weighting) of indicators and measures for constructing a ranking. In conducting this approach, relevant experts are invited to contribute to weighting decisions. The way in which opinions of experts are gathered, calculated, and utilised in a final ranking are numerous. Opinions can be collected through interviews, surveys or focus group consultations. Decisions relating to the definition and choice of 'experts' in such approaches are also context dependent.

By way of example, two of the more sophisticated approaches to the expert-decided weighting approaches are outlined here. The Angoff method (Zieky, 2001) is an approach used in standard setting contexts (for example in developing examinations). This approach involves working closely with a group 
of experts in a workshop setting to evaluate each measure and determine the minimal standard at which an institution should be achieving, thus developing a benchmark or threshold on which a measure should be determined. These benchmarks can be used to develop relative weightings for each measure in a ranking.

If measures have a hierarchical structure (similar to ours with dimensions in the top and measures at the bottom), analytic hierarchy process, or AHP (Saaty, 1990), is a popular method for determining weights. To carry out AHP, experts are asked to assign a set of numbers to measures in the form of paired comparisons based on their perceived importance of priorities in the ranking. These paired comparisons can form a matrix of pairwise comparisons of criteria given by the experts. With this matrix in hand, the priority vector can be computed, which is to normalise the principal eigenvector of the matrix into a vector with sum equal to one. The result will give the relative priority of the indicators measured on a ratio scale, which can then be used as the weights for the ranking measures.

Overall, expert-decided methods are somewhat subjective. They are usually limited to a small group of experts, chosen in a subjective way themselves. If applying sophisticated methods such as Angoff or AHP, there is also a potential for these approaches to be costly because they require the development of multiple workshops or questionnaires. Another difficulty is the time required of experts in such approaches. This can be significant depending on the number of measures or the complexity of the ranking. For example, in this project, the considerations not only span the number of measures identified but add the complexity of relative importance for each of the five different equity groups. For the AHP approach in particular, the comparison number is especially large due to the necessity to undertake paired comparisons. In the case of 20 measures, each expert would have to conduct 200 comparisons in order to generate the weights.

\section{Data-decided weighting method}

An alternative to relying on experts' opinion, is to decide on weights using the data itself. This approach utilises statistical models to determine a set of weights which generate the aggregate performance to meet certain criteria. If the goal is to find the relative relationship (represented as weights) with the index, principal component analysis (PCA) could be used to find the weights for each measure (Nardo et al., 2008). If the minimum variance of aggregate performance scores is desired, then the approach is called mean-variance analysis (Markowitz, 1952). If we are pursuing the maximum aggregate performance for an institution, that is, the weighted performance score (WPS) in equation (1), while constrained on a given variance, the approach is called the tangency method (Martellini, 2008).

Choice between the above approaches depends on the objectives of the ranking (or of the project). The mean-variance analysis and tangency method are commonly used in finance to purse a set of weights that will generate a portfolio with maximum returns (or scores). Therefore, they are not suitable for this project. As this project's ranking pursues maximum performance from each institution, the first approach, PCA, is the most appropriate of the options above. Weights generated from PCA offer an indication of the relevance of each measure to the overall ranking, which offers additional diagnostic information about whether the performance measures chosen are statistically suitable to form an index.

Despite the apparent benefits of data-driven approaches to weighting, these calculations work best when dealing with comparisons across a large number of institutions. This project has a total 'population' of 37 universities, which introduces limitations to the statistical power of PCA and other data-driven approaches to weighting (Nardo et al., 2008). 


\section{Data envelopment analysis}

Data envelopment analysis (DEA) is a popular method for comparing the efficiency or productivity among decision making units (DMUs) in a variety of commercial and government contexts where both input and output data are readily observable (Zhu, 2014). In the case of this analysis, the DMUs are universities. The DEA method has been applied to ranking productivity performance of Australian universities by several studies (Abbot \& Doucouliagos, 2003; Moore, Coates, \& Croucher, 2018; Moradi-Motlagh, Jubb, \& Houghton, 2016; Worthington \& Lee, 2008). If the input valuables are not available or it is hard to find inputs specific to outputs, we can still use DEA to form index by fixing all values of input variable at the same levels (Kao, 2010). In this project, we call the index built from this method performance index since there is no input variable involved.

This index is similar to the one built from weight-and-sum approach with data-decided weighting methods. However, the main difference is that DEA will construct a performance frontier (or benchmark) before assigning weights. The performance index for institutions is built by calculating the distance of each institution with respect to the benchmark, which is decided by the location of the institution and its position relative to the benchmark (Nardo et al., 2008; Zhang, 2008, 2010; Zhu, 2014). When number of measures are two and there are only few universities (DMU) involved, the score can be easily calculated by drawing a scatter plot.

The process to calculate such DEA performance index is illustrated in Figure 4. Assume that we have only two indicators, the retention rate and success rate, and have only four universities are involved in the ranking. After collecting both raw indicator scores for each university, we can draw a scatter plot to show all four data points. Clearly, as we have only two indicators, the universities with best performance on the either one of the indicators should be located on the top right side of the plot, which is university A, B, and $C$ (full dots). After linking the dots between these three, we can get the frontier. As these three universities perform best on either one of the indicators, they will get the equal score of 1 . As for university $D$ (hollow square), since it performed relatively worse than the others on either one of the indicators, DEA will not assign the full score to it. Instead, DEA assumes the best performance it might get by pushing its performance to the frontier, so we get University $\mathrm{D}^{\prime}$ on the frontier in the figure. DEA then calculates its improvement rate (latter on, we will call this $\emptyset_{o}$ ): the line $0 D^{\prime}$ (distance from point 0 to point $D^{\prime}$ ) divided by line $O D$ (distance from point 0 to point $D$ ). In other words, this is the ratio of an institution's actual performance to its benchmark performance. We can roughly observe that $\emptyset_{o}$ for university $D$ is $3 / 2$ (considering line $O D^{\prime}$ has distance 1 and line $O D$ has distance $2 / 3$ ), which means university $D$ need to increase both its output by $50 \%(3 / 2-1)$ (or all its indicator values multiplied by $3 / 2$ ) to get onto the frontier line. Considering university $D$ has the improvement rate larger than 1 , it indicates that it performs relatively worse than its peers (university $A, B$, and $C$ ). This will reflect on its final DEA score, $2 / 3$, which is the reciprocal of its improvement rate.

Generalising the logics above, we can apply that to any number of indicators and universities. 


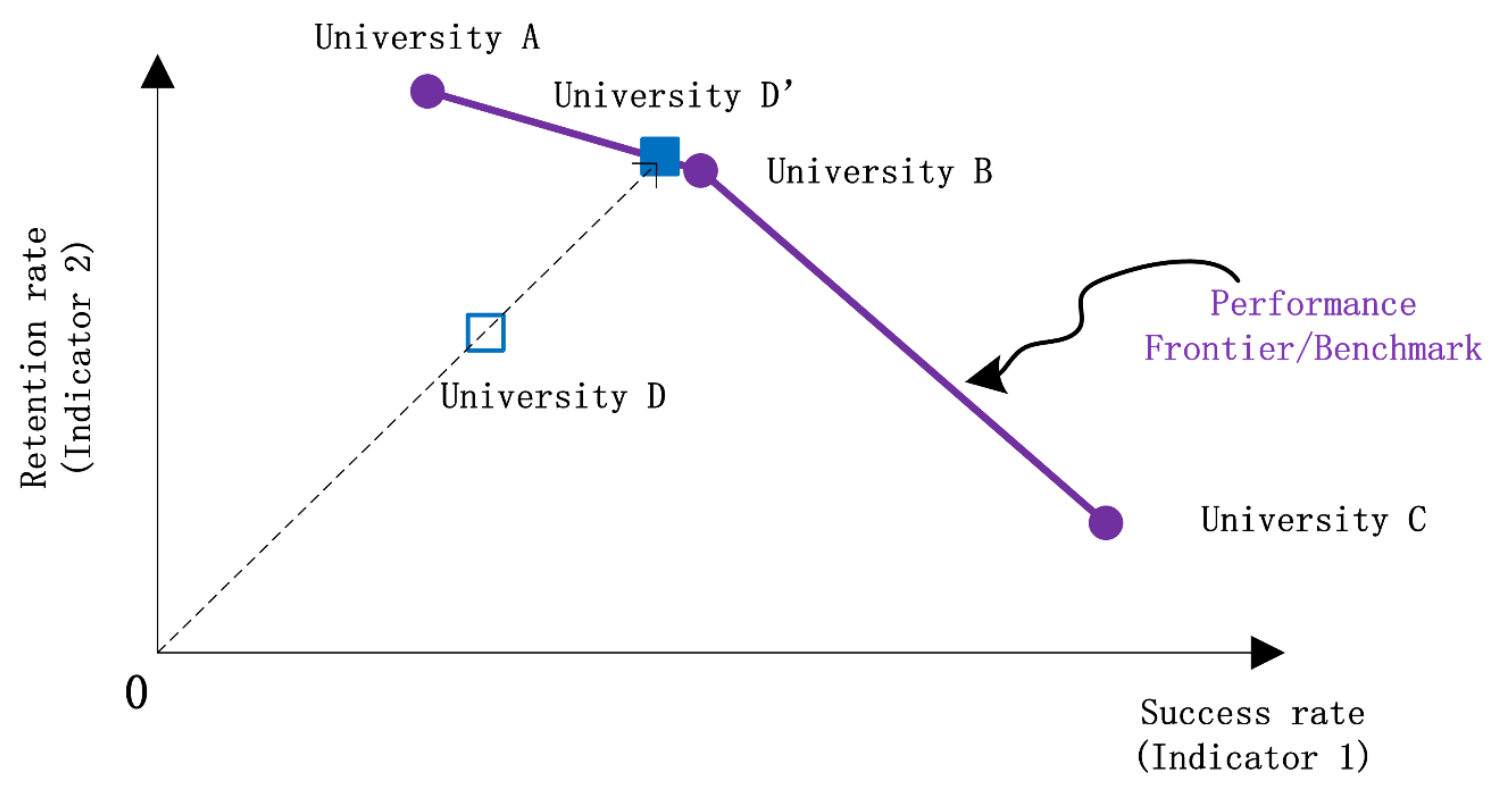

It is important to note that the benchmark derived from this approach is generally DMU-dependant (i.e. institutions/universities in this project). Different selection of institutions might lead to different benchmark. As the index is relative to the benchmark, this brings another main difference from weightand-sum approach with data-decided weighting methods: weights $w$ for measures generated from DEA are no longer fixed within indicators (this is so called indicator specific) but are different across DMUs since each institution might have different performance relative to the benchmark (represented by the distance discussed above). This implies that weights are institution specific. The selection of different institutions might result in different sets of weights.

\section{Comparing weight-and-sum and DEA}

The weight-and-sum approach has the main advantage of simplicity and transparency. If the weights and measure data used in a weight-and-sum are made public, anyone can easily replicate the results. By contrast, while DEA has a rigorous foundation based on statistical and mathematical models, its complex methodology reduces its transparency for most users.

The major drawback of the weight-and-sum approach is that the method behind the calculation or choice of weights is similarly obscure. For this reason, the choice of weights requires justification, especially when weights are generated from expert-decided method. The data-decided process is less transparent, and with small numbers of institutions involved in the ranking, as in this project, over-reliance on statistical imputation can be problematic. It is important to note that purely relying on either expertdecided method or data-decided method exposes a project to numerous risks. However, there are possibilities for using both expert-decided and data-decided approaches in a complementary rather than exclusive way, as outlined in the next section.

However, in addition to issues around the choice of weights, there is also a need to normalise measures with different scales, when using the weight and sum process. This transformation can often lead to difficulty in interpreting the weighted scores. In other words, the weighted performance score can only 
tell us that a university gets a rank relative to others (Poister, Aristigueta, \& Hall, 2014), with no meaningful interpretation for the weighted score itself.

In the case of DEA, since it starts from constructing the performance frontier based on ranked institution performance, it reflects the improvement from the current position to the frontier. Thus, the interpretation of the DEA result is easier as it reflects a rate of improvement. In fact, the DEA performance score is more like a rating score because there is a cut score (i.e. 100), indicating whether improvement is required.

TABLE 12 COMPARISONS BETWEEN APPROACHES OF BUILDING INDICES

\begin{tabular}{|c|c|c|}
\hline & Weight-and-sum & DEA \\
\hline Weights & - Indicator/measure specific & - Institution specific \\
\hline Advantages & $\begin{array}{l}\text { - Simplicity } \\
\text { - Transparency } \\
\text { - Easy to replicate the results given the data } \\
\text { and weights are provided } \\
\text { - Common usage in Higher Education context. }\end{array}$ & $\begin{array}{l}\text { - Rank institutions based on their best practice } \\
\text { (performance frontier) } \\
\text { - } \text { Focus on improvements } \\
\text { - Provide supplementary materials for } \\
\text { improvement such as peers and } \\
\text { improvement rates. } \\
\text { - Combine ranking and rating scores together } \\
\text { - Ranking results are generated based on } \\
\text { rigorous academic theories } \\
\text { - No need to normalise the raw performance } \\
\text { scores. }\end{array}$ \\
\hline Drawbacks & $\begin{array}{l}\text { - Weaker justifications in deciding weights } \\
\text { - Ranked institutions get nothing but the } \\
\text { ranking results } \\
\text { - Variety of approaches to weighting each with } \\
\text { pros and cons. }\end{array}$ & $\begin{array}{l}\text { Difficult to implement this approach due to } \\
\text { its complexity } \\
\text { - The general public are not familiar with this } \\
\text { approach, therefore may not be appropriate } \\
\text { for a ranking. }\end{array}$ \\
\hline
\end{tabular}

\section{Ranking approach used for this project}

Balancing the benefits and drawbacks of the different ranking approaches described above with the goals of this particular project, a weight-and-sum methodology has been employed for developing the equity rankings.

Given the significant variety in deciding weights within the weight-and-sum method, a range of different rankings have been developed. As discussed in more detail below, the project team has developed rankings based on a PCA data-decided weighting process and several iterations of an expert-decided weighting approach, in order to demonstrate the range of outcomes that can be derived from the combination of measures identified for use.

This section first details the overall approach taken in generating the weight-and-sum rankings. This approach applies to each of the iterations of the rankings that are presented later in the report. This is followed by a further discussion of the application of different approaches employed to weighting the measures within each of the ranks (i.e. the PCA approach and the expert-decided approach).

\section{Method used for ranking}

The weight-and-sum approach used for this project follows the steps outlined in the section above. The specifics for applying the weight-and-sum approach to this project are detailed here. In these rankings, 
we are ranking $N$ higher education institutions $\left(\mathrm{H}_{1}, \ldots, \mathrm{H}_{N}\right)$ and for each of these institutions, $\mathrm{G}$ sets of $J$ different measures of indicators are used where $N, G$ and $J$ are positive integers (whole numbers). As the weights of each measures could be derived from different method $r$, we denote $w_{r j}$ as the weight specific to set $g$ of measure $j$. The ranking is therefore based on the WPS of each institution which can be denoted as follows:

$$
W P S_{g r i}\left(R P S_{g i 1} \ldots, R P S_{g i J}\right)=\sum_{j=1}^{J} w_{r j} R P S_{g i j}
$$

where $R P S_{g i j}$ is the performance vector containing $J$ measures for institution $H_{i}$ with $g$-th set of measures.

No matter how the weights are derived, the sum of weights is always one:

$$
\sum_{j=1}^{J} w_{r j}=1
$$

Therefore, $S_{i}$ is the aggregate performance of all measures for institution $i$, which is calculated by summing up the multiplications between measure weights and the information vector.

Drawing on the approach outlined in the section above, the specific approach taken for developing the weight-and-sum rankings are listed below. Note that this process was undertaken five times for this project - one per equity group.

1. Raw performance scores: The RPS, or raw score, for each measure by university, is developed, as detailed in the 'calculating measures' section above.

2. Normalised performance scores: The RPSs are normalised on a scale of 0 to 100 to generate the NPS using the proximity-to-target transformation (Hsu \& Zomer, 2016; Lewis et al., 1994; The Economist Intelligence Unit, 2017):

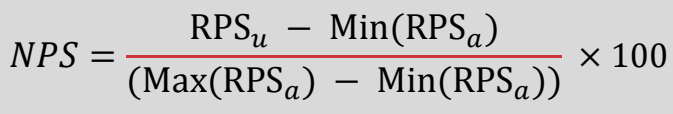

where $\mathrm{rs}_{\mathrm{u}}$ is a university's raw score for any given measure, RPS $\mathrm{a}$ is a vector of all universities raw score for any given measure, $\operatorname{Max}\left(\operatorname{RPS}_{\mathrm{a}}\right)$ and $\operatorname{Min}\left(\mathrm{RPS}_{\mathrm{a}}\right)$ are the highest and lowest value among universities for any given measure, which are also the targets for best and worst performance respectively in this project ${ }^{10}$. This stem is further discussed below.

3. Weighted performance scores: Each normalised performance score is multiplied by its final measure weight (weighted importance) to generate a WPS. Further specification of the measure weighting approaches is shown below.

\footnotetext{
${ }^{10}$ The best and worse target values can be replaced by any arbitrary positive values based on agreements among experts and institutions or decisions made by the Government (Yale Center for Environmental Law \& Policy, 2018). As there is no existing consensus on the targets in this project, we use maximum and minimum values for them following the general practices (Nardo et al., 2008; The Economist Intelligence Unit, 2017).
} 
4. Overall score: An overall score for each university is calculated by summing the weighted measure scores.

5. Ranking universities: University ranks are based upon the overall score.

The goal of normalisation step is to convert each measure raw score to a common scale so to render the measures comparable. We should note that this is not the only way to normalise the raw measure scores. For example, Longden (2011) proposes the use of the Z-score transformation with mean $=0$ and standard deviation $=1$ so these Z-scores are shown in terms of standard deviations from their means. A main drawback of this transformation is that some Z-scores are negative, leading to difficult interpretations. Although this can be fixed by further transforming the $Z$ scores with different means and standard deviation. However, the choices for means and standard deviations could be arbitrary. Another reason that we do not adopt this is that there could be no minimum and maximum scale when these Z-scores are summed together with the procedure above. This again leads to difficulty in interpretation. Fortunately, from our initial testing with measures of retention rate and retention ratio and 50/50 weighting, there is no major rank difference regarding using proximity-to-target normalisation or using Zscore method especially for those universities with high and low composite scores (other methods' empirical uses can be found in Ebert \& Welsch, 2004).

Note that the procedure above follows a linear transformation, which is commonly adopted for ranking methods (e.g. The Economist Intelligence Unit, 2017). Other transformation (for example, curvilinear transformation) is possible but empirical studies (Keeney, 1977) show that the transformation form have little effects on the ranking outcomes. Therefore, a straightforward and relatively understandable transformation was chosen for this project.

Recognising the range of options for deriving weights in this approach to ranking, and the potential for some of these approaches to be complementary, two overall approaches to weighting the measures were developed for the equity rankings. The first followed a data-decided weighting method, specifically applying PCA to identify weights for each measure. As noted in the section above, of the data-decided weighting methods considered for this project, PCA offers the most relevant approach for this particular project.

Following previous notations, from a set of raw performance scores RPS ${ }_{1}$ through to RPS , PCA can reduces the $J$ dimensions of all performance score dataset down to $M(M<J)$ principal components:

$$
\begin{gathered}
P C_{1}=a_{11} R P S_{1}+a_{12} R P S_{2}+\cdots+a_{1 J} R P S_{J} \\
\vdots \\
P C_{M}=a_{M 1} R P S_{1}+a_{M 2} R P S_{2}+\cdots+a_{M J} R P S_{J}
\end{gathered}
$$

where $a_{M}$ denotes the weights for the $M$-th principal component and the $J$-th RPS.

These principal components are ordered by the decreasing amount of variance explained, and in practice, only the weights of first PC is used for ranking (Berni et al., 2011; Lai, 2003; Vyas \& Kumaranayake, 2006). However, the weights we need are the squared weights since they are summed to one i.e. $a_{11}^{2}+$ $a_{12}^{2}+\cdots+a_{1 J}^{2}=1$, which exactly matches our needs for weights.

One drawback about PCA is that it needs enough data (i.e. number of institutions in this project) to calculate the weights. As the number of institutions are capped at 37 in this project, we apply the 3:1 
case-to-variables ratio and gain the standard of number of measures being less than 12 (Nardo et al., 2008, p. 66).

The second broad approach to deriving weights for these rankings was to follow a simplified expertdecided method. This method involved the project team drawing on information gathered through the consultation process, knowledge acquired through the literature (relating to both equity and to ranking methods and approaches), and testing of weighting scenarios through a workshop with experts from the Australian higher education sector.

A range of different weight applications was derived through this approach, with the software used to calculate rates being manipulated to apply and test scenarios. As detailed in the results section, the first weighting iteration developed in this way involved applying equal weights to all measures - considered as a 'baseline' case for exploring the rankings.

Based on the resources described above, the team derived large number of other scenarios, for comparison to the baseline and PCA-derived ranks. These included the following:

- Weighting focusing on three 'core' indicators (and their relevant measures) identified by experts during consultation: access/participation, retention and graduate outcomes.

- Weight applications ranging from full weighting allocated to national-rate comparison measures, to full weighting for within institution-relative comparison measures.

- Separate ranking scenarios each heavily-weighting measures for each of the following indicators: access/participation, retention, completion and graduate outcomes.

In developing the ranking, the project team has developed a graph for which to use in displaying outcomes. The intention of the stacked bar-chart graph is to be able to display not just the rank order of institutions, but rather to show the contribution of each measure to the overall summed score for each university.

In the following sections of this report, these stacked-bar charts are used to show outcomes for a number of the scenarios described above. Each chart has a range of colour bars to represent different measures included in the ranking. The extract of a graph below illustrates how this ranking score and relative position is articulated, with each colour in the 'measures' legend on the right linked to the relative side of the bar in the stack for each institution. This display helps to show the different contribution of each individual measure to an individual university's score as well as displaying how individual measures differ between universities. 
FIGURE 5: ILLUSTRATIVE EXAMPLE OF STACKED BAR-CHART DISPLAY FOR RANKINGS OUTPUT

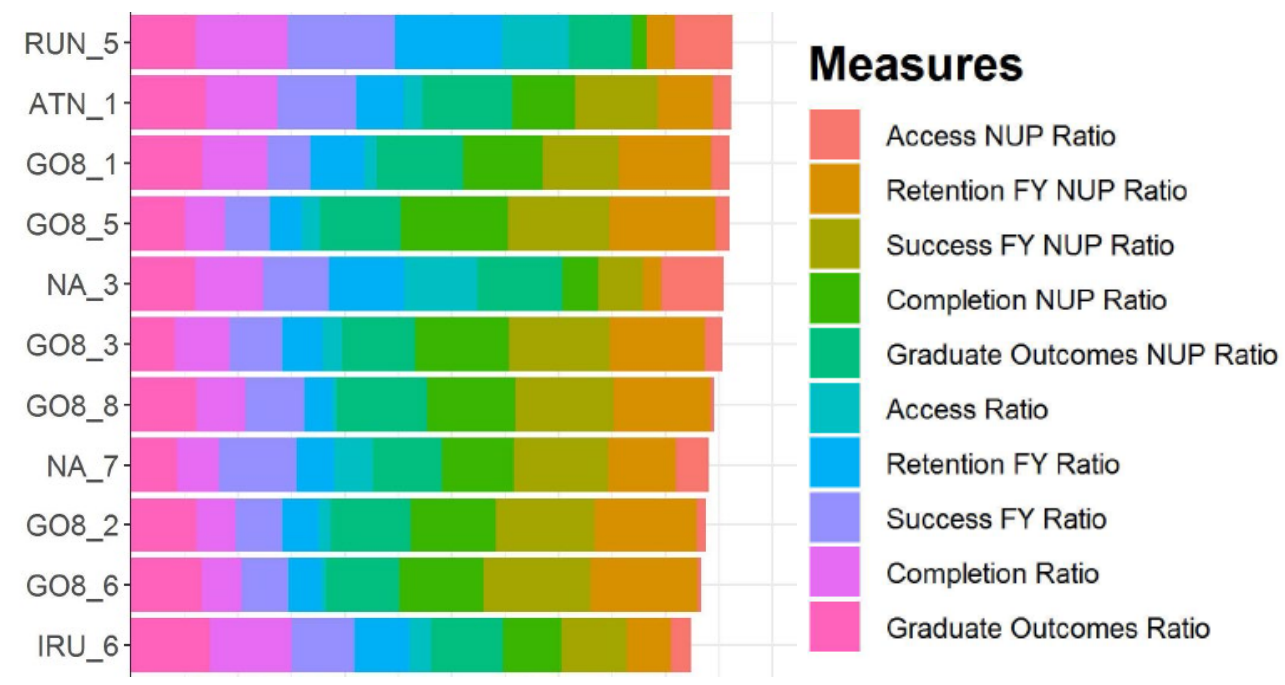

\section{De-identification of universities}

In the results displayed in the following sections, universities have been de-identified. The project team, along with the Department made a conscious decision to do this so that the approach, methodology and broad outcomes of this project would be the focus, rather than the specific positioning of individual universities.

In order to provide a contextual dimension to the de-identification, universities have been given labels that identify the institutional grouping to which they have membership (for example, IRU_1 and RUN_4). The list below provides the distribution of universities among these groups as allocated in this project. Please note that there has been some change/movement in universities across groupings in recent years. The project team have focussed on a grouping structure that best represents the groupings at the time of data collection but acknowledge the appropriation for this project does not reflect membership status in 2019.

- The Group of Eight (GO8): Australian National University (ANU); The University of Melbourne; Monash University; The University of Sydney; University of New South Wales (UNSW); The University of Queensland (UQ); The University of Western Australia (UWA); and The University of Adelaide.

- The Australian Technology Network (ATN): Curtin University; University of Technology Sydney (UTS); RMIT University (RMIT); Queensland University of Technology (QUT); and University of South Australia (UniSA).

- The Innovative Research Universities (IRU): Murdoch University; Flinders University; Griffith University; James Cook University (JCU); La Trobe University; Charles Darwin University (CDU); University of Newcastle.

- Regional Universities Network (RUN): Southern Cross University; University of New England (UNE); Federation University; University of the Sunshine Coast (USC); CQUniversity (CQU); and University of Southern Queensland (USQ).

- The Unaligned Universities (NA): Macquarie University; University of Wollongong; Deakin University; Charles Sturt University (CSU); University of Tasmania (UTAS); Australian Catholic 
University (ACU); University of Canberra; Edith Cowan University (ECU); Swinburne University; Western Sydney University; and Victoria University. 


\section{Part C: Testing the Higher Education Indicators in Various Ranking Scenarios}

\subsection{Introduction}

Using the measures of the indicators and methods described above, indicative rankings were developed for each of the five equity groups. As noted in the methodology, the team used a number of approaches to weighting for the ranking in order to test different assumptions based on expert decision and datadecided methods.

Expert-decided weights were derived from a combination of project team experience, prior research and stakeholder consultation. However, for the reasons outlined in the previous section, the project team did not seek to arrive at one finalised set of specific weights - and as such, a single ranking. Primarily, these relate to issues around the selection of weights in an expert-decided system, given its emphasis on using collective reasoning and the inherent difficulty in capturing the underlying 'drivers' in such a system compared with outcomes derived using an analytical focus. For this reason, a range of weighting combinations were used to develop a number of indicative rankings, in order to demonstrate the influence of different weight scenarios on the outcomes of a ranking and helped to test the influence of bias in particular measures. Consequently, for the testing phase:

1. First, a baseline model was introduced, which allocated equal weight to each of the ten measures included. This test was 'neutral' in the sense that no value judgements were made in regard to primacy of measures. This test was insightful in revealing potential biases in the raw data itself. Thus, it was not necessarily 'neutral' in all senses of the word.

2. Next, the rank was developed applying the PCA, data-decided approach to applying weights. This was instructive in revealing how correlations between measures potentially affect the final ranking and highlight their significance in shaping equity performance measurement.

3. Finally, a range of different ranking scenarios were explored, based on expert-determined weightings. They are designed to illustrate how focussing on particular domains of equity performance, and/or different measurements of equity performance, affect the final ranking.

As a reminder, the indicators and measures of these indicators used in the rankings are shown in Table 13. 
TABLE 13: INDICATORS AND MEASURES UTILISED FOR DEVELOPING THE EQUITY RANKINGS

\begin{tabular}{|c|c|c|}
\hline Indicator & $\begin{array}{l}\text { Measures } \\
\text { (indicator compared to...) }\end{array}$ & Legend \\
\hline \multirow{2}{*}{$\begin{array}{l}\text { Institution's proportion of enrolments in equity } \\
\text { group }\end{array}$} & National rate for that equity group & ACCESS NUP RATIO \\
\hline & State-based full population* & ACCESS RATIO \\
\hline \multirow{2}{*}{$\begin{array}{l}\text { Institution's first year retention rate of equity } \\
\text { group }\end{array}$} & National rate for that equity group & RETENTION FY NUP RATIO \\
\hline & $\begin{array}{l}\text { Rate for all other students at same } \\
\text { institution }\end{array}$ & RETENTION FY RATIO \\
\hline \multirow[t]{2}{*}{ Institution's first year success rate of equity group } & National rate for that equity group & SUCCESS FY NUP RATIO \\
\hline & $\begin{array}{l}\text { Rate for all other students at same } \\
\text { institution }\end{array}$ & SUCCESS FY RATIO \\
\hline \multirow[t]{2}{*}{ Institution's 9-year course completion rate } & National rate for that equity group & COMPLETION NUP RATIO \\
\hline & $\begin{array}{l}\text { Rate for all other students at same } \\
\text { institution }\end{array}$ & COMPLETION RATIO \\
\hline \multirow{2}{*}{$\begin{array}{l}\text { Institution's rate of graduates from equity group } \\
\text { either employed or studying in year after } \\
\text { graduation }\end{array}$} & National rate for that equity group & GRADUATE OUTCOMES NUP RATIO \\
\hline & $\begin{array}{l}\text { Rate for all other students at same } \\
\text { institution }\end{array}$ & GRADUATE OUTCOMES RATIO \\
\hline
\end{tabular}

${ }^{*}$ for ACT-based universities, the NSW state reference population is used

\section{2 'Baseline' rankings}

These rankings offer a relatively simple, initial insight into the outcomes for the ranking when an equal weighting is given to all ten of the measures chosen for the ranking. The intention is to demonstrate what might be seen as a 'Baseline' outcome for consideration and comparison to other options. This particular approach is simple in that it doesn't call for any additional judgement in terms of allocation of weights once the key measures are chosen. However, it is potentially problematic in that it can over-inflate outcomes especially where numerous measures are highly correlated. We further check this eventuality in the PCA weighting approach which follows.

The 'Baseline' ranking for each equity group is displayed in the figures which follow. In looking through the ranking for each equity group, it's interesting to see that the university grouping members represented in the 'top' and 'bottom' few levels are quite different depending on the equity group in focus. For example, Group of Eight (GO8) institutions occupy the first four positions in the low SES ranking, but this concentration is not replicated in any of the other 'Baseline' rankings. The relative success of universities from this research-intensive group of universities is achieved through strong scores for retention, success and completion at both the national comparison and the within institution levels. These areas account for six of the ten measures used in this 'Baseline' version of the ranking and as such high scores across these can significantly increase overall outcomes. For example, GO8_3 had no score for the access measures (both National and State), yet on the strength of scores across the retention, success and completion measures still managed to be placed second overall on the low SES 'Baseline' ranking. 
The relative success of these universities on other 'Baseline' rankings is notably less consistent mainly due to the fact that the within institution measure outcomes are not as high as they are for the low SES group. For example, for the Regional and Remote ranking, the GO8 universities had lower overall scores for the within institution measures, meaning that relative to all students, regional and remote students did not do as well as other students. However, other universities had outcomes on the institution-relative measures which bolstered their overall outcomes. The influence of the retention, success and completion variables on the rankings outcomes are explored and 'controlled' further later in this chapter in discussion of alternative scenarios such as the 'Expert-decided' rankings.

More specifically, in relation to the movement of individual universities across the different equity group rankings, university NA_2 is ranked first for Regional and Remote student equity performance, $17^{\text {th }}$ for low SES student performance, $19^{\text {th }}$ for Indigenous student performance, $6^{\text {th }}$ for students with disability, and $18^{\text {th }}$ for non-English speaking background students. This highlights the advantage of using separate ranks for each equity group, to avoid improper conflation of results. An important adjunct finding is that such an approach may be desirable given Australia's recent history of policy initiatives for individual equity groups - e.g. HEPPP for low SES students, 'Closing the Gap' initiatives for Indigenous students (see Council of Australian Governments, 2009), and the development of funding initiatives for regional and remote students.

Another ranking outcome the baseline scenario illustrates is how some universities derive their ranking from an overreliance on a small number of measures, whereas others perform more universally. An example of the former is the university RUN_5's rank for NESB students, whilst university GO8_2's performance for Indigenous students shows greater uniformity in all measures.

Generally, the effect of a baseline ranking system is to reward institutions that demonstrate across-theboard positive performance, rather than positive performance in more defined domains. This does not mean however, that the derived ranking is unbiased. For example, the data reveal a relatively strong correlation between the Retention and Completion measures, and another, though less-strong, correlation between the Retention and Success measures. Thus, institutions performing well in retention have a very high likelihood of a similar positive performance in completion, and some correlation with the success measure. Consequently, the baseline scenario results in a degree of bias towards these institutions. This bias is compounded further when the partial correlation between the retention and success measures is considered. Since both of these indicators fall into the First-Year domain - and since all other domains have only one indicator, this creates a multiplier effect for certain institutions. 
FIGURE 6: 'BASELINE' RANKING EQUAL WEIGHTS - LOW SES

\section{Equity Performance Ranking (Year 2018)}

Low SES Weighted Scores (Baseline)

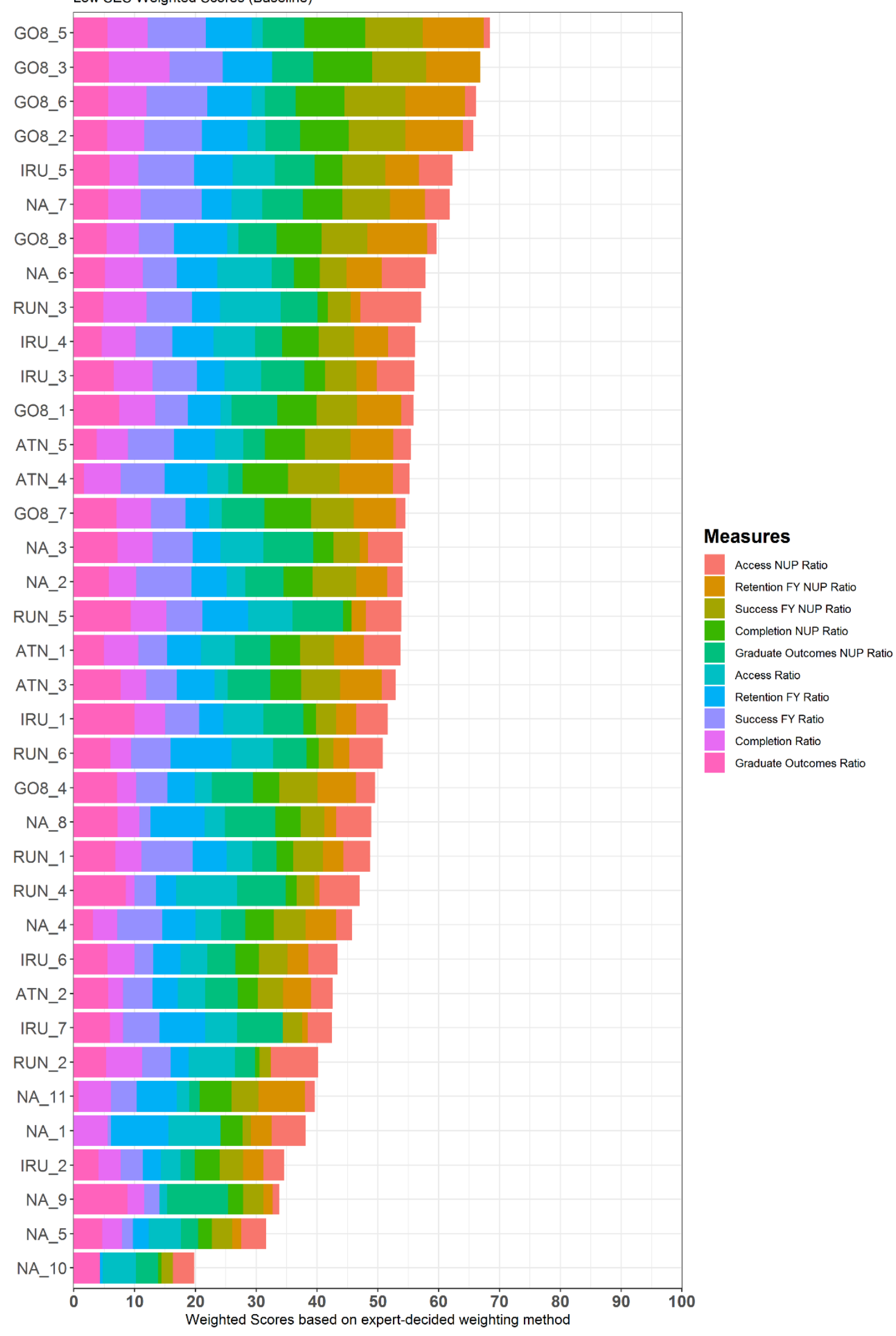


Figure 7 'BASEline’ RANKing equal Weights - Regional And Remote

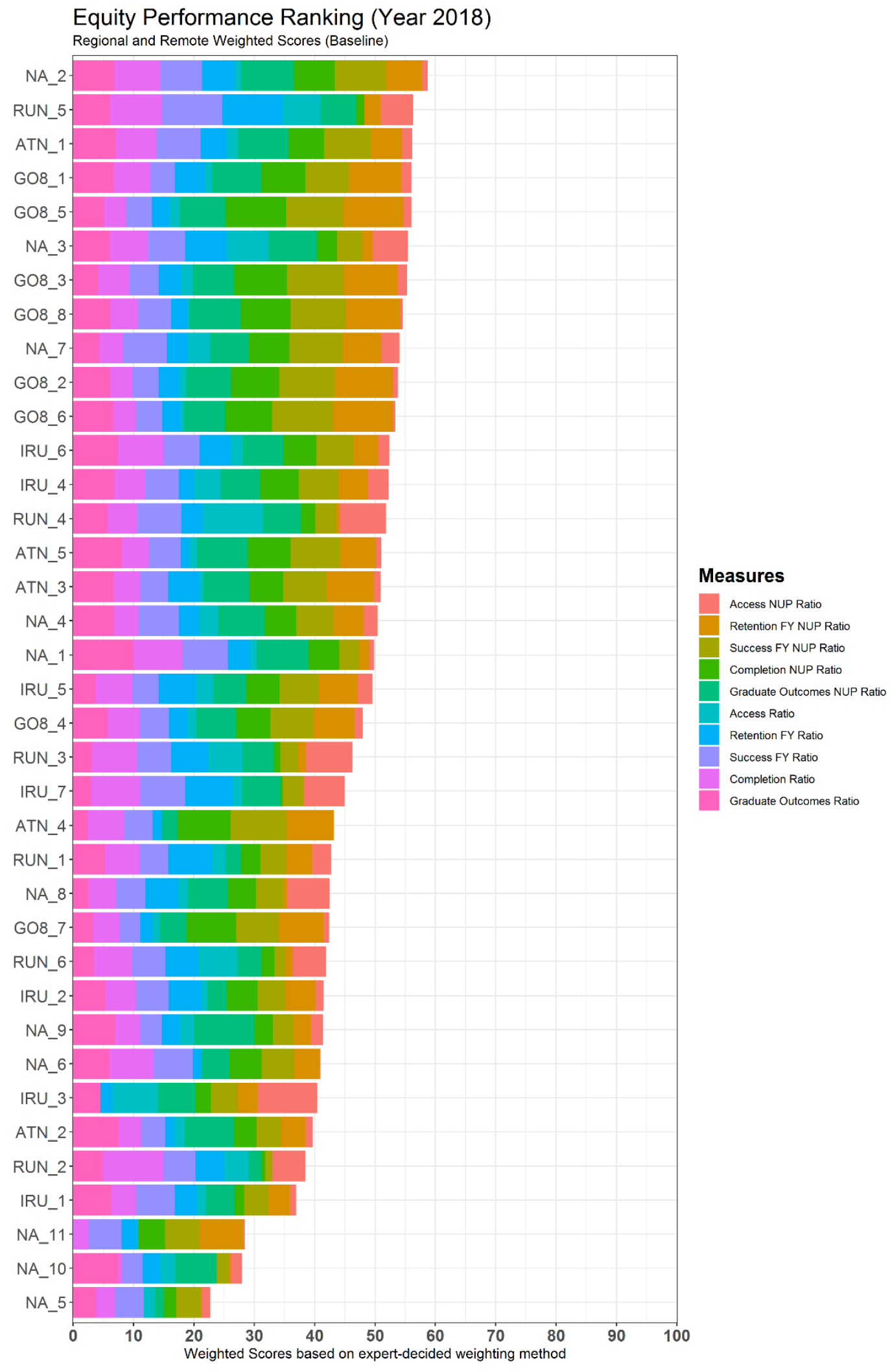


FIgURE 8: 'BASELINE' RANKING EQUAL WEIGHTS - INDIGENOUS ${ }^{11}$

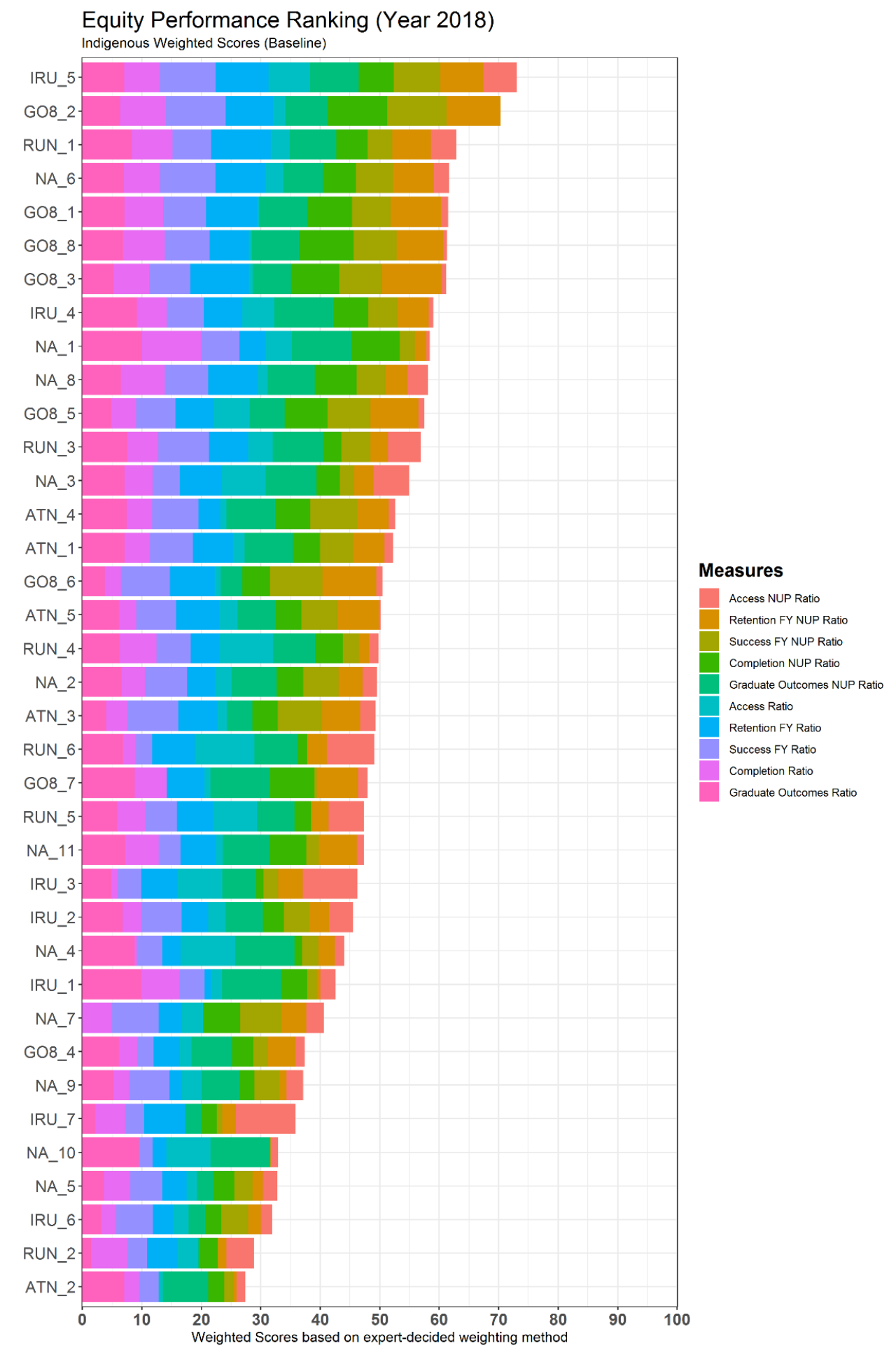

\footnotetext{
${ }^{11}$ Note that the graduate outcomes measures in this ranking should be interpreted with caution. 30 of the 37 institutions have data based on fewer than 25 responses - i.e. below the Department's threshold for public release.
} 
FigURE 9: 'BASELINE' RANKING EQUAL WEIGHTS - DISABILITY ${ }^{12}$

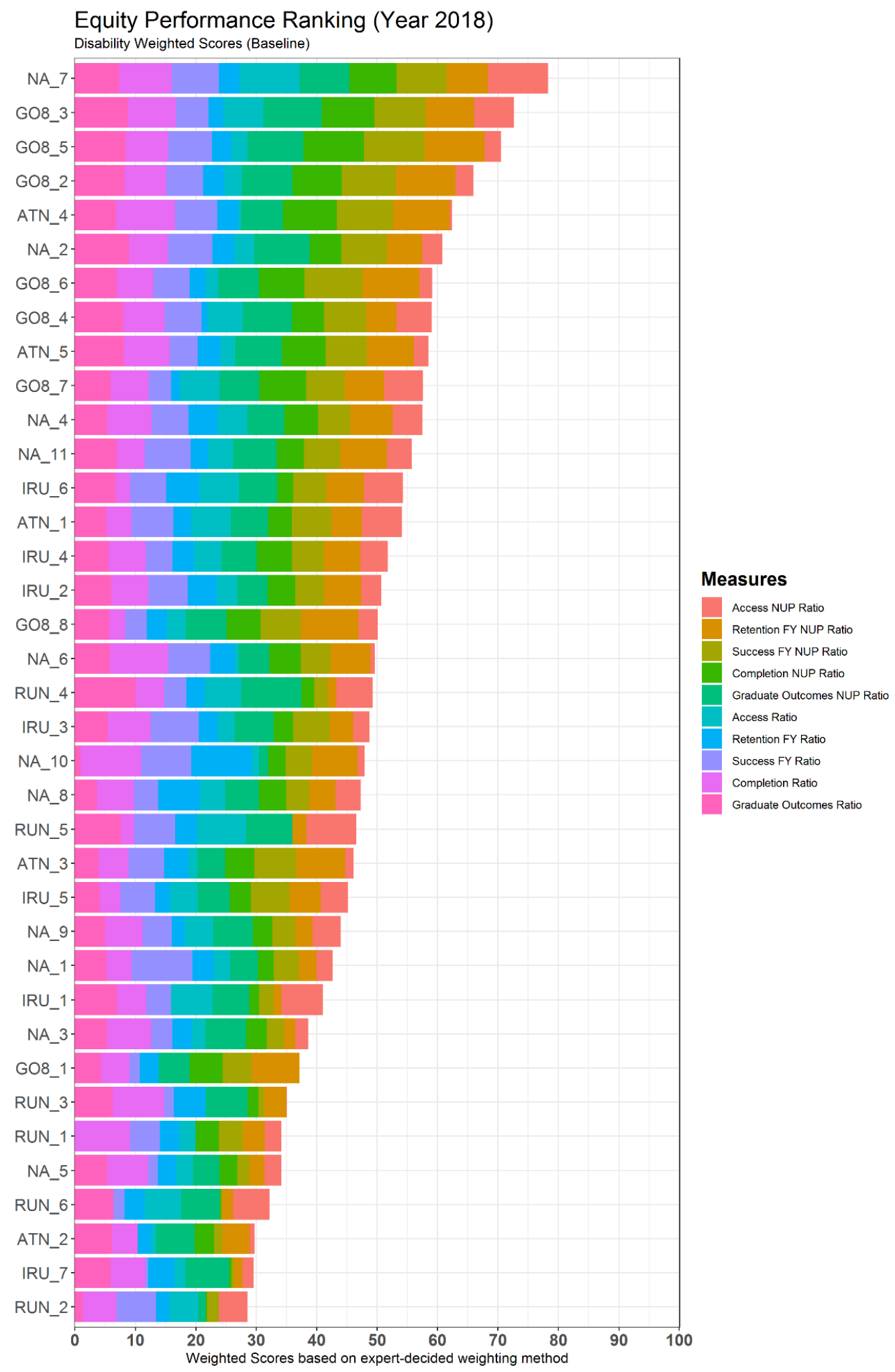

12 Note that the graduate outcomes measures in this ranking should be interpreted with caution. 1 of the 37 institutions has data based on fewer than 25 responses - i.e. below the Department's threshold for public release. 
FIgURE 10: 'BASELINE' RANKING EQUAL WEIGHTS - NESB

Equity Performance Ranking (Year 2018)

NESB Weighted Scores (Baseline)

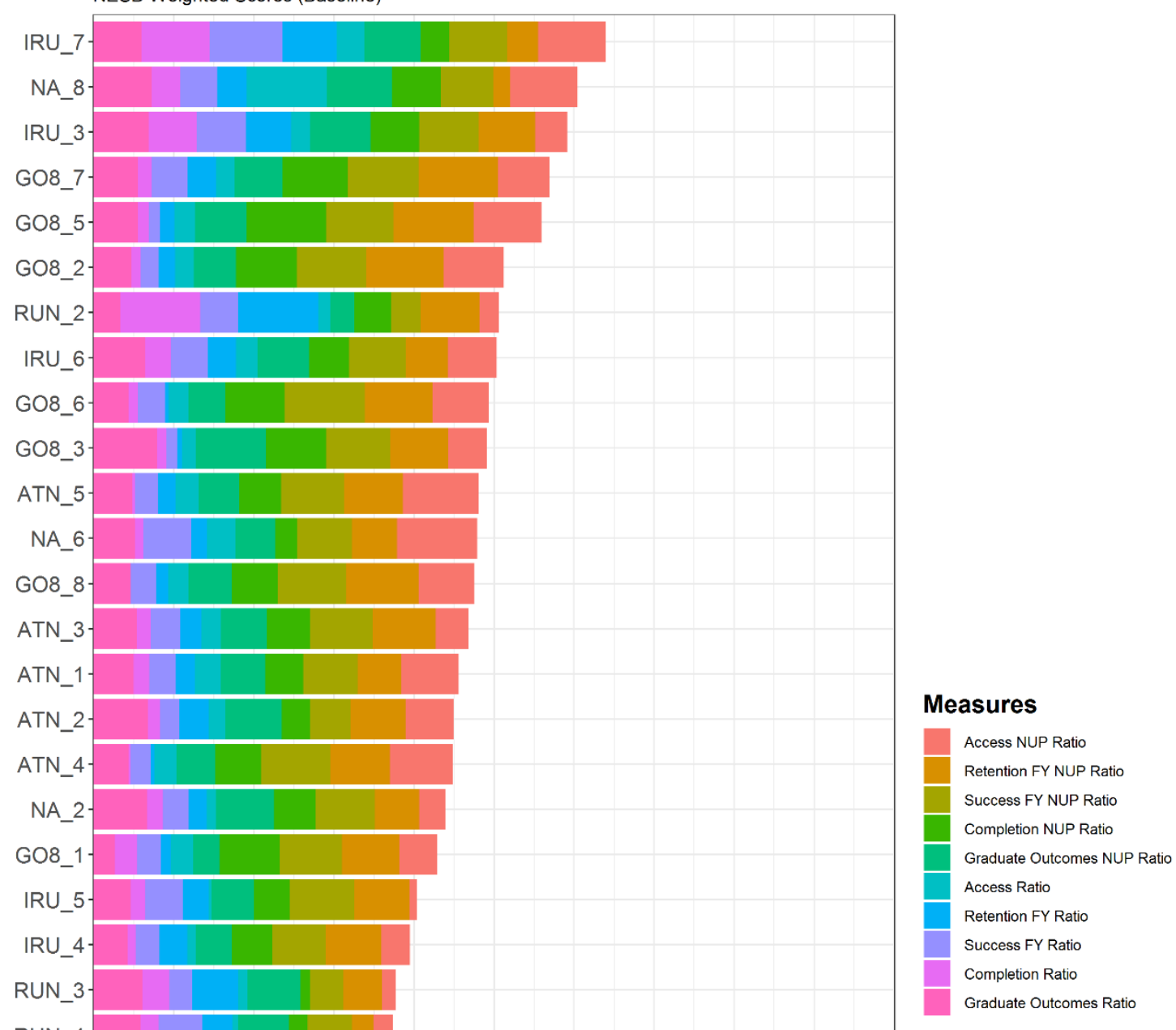

RUN_4

NA_7

NA_11

NA_3

IRU_2

GO8_4

NA_1

RUN_1

RUN_6

IRU_

NA_4

NA_10

NA_9

NA_5 -

RUN_5

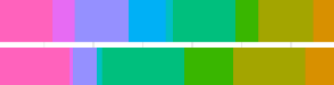

Graduate Outcomes Ratio 


\subsection{Data-driven (PCA) weighted rankings}

As described in the previous section, PCA-derived weights examine relationships between measures and allocate weights based on the relative proximity of measures. PCA computes a number of dimensions that the measures contribute to. Using the example of low SES students, we find through PCA analysis that the national retention ratio measure explains more than half (52.7 per cent) of the variance in outcomes. More specifically, the PCA approach places the most significant weight first in retention (national comparison), then completion (national comparison) and then on success (national comparison) (see Figure 11). It is useful to note that that the same three measures similarly dominated in the PCA analyses for all other equity-groups students except the NESB group (which had the national access rate alongside these three).

While this data-driven approach is interesting, in the scenario shown here it could be argued that it leads to perverse outcomes due to the emphasis on highly correlated variables that may not properly reflect the picture of equity intended through the project and in the selection of indicators for the ranking. Essentially, a ranking system derived from PCA analysis introduces a bias for the same reasons that the baseline-rank does, but to a greater extent, due to the dominance of the retention measure. The results are shown in Figure 12. Due to the PCA approach, universities that have good retention rates dominate the top of the rankings, even when they enrol, proportionately, very few equity-group students.

Consequently, if a PCA or similar approach was used to determine equity performance rankings, then the evidence is that institutions enrolling relatively few, but high-achieving, equity students, would be perceived as performing better than institutions enrolling many more, but lower-achieving, equity-group students.

FiguRE 11: PCA-DERIVED WEIGHTING CONTRIBUTION (DIMENSION 1) - LOW SES

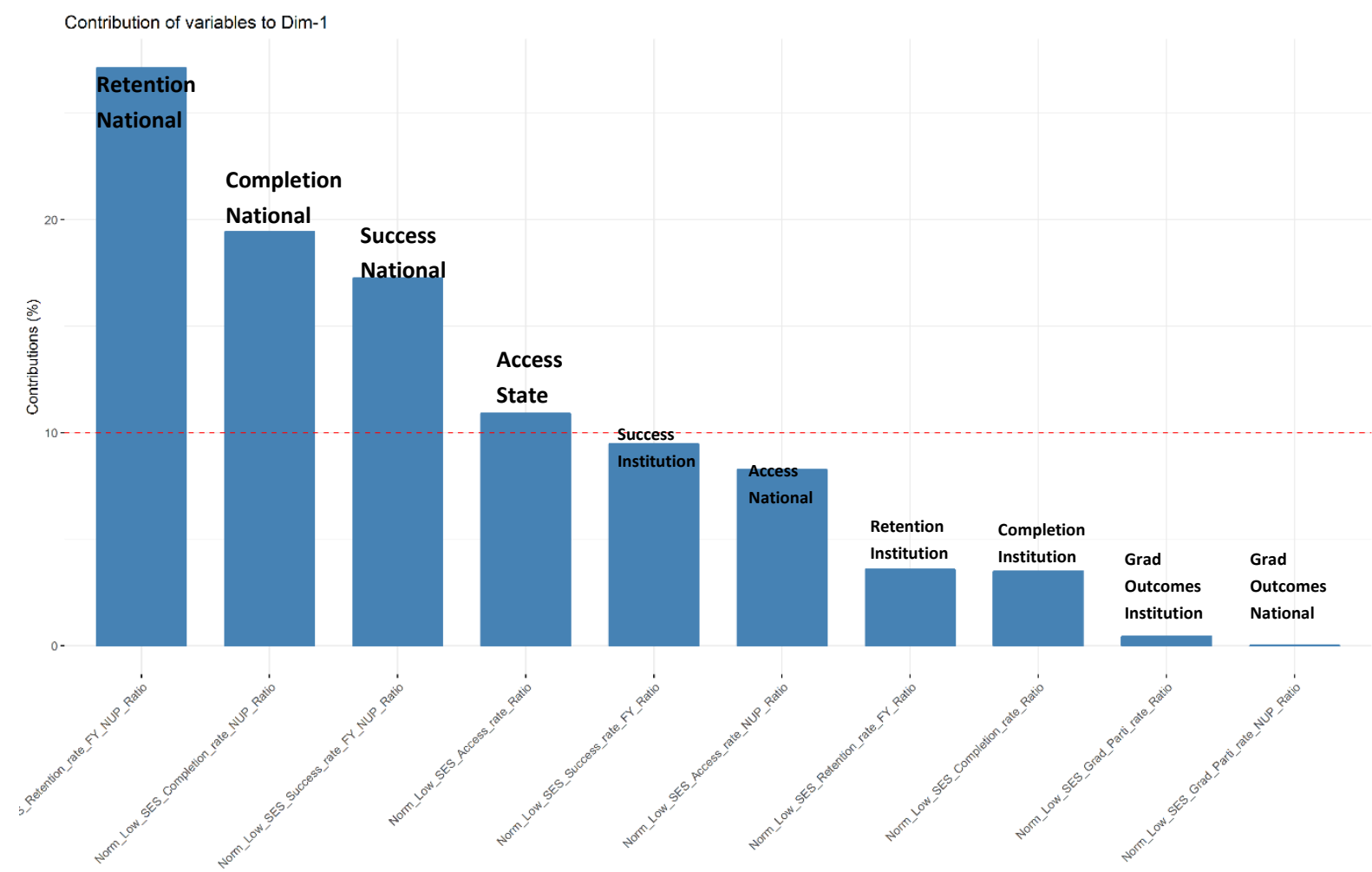


FIGURE 12: DATA-DRIVEN RANKING (PCA WEIGHTS) - LOW SES

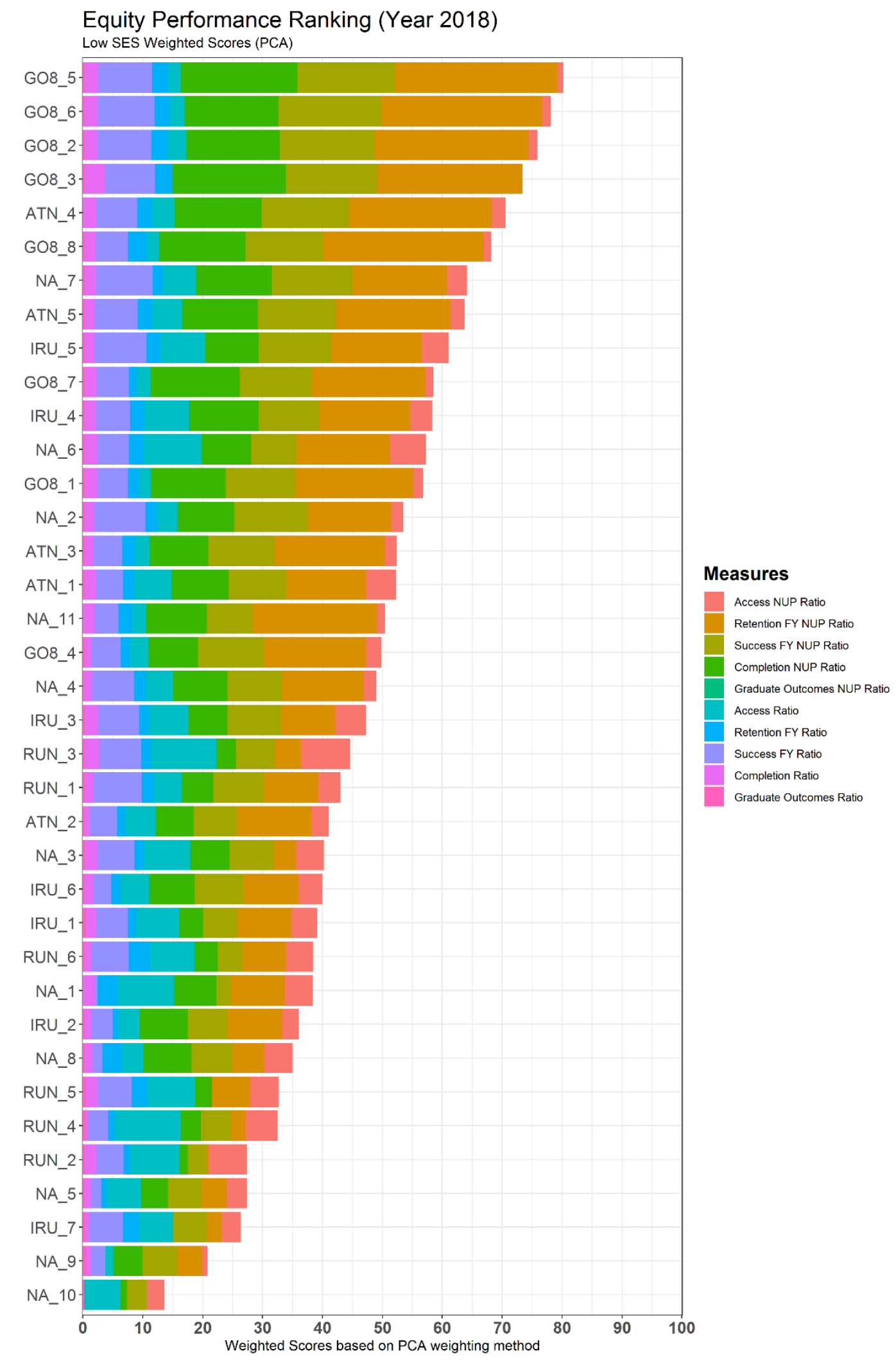




\subsection{Rankings based on a range of expert-determined weighting scenarios}

The ranking model developed for this project allowed the testing of a range of weighting combinations to test ideas and explore a range of scenarios. In this section of the report, we use the low SES student equity ranking data to demonstrate these. Again, the effects were, broadly speaking, the same for other equity-groups.

In constructing different weighting scenarios, the project team was able to manipulate the emphasis applied to each of the indicators and their relevant measures. In some scenarios tested, a number of measures were given a ' 0 ' weight (i.e. 'turned off'). As per the methodology described earlier, as long as the sum of all weights equal 1 , a ranking could be constructed.

This exploration begins with a combination of weights that focus on responding to the suggestions of a number of experts during the consultation phase of the project. Overall, there was a broad consensus to:

- Keep the calculation simple, by using fewer rather than more indicators;

- Specifically, to focus on/weight towards access and participation, retention, and graduate outcomes; and

- Consider, and make transparent, the effect of biasing national performance measures versus within-institution, or state-specific, measures.

The guidance gained through the consultation phase emphasised the potential pitfalls of having too many measures that were correlated. As noted earlier in the discussion of the 'Baseline' ranking scenarios, the inclusion of national relative and within institution measures for retention, success and completion has the potential to skew results due to the weight of numbers in these relatively correlated measures. By paring back the number of measures for the expert-decided rankings, there is a sense that some of the skewing based on correlated measures is muted.

\subsubsection{Expert-decided, equal weighting}

First, the project team derived a rank where the six relevant measures were evenly weighted. That is, access, retention and graduate outcomes were all considered to be of equal importance, as was the national and internal comparator. The results are shown in Figure 13, using the low SES equity group as the example. As would be expected with an equally-weighted approach, universities are able to compensate for a deficit in one measure with a corresponding surplus in another. For example, the top three-ranked universities have distinctly different retention outcomes for students. 
FIGURE 13: EXPERT-DECIDED RANKING, FOCUS ON ACCESS, RETENTION AND GRADUATE OUTCOMES - LOW SES

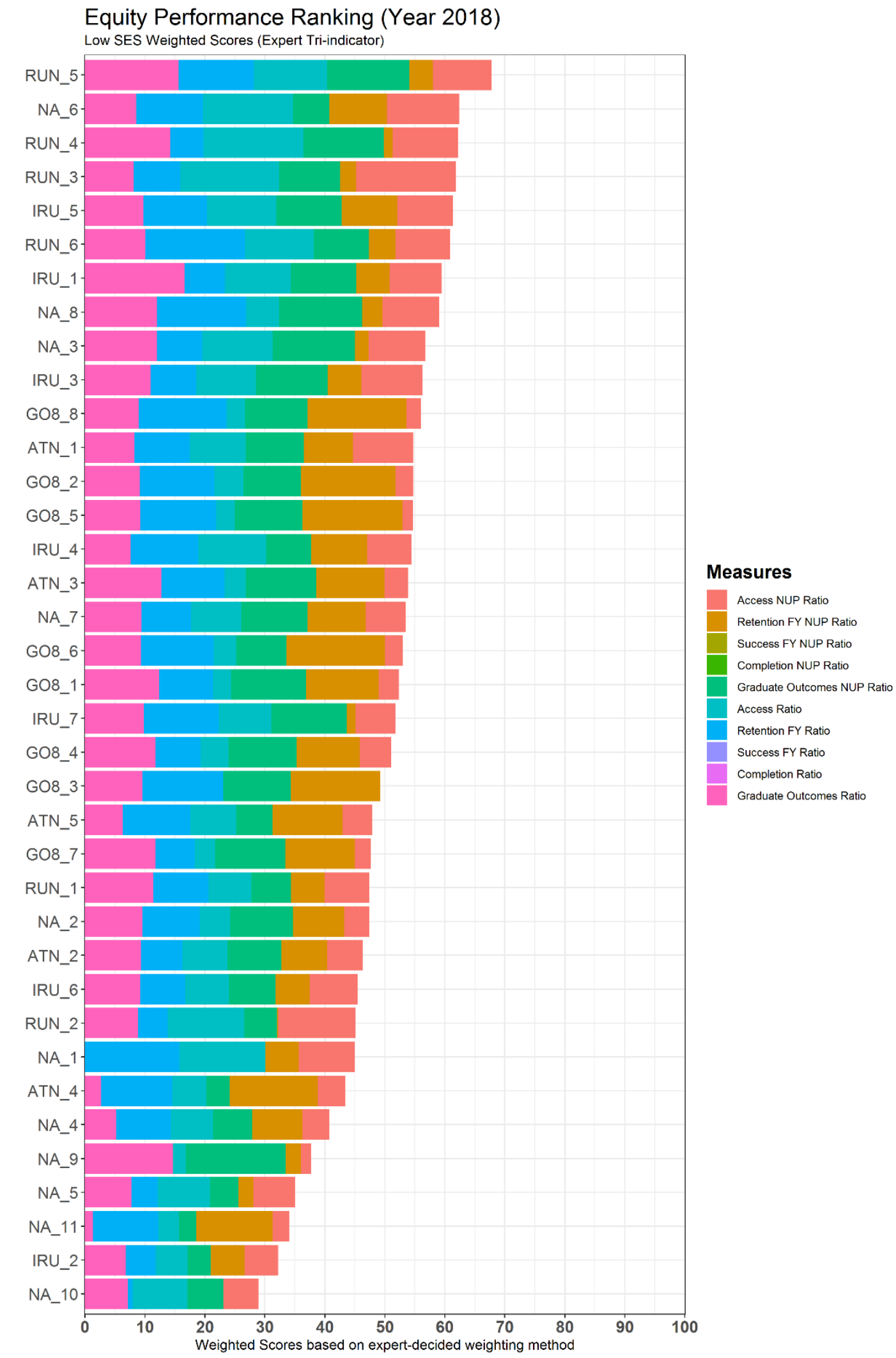




\subsubsection{Expert-decided, access-focussed weighting}

Next, the project team, modelled a rank where access measures had a significantly higher weighting, compared to retention and gradate outcomes. The results, for low SES students are shown in Figure 14. The top three institutions have low SES participation rates not only above sector average, but also above national average i.e. low SES students are enrolled at a rate even higher than their representation in the national population. Only two institutions in the top ten-ranked institutions have retention rates above 80.0 .

FIGURE 14: RANKING WEIGHTED TOWARDS ACCESS MEASURES - LOW SES STUDENTS

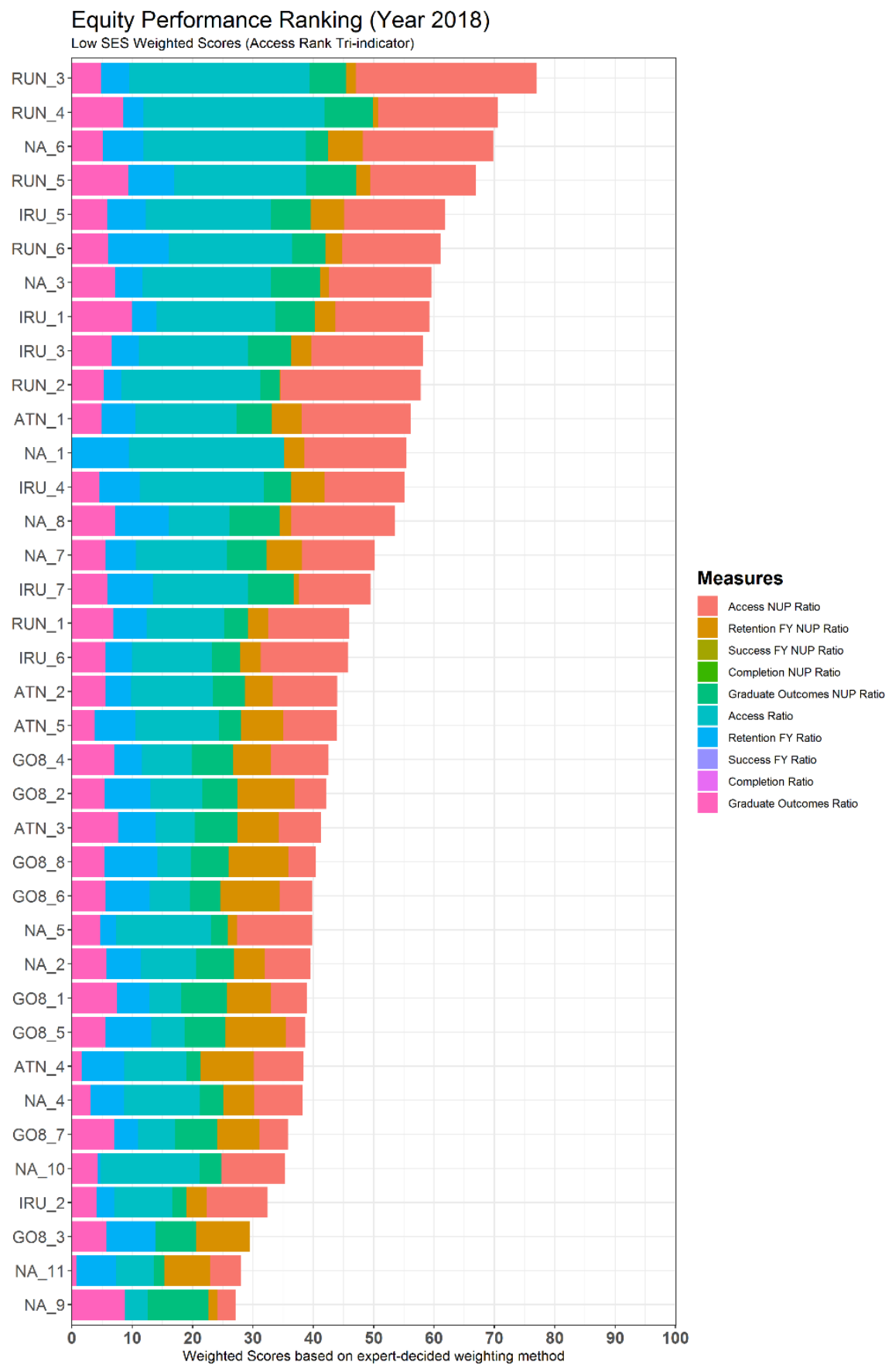




\subsubsection{Expert-decided, retention-focussed weighting}

This rank included a significant weighting towards retention measures and the results are shown in Figure 15. The ranking differs significantly from the earlier, PCA defined model, because the multiplier effect of the success and completion measures has been removed. Consequently, the top quartile of the rank shows a degree of diversity in terms of institutional type. One could be characterised as highretention/high-participation; six as low-participation/high-retention; and one as high-participation/highretention/high-graduate outcomes. However, within this particular stratification the bias towards retention is clear. For example, the top four-ranked institutions are ranked higher than the highretention/high-participation and high-participation/high-retention/high-graduate outcomes ones, due to their retention 'score' counting for the most.

FIGURE 15: RANKING WEIGHTED TOWARDS RETENTION MEASURES - LOW SES STUDENTS

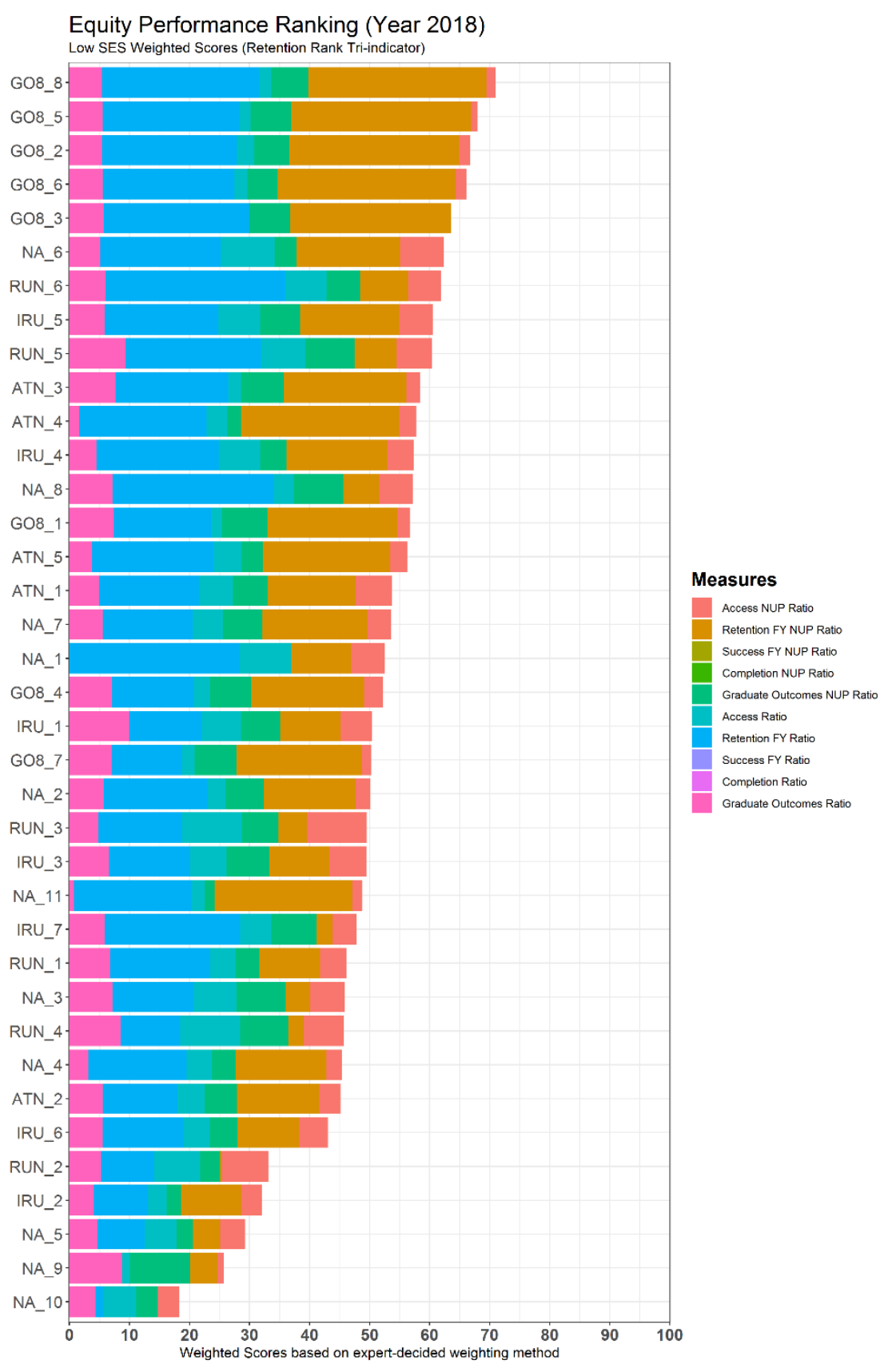




\subsubsection{Expert-decided, graduate outcomes-focussed weighting}

This rank weighted towards graduate outcomes and the results are shown in Figure 16. Again, this reorders the ranking somewhat, but institutions are re-sorted within their general location of ranking in comparison with the earlier weightings. This somewhat reflects the lower influence of graduate outcomes in this model compared with that of retention.

FIGURE 16: RANKING WEIGHTED TOWARDS GRADUATE OUTCOME MEASURES - LOW SES STUDENTS

Equity Performance Ranking (Year 2018)

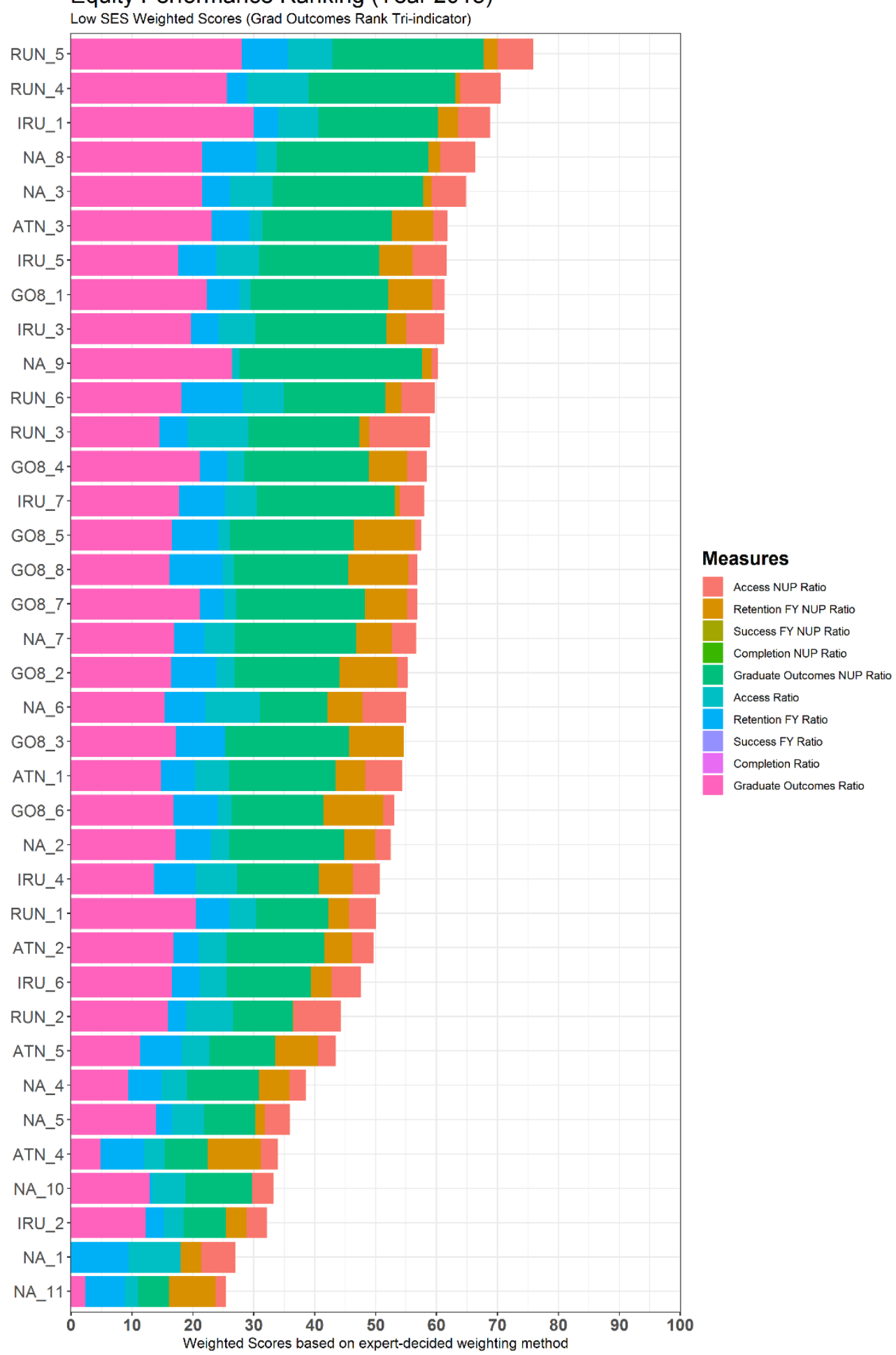


Through modelling these four scenarios (i.e. equal-weighting, access-focussed, retention-focussed and graduate outcomes-focussed), it is apparent that no particular institutions stand out as being exemplars in equity performance. This is highlighted in Figure 17, where the effect of changing the weightings is shown by plotting the rank of each university for the above scenarios onto a 'bump chart'.

The main point the chart demonstrates is that different applications (weightings) of the same set of measures can vastly alter outcomes. For the majority of institutions, the weighting given to indicators in the three domains of access, first-year success and graduate outcomes has a significant impact on their final position in the ranking. Importantly, this variation is revealed in what is a relatively simple ranking scenario (i.e. three indicators, each measured two ways). Returning to the point at which this report began, the outcomes here are demonstrative of how important the definition of 'equity performance' can be as a determinant of rank in such performance measures.

Further exploring the outcome in the figure below, the example of university RUN_3 is indicative of the institution-level change from these adjustment to weight. RUN_3 is ranked $1^{\text {st }}$ when access is prioritised, $23^{\text {rd }}$ when retention is prioritised and $12^{\text {th }}$ when graduate outcomes are prioritised. However, some universities demonstrate more uniform performance. For example, the university RUN_5 and university IRU_5 maintain a place in the top ten in all three scenarios. One more (RUN_6) is ranked in the top 10 for Access and Retention and falls to $11^{\text {th }}$ in Graduate Outcomes. At the other end of the scale, three universities remain in the bottom-ten ranked universities across all three scenarios. 
FIGURE 17: RANKING RESULT COMPARISON WITH BUMP CHART

Ranking result comparisons with a bump chart (Low SES)

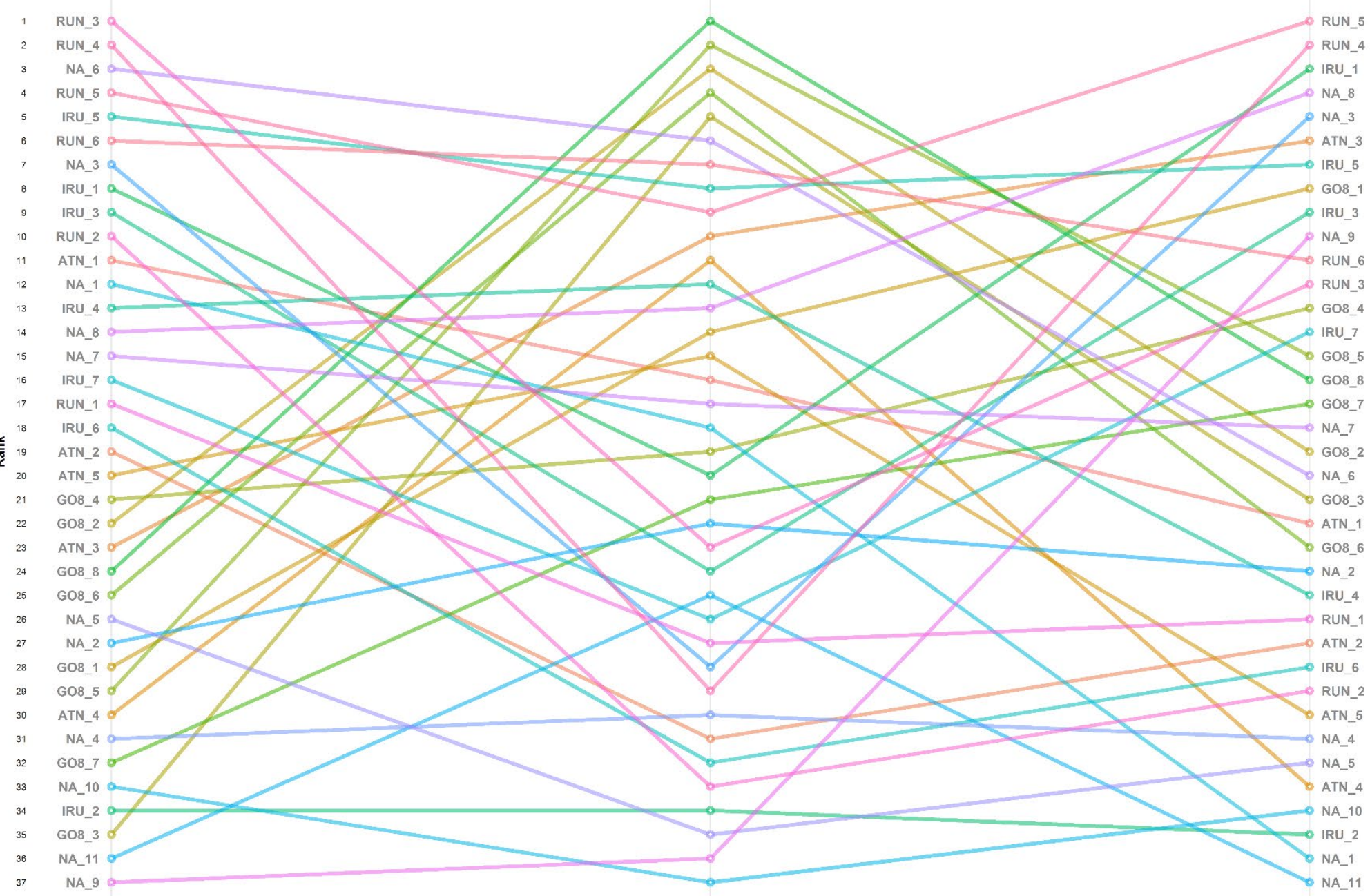




\subsubsection{National vs within-institution comparisons}

Equally, there is much variance in ranking positions depending on whether an 'external' or 'internal' view of higher education equity performance is prioritised. When the external view is taken, then the performance of the institution relative to the entire sector is considered to have primacy, for any particular equity group - that is outcomes are measured based on national averages within the equity group of interest. Conversely, the internal view compares the performance of the equity-group students to the other students within the same institution. Figure 18 shows how institutions move up and down the rankings depending on whether the national or within-institution comparator is used. The majority of universities see significant changes in their ranking order across the two comparators. 
FIGURE 18: RANKINGS COMPARISON, NATIONAL COMPARISON WEIGHTS TO WITHIN-INSTITUTION WEIGHTS - LOW -SES

\section{Ranking result comparisons with a bump chart (Low SES)}

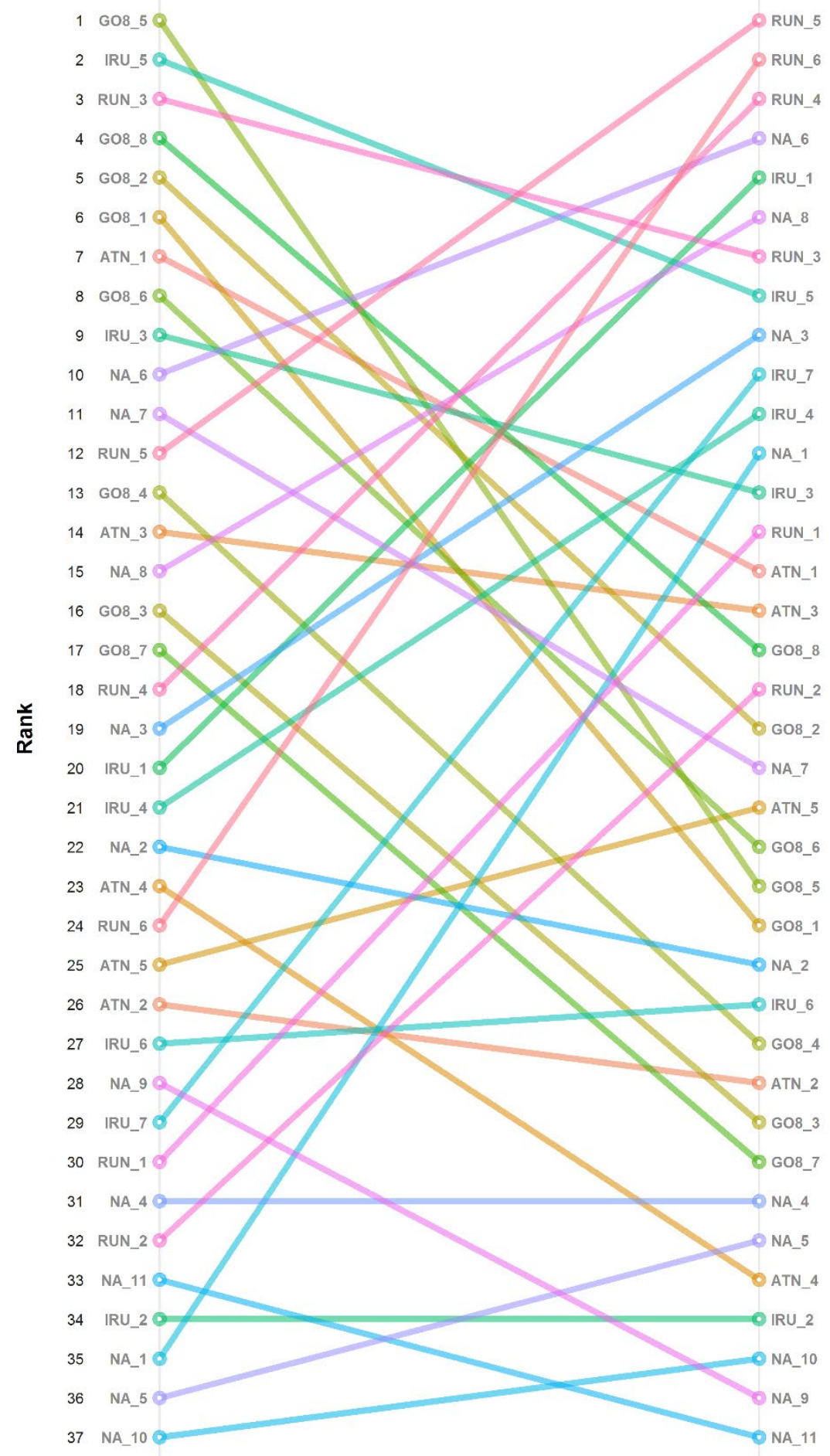




\section{Part D: Conclusion}

\subsection{Using a higher education ranking system to measure equity performance}

Using currently available data, it is possible to construct a higher education equity ranking system for the purpose of monitoring higher education performance in this respect. A ranking system has the advantage of being easily understood and visualised by stakeholders. Also, providing the methodology is clearly explained, a ranking system can be transparent and make clear to stakeholders what behaviours will drive improvement to higher education equity performance.

However, while it is feasible to develop a ranking, it is important to note that a ranking system does not measure absolute performance, it measures relative performance. That is, it is possible for an institution to achieve a high rank even with sub-optimal equity performance, so long as it is above average compared to other, underperforming institutions. The opposite is also true. For example, in 2016, no institution achieved proportional representation of students from non-English speaking backgrounds. However, a ranking system would have had to, by definition, rank as first the least-worst performing university. Furthermore:

- Only eight out of 42 institutions achieved proportional representation for people with disability;

- Only eight achieved proportional representation of students from a low-SES background;

- Only ten achieved proportional representation of Indigenous persons; and

- Only 13 achieved proportional representation from students from a regional/remote background. ${ }^{13}$

Similar results are achieved when institutions are ranked based on retention, success or completion rates, where 'proportional' is defined as a rate the same as or greater than the overall student rate.

\subsection{Domains of higher education equity performance}

The project has identified six domains in which higher education equity policy could be applicable, and in which it is possible for higher education institutions to influence outcomes to some extent. These domains are:

- Aspiration - actions and outcomes helping equity-group students to aspire to higher education.

- Academic preparation - actions and outcomes helping equity-group students prepare for higher education success.

- Access and participation - increasing the proportion of equity-group students in the overall higher education student population.

- First-year experience - helping equity-group students successfully transition through the critical first year of study.

\footnotetext{
${ }^{13}$ Figures sourced from: Higher Education Statistics Series 2016: Appendix 5- Equity performance data
} 
- Progress during higher education study - supporting equity-group students to continue with and complete their course of study.

- Graduation outcomes - achieving positive graduation outcomes, as measured by employment and/or further study.

\subsection{Indicators for measuring higher education equity performance}

Out of 50-plus indicators considered in this project, the project team used its SMARVR methodology to identify five core indicators for measuring higher education equity performance:

- Indicator 1: Enrolment in higher education

- Indicator 2: First-year retention

- Indicator 3: First-year success

- Indicator 4: Completion after nine years

- Indicator 5: Being employed or undertaking further study within 12 months of graduation.

The research revealed that, currently, reliable indicators do not exist to measure performance in the domains of Aspiration and Academic Preparation. Further, the research revealed that the measure for Graduation Outcomes (Indicator 5) is based on relatively small data sets, which have the potential to skew the subsequent rankings.

Therefore, the ranking system explored through this research is deficient in these respects.

\subsection{Measuring equity performance through the indicators}

This project explored measuring institutional performance against each of the five chosen indicators in two ways:

1. Based on national comparisons. Whereby an outcome on an indicator for equity group students in an institution is calculated relative to the national average for other students in the same equity group.

2. Based on within-institution comparisons. Whereby an outcome on an indicator for equity group students in an institution is calculated relative to the average within the same institution for students not in the equity group. ${ }^{14}$

This results in 10 separate calculations to measure higher education equity performance in the ranking approach developed in this project.

\footnotetext{
${ }^{14}$ For the enrolment indicator, the second measure is based on a state-based comparison, whereby an outcome on the enrolment indicator is calculated relative to the state-based share of the population for that equity group
} 


\subsection{Constructing a ranking}

A weight-and-sum approach was used to construct the rankings. A range of indicative weightings were used to generate ranks for analysis and explore potential outcomes of a ranking system in this context. The analysis indicated varying equity performance for most institutions, with most institution's final rank varying significantly depending on: which equity group was being measured; which aspect of equity performance was the area of focus (i.e. was weighted the most heavily); and whether equity-group performance was compared to the corresponding performance for other students in the same institution or against the national average for the same equity-group's performance.

Through the research, the project team concluded that there was no 'optimum' weighting methodology for the purposes of objectively measuring higher education equity performance at the institutional level. There were several reasons for this, with the most significant being:

- Whilst there is broad agreement on what higher education equity is, and how it can be defined, there is less consensus - in extant research, international higher education policy and with stakeholders - on how higher education might be precisely defined and measured. Without this precision, it is not possible to advise what the optimum weighting method might be.

- Conversely, it is possible to more precisely determine weightings in the presence of specific higher education equity goals and targets; for example, such as those set out in the 2008 Review of Higher Education (Bradley et al., 2008). This is because in this instance, the intention of the ranking system becomes more a means of promoting certain actions and behaviours within institutions, to synchronise activities with Government higher education policy intention. That is, the ranking systems becomes a change agent, rather than a neutral measurement tool. In this case, weightings can be more precisely calibrated to engender the requisite behaviour. However, in the current policy environment, targets such as this either do not exists and/or are not being actively pursued.

- $\quad$ Furthermore, in some domains the data do not currently exist to apply weightings to; most notably in the domains of Aspiration and Academic Preparation.

\subsection{Findings and thoughts for the future}

This report demonstrates the type of choices and trade-offs inherent in the construction of any equity performance ranking. To summarise:

1. It is possible to construct a Ranking System to measure equity in Australian universities.

2. Based on thorough review and consultation, the indicators used and testing the development of this ranking are the most appropriate indicators currently available in Australia. However, these do not cover all the domains that would ideally be included in a comprehensive performance measure.

3. In terms of developing potential new indicators, the focus should be on the aspiration and academic preparation domains, where currently there are no reliable indicators.

4. To ensure transparency and understanding of a ranking, the project team recommended that the fewer indicators in a ranking the better. As such the approach in this project was to focus on 'only' five indicators. 
5. Any ranking system should involve a separate rank for each equity group, to reflect the often significantly different performance of each group at the institutional level.

6. Equity performance can be conceptualised both in terms of national and within-institution comparators, or in the case of participation, in terms of national and 'local' performance.

7. A weight and sum approach is the best means of constructing the ranking system - particularly if the intention of the ranking is to be transparent and accessible.

8. The weightings applied to measures can make substantial difference to the ordering of institutions in a ranking. 'Objective' data-driven weighting approaches can have unintended perverse outcomes, while expert-decided approaches can result in vastly different outcomes depending on the subjective importance placed on measures.

9. Further to (8) above, the raw population of at least two equity groups (namely: Indigenous students and students with disability) results in relatively small cell counts at the institutional level, particularly in respect of Indicator 5 (Being employed or undertaking further study within 12 months of graduation). Consequently, any published rankings being applied for these groups would need to take this into account.

10. Given the limitations of a ranking system to measure higher education equity performance, other options should be explored. As these alternatives fell outside the scope of the project a more definitive answer cannot be provided, however the following section outlines potential avenues for further research.

\subsection{Alternative approaches to measuring higher education equity performance}

As advised above, further research should be conducted to establish whether an alternative approach to a ranking system should be used for measuring higher education equity performance. Based on the research conducted as part of this project, two options are suggested for further consideration:

\subsubsection{Rating system}

Rating systems measure individual organisations not against each other, but against an extra value that is generally external to the system indicators, often referred to as a 'benchmark'. As individuals/institutions are not measured relative to each other, it is theoretically possible for all to be given the same value.

Ratings can sometimes be more beneficial than rankings, for example, where the individual assessments, against the criteria, are clustered very closely together and a ranking system would result in 'spurious precision' (Soh, 2017). Ratings are also useful where the purpose of assessment is to change organisational behaviour to align with an external policy imperative; for example, when the desire is for institutions to meet a defined goal or target, rather than compete against each other. For example, this was the intention of the mission-based compacts, which were developed following the Bradley Review of the Australian Higher Education system. Amongst other things, under the compacts included a measure of the participation of students from a low-SES background and was measured as a proportion of all domestic undergraduate students. A university was deemed as 'excellent' for the low SES indicator if their crude rate in the year of assessing the performance target was greater than or equal to their excellence target (Higher Education Group, 2011). 


\subsubsection{Data Dashboard approach}

A data dashboard would involve the construction of an information management tool to track, analyse and displays higher education equity performance. Data dashboards are an efficient means of tracking and visualising multiple data sources and allow specific stakeholders to monitor specific elements of equity performance and be provided with more detailed information and insights than would be available in other systems (e.g. publicly released rankings and ratings). Further, data dashboards provide institutions with considerable flexibility for benchmarking against similar institutions as part of their internal analysis and reporting on equity issues. 


\section{APPENDIX A: Berlin Principles on Ranking of Higher Education Institutions}

The International Ranking Expert Group (IREG) was founded in 2004 by the UNESCO European Centre for Higher Education (UNESCO-CEPES) in Bucharest and the Institute for Higher Education Policy in Washington, DC. At IREG's second meeting (Berlin, 18 to 20 May 2006) a set of principles of quality and good practice in HEl rankings (aka the Berlin Principles) were developed. These principles are outlined below. A copy of the principles were downloaded on the $14^{\text {th }}$ of March, 2018, from http://www.ihep.org/sites/default/files/uploads/docs/pubs/berlinprinciplesranking.pdf

\section{A) Purposes and Goals of Rankings}

1. Be one of a number of diverse approaches to the assessment of higher education inputs, processes, and outputs. Rankings can provide comparative information and improved understanding of higher education but should not be the main method for assessing what higher education is and does. Rankings provide a market-based perspective that can complement the work of government, accrediting authorities, and independent review agencies.

2. Be clear about their purpose and their target groups. Rankings have to be designed with due regard to their purpose. Indicators designed to meet a particular objective or to inform one target group may not be adequate for different purposes or target groups.

3. Recognize the diversity of institutions and take the different missions and goals of institutions into account. Quality measures for research-oriented institutions, for example, are quite different from those that are appropriate for institutions that provide broad access to underserved communities. Institutions that are being ranked and the experts that inform the ranking process should be consulted often.

4. Provide clarity about the range of information sources for rankings and the messages each source generates. The relevance of ranking results depends on the audiences receiving the information and the sources of that information (such as databases, students, professors, employers). Good practice would be to combine the different perspectives provided by those sources in order to get a more complete view of each higher education institution included in the ranking.

5. Specify the linguistic, cultural, economic, and historical contexts of the educational systems being ranked. International rankings in particular should be aware of possible biases and be precise about their objective. Not all nations or systems share the same values and beliefs about what constitutes "quality" in tertiary institutions, and ranking systems should not be devised to force such comparisons.

\section{B) Design and Weighting of Indicators}

6. Be transparent regarding the methodology used for creating the rankings. The choice of methods used to prepare rankings should be clear and unambiguous. This transparency should include the calculation of indicators as well as the origin of data.

7. Choose indicators according to their relevance and validity. The choice of data should be grounded in recognition of the ability of each measure to represent quality and academic and institutional strengths, 
and not availability of data. Be clear about why measures were included and what they are meant to represent.

8. Measure outcomes in preference to inputs whenever possible. Data on inputs are relevant as they reflect the general condition of a given establishment and are more frequently available. Measures of outcomes provide a more accurate assessment of the standing and/or quality of a given institution or program, and compilers of rankings should ensure that an appropriate balance is achieved.

9. Make the weights assigned to different indicators (if used) prominent and limit changes to them. Changes in weights make it difficult for consumers to discern whether an institution's or program 's status changed in the rankings due to an inherent difference or due to a methodological change.

\section{C) Collection and Processing of Data}

10. Pay due attention to ethical standards and the good practice recommendations articulated in these Principles. In order to assure the credibility of each ranking, those responsible for collecting and using data and undertaking on-site visits should be as objective and impartial as possible.

11. Use audited and verifiable data whenever possible. Such data have several advantages, including the fact that they have been accepted by institutions and that they are comparable and compatible across institutions.

12. Include data that are collected with proper procedures for scientific data collection. Data collected from an unrepresentative or skewed subset of students, faculty, or other parties may not accurately represent an institution or program and should be excluded.

13. Apply measures of quality assurance to ranking processes themselves. These processes should take note of the expertise that is being applied to evaluate institutions and use this knowledge to evaluate the ranking itself. Rankings should be learning systems continuously utilizing this expertise to develop methodology.

14. Apply organizational measures that enhance the credibility of rankings. These measures could include advisory or even supervisory bodies, preferably with some international participation.

\section{D) Presentation of Ranking Results}

15. Provide consumers with a clear understanding of all of the factors used to develop a ranking and offer them a choice in how rankings are displayed. This way, the users of rankings would have a better understanding of the indicators that are used to rank institutions or programs. In addition, they should have some opportunity to make their own decisions about how these indicators should be weighted.

16. Be compiled in a way that eliminates or reduces errors in original data and be organized and published in a way that errors and faults can be corrected. Institutions and the public should be informed about errors that have occurred. 


\section{References}

Abbot, M., \& Doucouliagos, C. (2003). The efficiency of Australian universities: A data envelopment analysis. Economics of Education Review, 22(1), 89-97. http://dx.doi.org/10.1016/S02727757(01)00068-1

Academic Ranking of World Universities. (2014). Ranking Methodology of Academic Ranking of World Universities - 2014. Retrieved from http://www.shanghairanking.com/ARWUMethodology-2017.html

Atherton, G., Dumangane, C., \& Whitty, G. (2016). Charting Equity in Higher Education: Drawing the Global Access Map. London:

Australian Institute of Health and Welfare. (2013). Towards a performance measurement framework for equity in higher education. D. o. Innovation. Retrieved from http://www.innovation.gov.au/highereducation/Policy/Pages/NationalEquityinHigherEducat ionPolicyForum2013.aspx

Baik, C., Naylor, R., \& Arkoudis, S. (2015). The First Year Experience in Australian Universities: Findings from Two Decades, 1994-2014. Melbourne Centre for the Study of Higher Education,

Behrendt, L., Larkin, S., Griew, R., \& Kelly, P. (2012). Review of higher education access and outcomes for Aboriginal and Torres Strait Islander people.

Bell, S., \& May, R. (2016). Ladders of opportunity: Postgraduate equity, professions and the academic workforce Student Equity in Australian Higher Education (pp. 241-255): Springer.

Bexley, E. (2008). The first-year experience at La Trobe University. Melbourne, Australia: Centre for the Study of Higher Education.

Bradley, D., Noonan, P., Nugent, H., \& Scales, B. (2008). Review of Australian higher education: Final report. Canberra: Department of Education, Employment and Workplace Relations.

Britton, J., Dearden, J., Shephard, N., \& Vignoles, A. (2016). How English domiciled graduate earnings vary with gender, institution attended, subject and socioeconomic background. London: Retrieved from http://www.ifs.org.uk/uploads/publications/wps/wp201606.pdf

Bronfenbrenner, M. (1973). Equality and Equity. The Annals of the American Academy of Political and Social Science, 409, 9-23. Retrieved from http://www.jstor.org/stable/1041487

Cabinet Office Strategy Unit. (2009). Unleashing Aspiration: The Final Report of the Panel on Fair Access to the Professions. London: Retrieved from http://webarchive.nationalarchives.gov.uk/20100407163903/http://www.cabinetoffice.gov. uk/strategy/work areas/accessprofessions.aspx

Cameron, S., Daga, R., \& Outhred, R. (2018). Setting out a conceptual framework for measuring equity in learning. In UNESCO (Ed.), Handbook for meausring equity in education (pp. 16-44). Montreal: UNESCO Institute for Statistics.

Canberra Times. (1972, 07 March 1972). Education and the rich shall inherit the earth. Tharunka (Kensington, NSW : 1953 - 2010). p. 4. Retrieved from http://nla.gov.au/nla.newsarticle228113957

Chapman, B., \& Ryan, C. (2005). The access implications of income-contingent charges for higher education: lessons from Australia. Economics of Education Review, 24(5), 491-512. http://dx.doi.org/http://dx.doi.org/10.1016/i.econedurev.2004.08.009

Cherastidtham, I., \& Norton, A. (2018). University attrition: what helps and what hinders university completion? Melbourne: Retrieved from https://grattan.edu.au/wpcontent/uploads/2018/04/University-attrition-background.pdf

CollegeNet. (2017). 2017 Social Mobility Index. Retrieved from http://www.socialmobilityindex.org/ Council of Australian Governments. (2009). Council of Australian Governments. National Indigenous Reform Agreement (Closing the Gap). Canberra: Council of Australian Governments. 
Dalley-Trim, L., \& Alloway, N. (2010). Looking "outward and onward" in the outback: Regional Australian students' aspirations and expectations for their future as framed by dominant discourses of further education and training. The Australian Educational Researcher, 37(2), 107-125. http://dx.doi.org/10.1007/bf03216925

Dawkins, J. (1988). Higher education: a policy statement. Canberra: Australian Government Publishing Service.

Department of Education. (2014). Completion rates of domestic bachelor students 2005 - 2012: A cohort analysis. Canberra: Department of Education.

Department of Education. (2015). Completion rates of domestic bachelor students - A cohort analysis: 2005 - 2013: . Canberra: Department of Education.

Department of Education and Training. (2017a). Selected Higher Education Statistics, 2016. Retrieved from https://www.education.gov.au/selected-higher-education-statistics-2016student-data

Department of Education and Training. (2017b). Undergraduate Offers and Acceptances, 2017. Retrieved from https://education.gov.au/undergraduate-applications-offers-andacceptances-publications

Department of Education Employment and Workplace Relations. (2010). Regional participation: The role of socioeconomic status and access. Canberra:

Department of Employment Education and Training. (1990). A fair chance for all. Canberra: Australian Governmen Printing Service.

Department of Employment Education and Training. (1993). National report on Australia's higher education sector [the blue book]. Canberra, Australia: Retrieved from http://hdl.voced.edu.au/10707/108554

Dill, D. D., \& Soo, M. (2005). Academic quality, league tables, and public policy: A cross-national analysis of university ranking systems. Higher Education, 49(4), 495-533. http://dx.doi.org/10.1007/s10734-004-1746-8

Dougherty, K. J., Jones, S. M., Lahr, H., Natow, R. S., Pheatt, L., \& Reddy, V. (2014). Performance Funding for Higher Education:Forms, Origins, Impacts, and Futures. The ANNALS of the American Academy of Political and Social Science, 655(1), 163-184. http://dx.doi.org/10.1177/0002716214541042

Dow, K., Adams, B., Dawson, J., \& Phillips, D. (2010). Report advising on the development of the Victorian Tertiary Education Plan. Melbourne: Retrieved from http://www.education.vic.gov.au/about/research/Pages/vteplan.aspx

Ebert, U., \& Welsch, H. (2004). Meaningful environmental indices: a social choice approach. Journal of Environmental Economics and Management, 47(2), 270-283. http://dx.doi.org/https://doi.org/10.1016/i.jeem.2003.09.001

Edwards, D., \& McMillan, J. (2015a). Completing university in a growing sector: Is equity an issue? Adelaidde, SA:

Edwards, D., \& McMillan, J. (2015b). Completing university in Australia: A cohort analysis exploring equity group outcomes. Camberwell, Victoria: Australian Council for Educational Research.

Equality of Opportunity Project. (2017). Data and Replication Code. Retrieved from http://www.equality-of-opportunity.org/data/

Gale, T., Hattam, R., Parker, S., Comber, B., Bills, D., \& Tranter, D. (2010). Interventions early in school as a means to improve higher education outcomes for disadvantaged (particularly low SES) students. Canberra: C. o. Australia.

Gale, T., Parker, S., Rodd, P., Stratton, G., Sealey, T., \& Moore, T. (2013). Student Aspirations for Higher Education in Central Queensland: A survey of school students' navigational capacities. Melbourne:

Gemici, S., Bednarz, A., \& Karmel, T. (2014). The factors affecting the educational and occupational aspirations of young Australians. Adelaide: 
Gemici, S., Lim, P., \& Karmel, T. (2013). The Impact of Schools on Young People's Transition to University. Longitudinal Surveys of Australian Youth. Research Report 61. Adelaide: National Centre for Vocational Education Research Ltd.

Graduate Careers Australia. (2014). Graduate salaries 2013: A report on the earnings of new Australian graduates in their first full-time employment. Melbourne: Graduate Careers Australia Ltd.

Hahn, A., Leavitt, T., \& Aaron, P. (1994). Evaluation of the Quantum Opportunities Program (QOP). Did the program work? A report on the post secondary outcomes and cost-effectiveness of the QOP program (1989-1993)

. Waltham, MA:

Harvey, A., Burnheim, C., \& Brett, M. (2016). Towards a Fairer Chance for All: Revising the Australian Student Equity Framework. In A. Harvey, C. Burnheim \& M. Brett (Eds.), Student Equity in Australian Higher Education: Twenty-five years of A Fair Chance for All (pp. 3-20). Singapore: Springer Singapore. http://dx.doi.org/:10.1007/978-981-10-0315-8 1

Higher Education Group. (2011). Performance Funding Technical Guidelines. Canberra:

Higher Education Standards Panel. (2017). Improving retention, completion and success in higher education. Retrieved from https://docs.education.gov.au/node/50816

Higher Education Statistics Agency. (n.d.). Guide to the UKPIs. Retrieved from https://www.hesa.ac.uk/data-and-analysis/performance-indicators/guide

Hnat, H., Mahony, D., Fitzgerald, S., \& Crawford, F. (2014). Distributive justice and higher education resource allocation: perceptions of fairness. Innovative Higher Education,(March), 1-15. http://dx.doi.org/10.1007/s10755-014-9294-3

Hodges, B., Bedford, T., Hartley, J., Klinger, C., Murray, N., O'Rourke, J., \& Schofield, N. (2013). Enabling retention: processes and strategies for improving student retention in universitybased enabling programs. Sydney: Office for Learning and Teaching.

Horne, J., \& Sherington, G. (2012). Sydney: the making of a public university. Melbourne: The Miegunyah Press.

Hsu, A., \& Zomer, A. (2016). Environmental performance index`. Wiley StatsRef: Statistics Reference Online, http://dx.doi.org/10.1002/9781118445112.stat03789.pub2

International Ranking Expert Group. (2006). Berlin Principles on Ranking of Higher Education Institutions Berlin: UNESCO. Retrieved from http://www.ihep.org/sites/default/files/uploads/docs/pubs/berlinprinciplesranking.pdf

James, R. (2001). Participation disadvantage in Australian higher education: An analysis of some effects of geographical location and socioeconomic status. Higher Education, 42(4), 455-472. Retrieved from http://www.jstor.org/stable/3448100

Jaschik, S. (2018, 10 September 2018). The 'U.S. News' Rankings' (Faux?) Embrace of Social Mobility. Inside Higher $\mathrm{Ed}$. Retrieved from https://www.insidehighered.com/admissions/article/2018/09/10/us-news-says-it-hasshifted-rankings-focus-social-mobility-has-it

Kao, C. (2010). Weight determination for consistently ranking alternatives in multiple criteria decision analysis. Applied Mathematical Modelling, 34(7), 1779-1787.

Keeney, R. L. (1977). The art of assessing multiattribute utility functions. Organizational behavior and human performance, 19(2), 267-310.

Kemp, D., \& Norton, A. (2014). Review of the demand driven funding system report. Canberra: Department of Education.

Koshy, P. (2016). Equity policy in Australian higher education: Past, present and prospective. In M. Hill, A. Hudson, S. McKendry, N. Raven, D. Saunders, J. Storan \& T. Ward (Eds.), Closing the Gap: Bridges for Access and Lifelong Learning (pp. 277-302). London: Forum for Access and Continuing Education. 
Koshy, P., Seymour, R., \& Dockery, M. (2016). Are there institutional differences in the earnings of Australian higher education graduates? Economic Analaysis and Policy, 51, 1-11. Retrieved from http://www.sciencedirect.com/science/article/pii/S0313592615301417

Lewis, D. R., Johnson, D. R., Erikson, R. N., \& Bruininks, R. H. (1994). Multiattribute evaluation of program alternatives within special education. Journal of Disability Policy Studies, 5(1), 77112.

Lim, P., Bednarz, A., \& Karmel, T. (2014). The impact of school academic quality on low socioeconomic status students. Adelaide:

Linke, R. D., \& et al. (1984). Report of a Study Group on the Measurement Of Quality and Efficiency in Australian Higher Education. Canberra:

Lomax-Smith, J., Watson, L., \& Webster, B. (2011). Higher Education Base Funding Review: final report. Canberra:

Long, J., \& Harvey, A. (2015). Equity and diversity should figure in any rankings system Melbourne: La Trobe University. Retrieved from

https://www.latrobe.edu.au/news/announcements/2016/equity-And-diversity-in-universityranking

Longden, D. (2011). Ranking indicators and weights. In J. C. Shin, R. K. Toutkoushian \& U. Teichler (Eds.), University rankings: Theoretical basis, methodology and impacts on global higher education (pp. 73-104). New York: Springer.

Luzeckyj, A., King, S., Scutter, S., \& Brinkworth, R. (2011). The significance of being first: A consideration of cultural capital in relation to "first in family" student's choices of university and program. A Practice Report. The International Journal of the First Year in Higher Education and Culture, 2(2), 91-96. http://dx.doi.org/doi:10.5204/intjfyhe.v2i2.89

Marginson, S. (2011). Equity, status and freedom: A note on higher education. Cambridge Journal of Education, 41(1), 23-36.

Markowitz, H. (1952). Portfolio selection. The Journal of Finance, 7(1), 77-91.

Martellini, L. (2008). Toward the design of better equity benchmarks: Rehabilitating the tangency portfolio from modern portfolio theory. Journal of Portfolio Management, 34(4), 34.

Martin, L. (1994). Equity and General Performance Indicators in Higher Education. Canberra: Australian Government Publishing Service.

McCowan, T. (2016). Three dimensions of equity of access to higher education. Compare: $A$ Journal of Comparative and International Education, 46(4), 645-665. http://dx.doi.org/10.1080/03057925.2015.1043237

Meyer, H.-D. (2013). Reasoning about fairness to access in higher education: common sense, normative and institutional perspectives. In H.-D. Meyer, E. St John, M. Chankseliani \& L. Uribe (Eds.), Fairness in access to higher education in a global perspective (pp. 15-40). Rotterdam: Sense Publishers.

Moed, H. F. (2017). A critical comparative analysis of five world university rankings. Scientometrics, 110(2), 967-990.

Moore, K., Coates, H., \& Croucher, G. (2018). Investigating applications of university productivity measurement models using Australian data. Studies in Higher Education, 1-15. http://dx.doi.org/10.1080/03075079.2018.1479846

Moradi-Motlagh, A., Jubb, C., \& Houghton, K. (2016). Productivity analysis of Australian universities. Pacific Accounting Review, 28(4), 386-400.

Nardo, M., Saisana, M., Saltelli, A., Tarantola, S., Hoffmann, A., \& Giovannini, E. (2008). Handbook on constructing composite indicators: Methodology and user guide. Paris: OECD.

National Centre for Student Equity in Higher Education. (2013). Synergies and differences in the context of the development of an Equity and Aboriginal and Torres Strait Islander Performance Framework for Australian Higher Education. Perth:

National Centre for Student Equity in Higher Education. (2017). Equity student particiation in higher education: 2011-2016. Perth: 
Naylor, R., Baik, C., \& James, R. (2013). Developing a Critical Interventions Framework for advancing equity in Australian higher education. D. o. Innovation. Retrieved from http://www.innovation.gov.au/highereducation/Policy/Pages/NationalEquityinHigherEducat ionPolicyForum2013.aspx

Nelson, K., Duncan, M., \& Clarke, J. (2009). Student success: The identification and support of first year university students at risk of attrition. Studies in Learning, Evaluation, Innovation and Development, 6(1), 1-15.

O'Hare, J. (2015, 15 July). Equity and diversity integral to new university ranking. Opinion The Australian. Retrieved from https://www.theaustralian.com.au/higher-education/equity-anddiversity-integral-to-new-university-ranking/newsstory/b2751326f5d0992d3e355ad6844225c4

Organisation for Economic Co-operation and Development. (2006). Higher Education: Quality, equity and efficiency. Retrieved from http://www.oecd.org/dataoecd/30/7/36960580.pdf

Organisation for Economic Co-operation and Development. (2018). Education at a Glance 2018: OECD Indicators. OECD Publishing: OECD. In O. Publishing (Series Ed.) http://dx.doi.org/:https://doi.org/10.1787/eag-2018-en

Parker, S., Stratton, G., Gale, T., Rodd, P., \& Sealey, T. (2013). Higher Education and Student Aspirations: A survey of the adaptive preferences of Year 9 students in Corio, Victoria. Deakin University, Victoria:

Phillimore, J., \& Koshy, P. (2010). Meeting the Rudd Government's Equity Targets for Universities: Three Scenarios. People and Place, 18(1), 1-18.

Pitman, T. (2009). Recognition of prior learning: The accelerated rate of change in Australian universities. Higher Education Research \& Development, 28(2), 227-240. Retrieved from http://www.informaworld.com/10.1080/07294360902725082

Pitman, T. (2014). Understanding 'fairness' in student selection: are there differences and does it make a difference anyway? Studies in Higher Education, 1-14. http://dx.doi.org/10.1080/03075079.2014.968545

Pitman, T. (2017). Widening participation in higher education: a play in five acts. Australian Universities' Review, The, 59(1), 37.

Pitman, T., Harvey, A., McKay, J., Devlin, M., Trinidad, S., \& Brett, M. (2017). The Impact of Enabling Programs on Indigenous Participation, Success and Retention in Australian Higher Education. In J. Frawley, S. Larkin \& J. Smith (Eds.), Indigenous Pathways, Transitions and Participation in Higher Education (pp. 235-249): Springer.

Pitman, T., \& Koshy, P. (2014). A framework for measuring equity performance in higher education: draft framework document V1.6. Perth: Retrieved from https://www.ncsehe.edu.au/wpcontent/uploads/2014/11/Draft Equity Performance Framework Report V1.6.pdf

Pitman, T., \& Koshy, P. (2015). A framework for measuring equity performance in Australian higher education. Perth:

Pitman, T., Koshy, P., \& Phillimore, J. (2014). Does accelerating access to higher education lower its quality? The Australian experience. Higher Education Research \& Development, 1-15. http://dx.doi.org/10.1080/07294360.2014.973385

Pitman, T., Roberts, L., Bennett, D., \& Richardson, S. (2017). An Australian study of graduate outcomes for disadvantaged students. Journal of Further and Higher Education, 1-13. http://dx.doi.org/10.1080/0309877X.2017.1349895

Podinovskii, V. V. (1994). Criteria importance theory. Mathematical social sciences, 27(3), 237-252. http://dx.doi.org/10.1016/0165-4896(93)00737-F

Poister, T. H., Aristigueta, M. P., \& Hall, J. L. (2014). Managing and measuring performance in public and nonprofit organizations: an integrated approach (2 ed.). San Francisco: John Wiley.

QS. (2014). QS World University Rankings: Methodology. . Retrieved from http://www.topuniversities.com/university-rankings-articles/world-university-rankings/qsworld-university-rankings-methodology 
Raphael, D. D. (1946). Equality and Equity. Philosophy, 21(79), 118-132.

http://dx.doi.org/doi:10.1017/S0031819100005301

Reay, D., Crozier, G., \& Clayton, J. (2009). 'Strangers in paradise'? : Working-class students in elite universities. Sociology, 43(6), 1103-1121. Retrieved from http://soc.sagepub.com/content/43/6/1103

Saaty, T. L. (1990). How to make a decision: the analytic hierarchy process. European Journal of Operational Research, 48(1), 9-26.

Salmi, J., \& Bassett, R. (2012). Opportunities for all? The equity challenge in tertiary education. In S. G. Seminars (Ed.), Salzburg Global Seminar, held in Salzburg, Austria,

Sellar, S., \& Gale, T. (2011). Mobility, Aspiration, Voice: A New Structure of Feeling for Student Equity in Higher Education. Critical Studies in Education, 52(2), 115-134.

Selleck, R. J. W. (2003). The Shop: The University of Melbourne 1850-1939. Melbourne: Melbourne University Press.

Soh, K. (2017). The seven deadly sins of world university ranking: a summary from several papers. Journal of Higher Education Policy and Management, 39(1), 104-115. http://dx.doi.org/10.1080/1360080X.2016.1254431

Southgate, E., Douglas, H., Scevak, J., S, M., Rubin, M., \& Lindell, C. (2014). The academic outcomes of first-in-family in an Australian university:An exploratory study. International Studies in Widening Participation, 1(2), 31-45.

Stephens, N. M., Fryberg, S. A., Markus, H. R., Johnson, C. S., \& Covarrubias, R. (2012). Unseen disadvantage: how American universities' focus on independence undermines the academic performance of first-generation college students. Journal of personality and social psychology, 102(6), 1178.

The Economist Intelligence Unit. (2017). The worldwide educating for the future index: A benchmark for the skills of tomorrow. UK: The Economist.

The Pell Institute, \& PennAhead. (2015). Indicators of higher education equity in the United States. Washington DC: Retrieved from http://www.pellinstitute.org/downloads/publicationsIndicators of Higher Education Equity in the US 45 Year Trend Report.pdf

UN Economic and Social Council. (1999). General Comment No. 13: The Right to Education (Art. 13 of the Covenant). 8 December 1999 Retrieved from http://www.refworld.org/docid/4538838c22.html

UNESCO. (2018). Handbook on Measuring Equity in Education Montreal: UNESCO Institute for Statistics.

Victorian Parliament's Education and Training Committee. (2009). Inquiry into Geographical Differences in the Rate in which Victorian Students Participate in Higher Education Melbourne: Retrieved from https://www.parliament.vic.gov.au/57thparliament/etc/inquiries/article/170

Washington Monthly. (2016a). 2016 College Guide and Rankings. Retrieved from https://washingtonmonthly.com/college guide

Washington Monthly. (2016b). 2016 College Rankings: What can College do for the Country? Washington: Retrieved from http://wmf.washingtonmonthly.com/college guide/2016/WM 2016 Embargoed Rankings. $\underline{\mathrm{pdf}}$

Worthington, A., \& Lee, B. L. (2008). Efficiency, technology and productivity change in Australian universities, 1998-2003. Economics of Education Review, 27(3), 285-298.

Zeleny, M. (1982). Multiple criteria decision making. New York: McGraw-Hill.

Zhang, L. (2008). A Study on the Educational Expenditure Adequacy among Elementary Schools in Taipei City - Cost Function Approach Masters University of Taipei, Tapei, Taiwan.

Zhang, L. (2010). Measuring elementary school efficiency in Taipei, Taiwan: Two-stage data envelopment analysis 35th annual conference of the American Education Finance Association, held in Richmond, VA, 
Zhang, L., \& Worthington, A. (2017). The impact of scale and scope on global university rankings: What we know and what we need to learn. In K. Downing \& F. A. Ganotice (Eds.), World university rankings and the future of higher education (pp. 140-160). Hershey, PA: IGI Global.

Zhu, J. (2014). Quantitative models for performance evaluation and benchmarking: Data envelopment analysis with spreadsheets (Vol. 213). New York: Springer.

Zieky, M. J. (2001). So much has changed: How the setting of cutscores has evolved since the 1980s. In G. J. Cizek (Ed.), Setting performance standards (pp. 19-52). Mahwah, NJ: Lawrence Erlbaum Associates. 